\title{
WestVirginiaUniversity
}

THE RESEARCH REPOSITORY @ WVU

Graduate Theses, Dissertations, and Problem Reports

2008

\section{Communicative functions of young children's visual art}

Clover Simms Wright
West Virginia University

Follow this and additional works at: https://researchrepository.wvu.edu/etd

\section{Recommended Citation}

Wright, Clover Simms, "Communicative functions of young children's visual art" (2008). Graduate Theses, Dissertations, and Problem Reports. 2867.

https://researchrepository.wvu.edu/etd/2867

This Dissertation is protected by copyright and/or related rights. It has been brought to you by the The Research Repository @ WVU with permission from the rights-holder(s). You are free to use this Dissertation in any way that is permitted by the copyright and related rights legislation that applies to your use. For other uses you must obtain permission from the rights-holder(s) directly, unless additional rights are indicated by a Creative Commons license in the record and/ or on the work itself. This Dissertation has been accepted for inclusion in WVU Graduate Theses, Dissertations, and Problem Reports collection by an authorized administrator of The Research Repository @ WVU.

For more information, please contact researchrepository@mail.wvu.edu. 
Communicative Functions of Young Children's Visual Art

\author{
Clover Simms Wright
}

\author{
Dissertation submitted to the \\ College of Human Resources and Education \\ at West Virginia University \\ in partial fulfillment of the requirements \\ for the degree of \\ Doctor of Education \\ in \\ Curriculum and Instruction \\ Joy Saab, Ed. D., Chair \\ Patricia Obenauf, Ph. D. \\ Perry Philips, Ed. D \\ Jaci Webb-Dempsey, Ph. D. \\ Ardeth Deay, Ed. D. \\ Allison Dagan, Ed. D. \\ College of Human Resources and Education \\ Morgantown, West Virginia \\ 2008
}

Keywords: Early Childhood, Visual Art, Language, Communication

Copyright 2008 Clover Simms Wright 


\section{ABSTRACT \\ Communicative Functions of Young Children’s Visual Art \\ Clover Simms Wright}

How can young children use visual art to communicate? This study used Halliday’s communicative functions of language (Halliday, 1973), to frame the answer to this question; Halliday's categories of communicative functions are: instrumental, regulatory, interactional, personal, heuristic, imaginative, and representational/informative. Five children, between the ages of three and five, were observed and interviewed as they voluntarily created visual art over a six-week period. In that time period, each of the seven functions of language was demonstrated collectively by the participants. The research was conducted by an educator employed in the early childhood setting. Qualitatively, this study confirmed that young children are capable of utilizing art in a variety of ways to communicate. 


\section{Table of Contents}

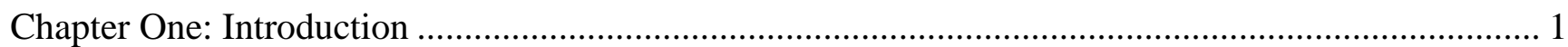

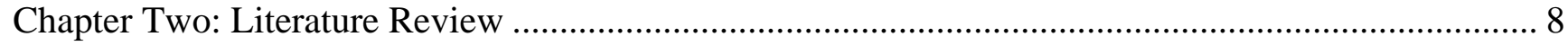

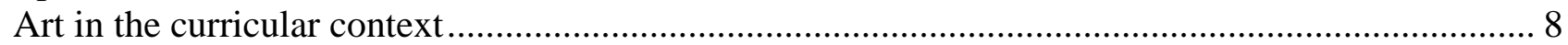

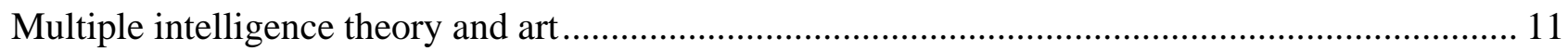

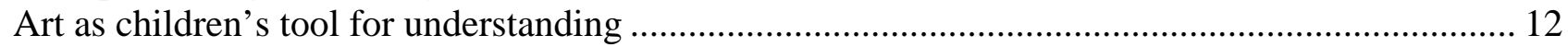

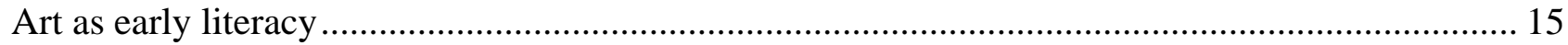

Art as a language in Reggio Emilia ............................................................................................ 19

Halliday's Communicative Functions of Language …………......................................................... 20

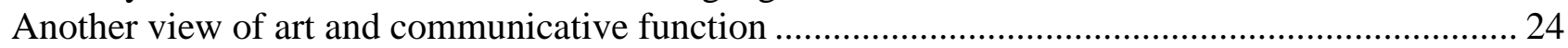

Research design. implications, limitations..................................................................................... 25

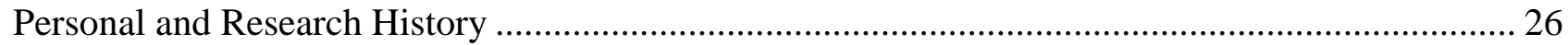

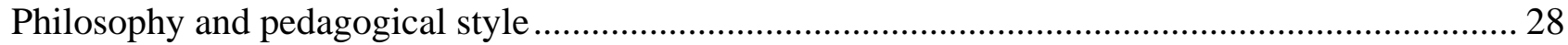

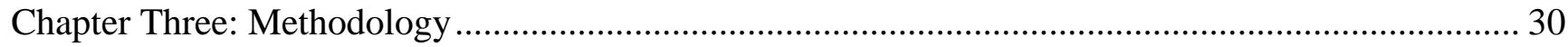

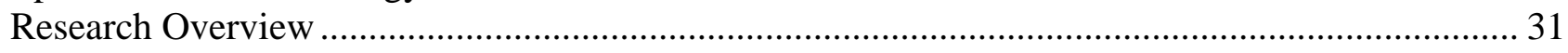

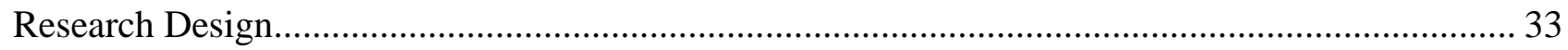

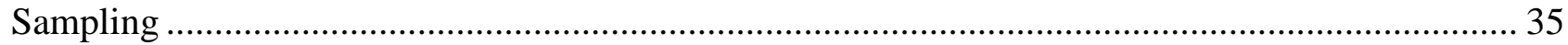

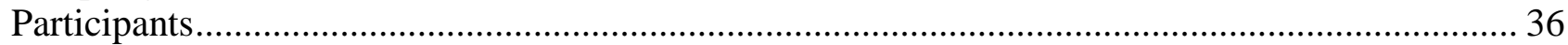

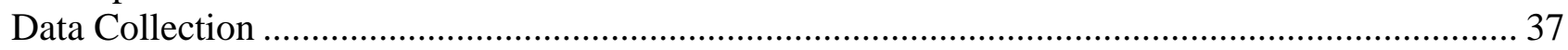

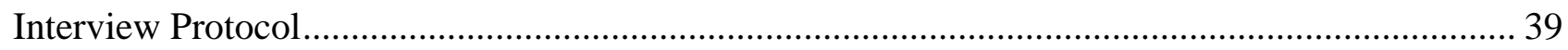

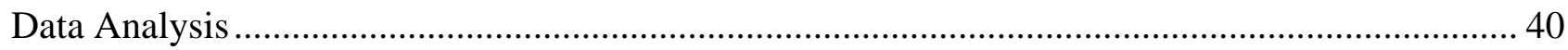

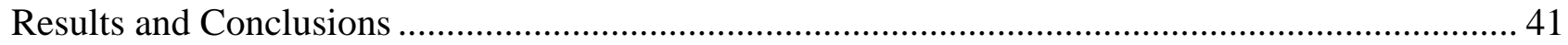

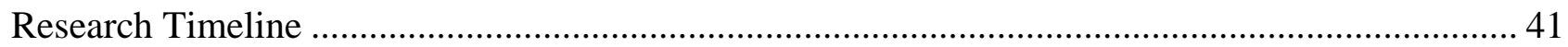

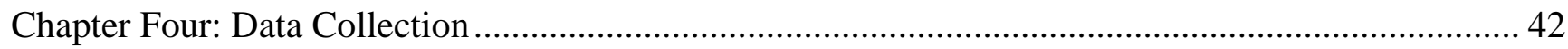

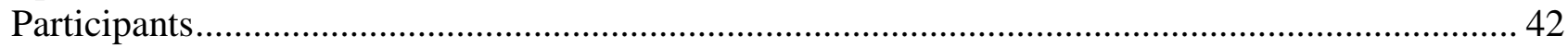

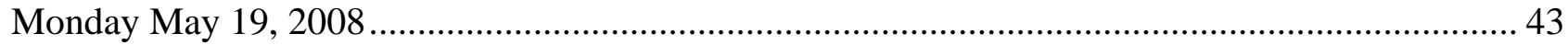

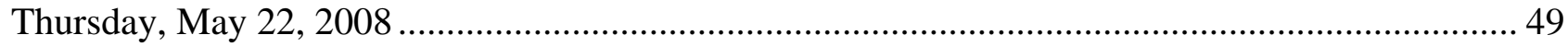

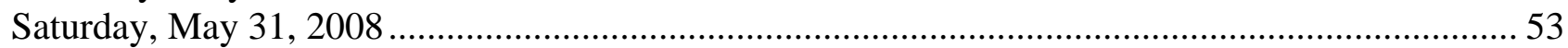

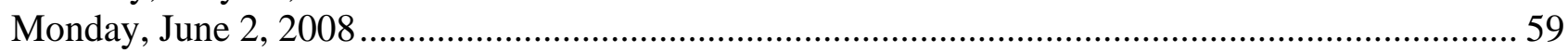

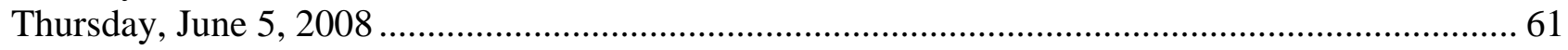

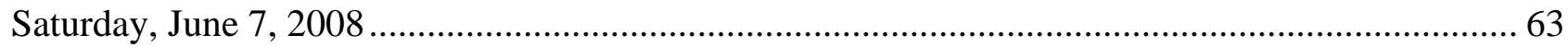

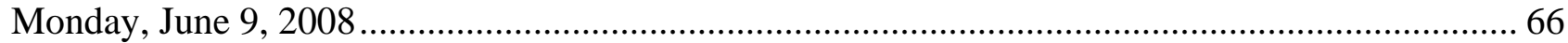

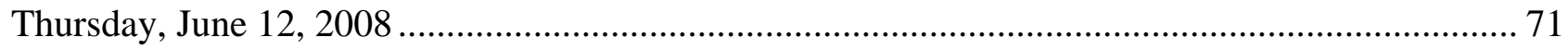

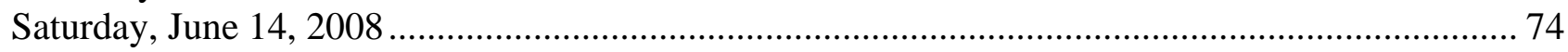

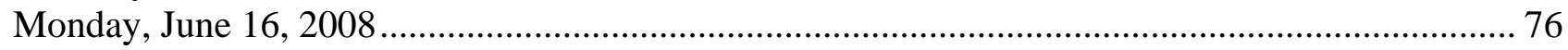

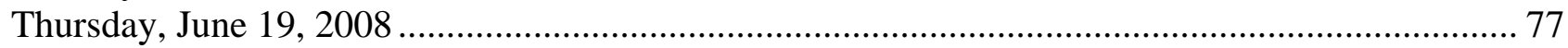

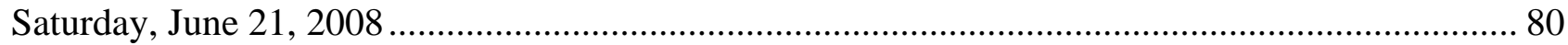

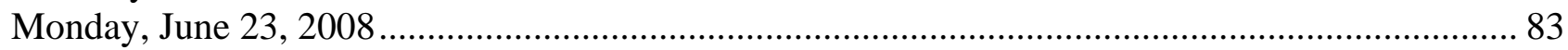

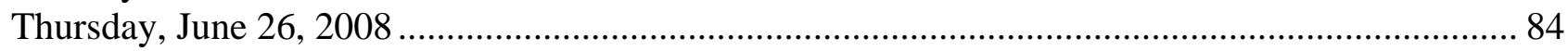

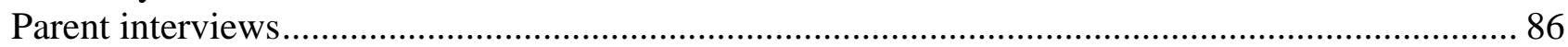

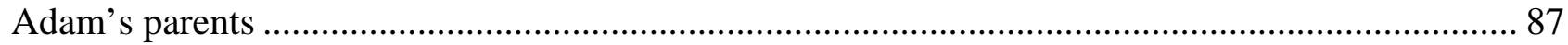

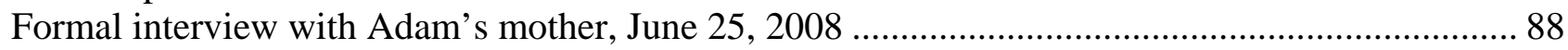

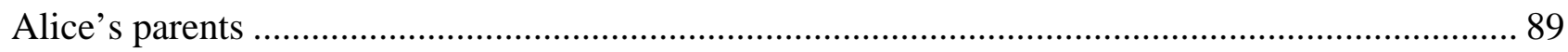




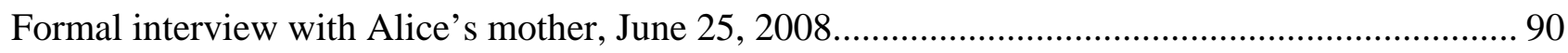

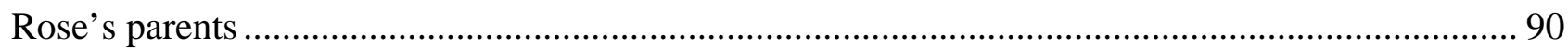

Formal interview with Rose's father, July 2, 2008 (by telephone)................................................... 91

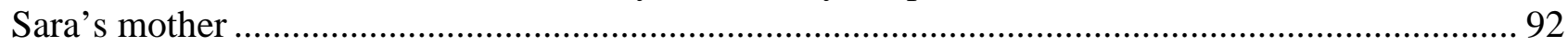

Formal interview with Sara's mother, June 29, 2008 ..................................................................... 92

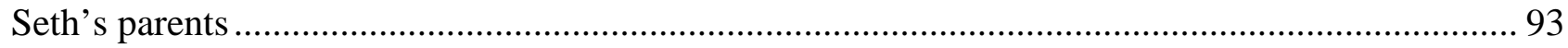

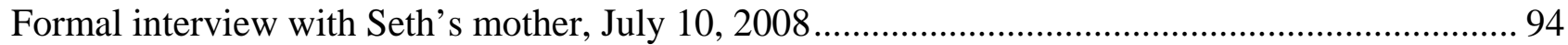

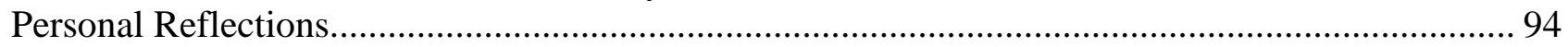

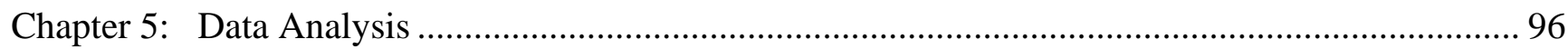

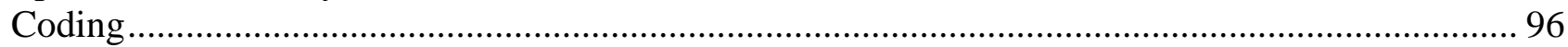

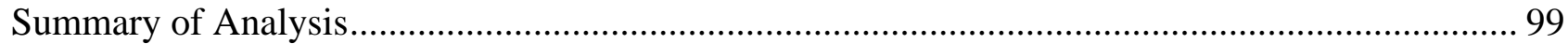

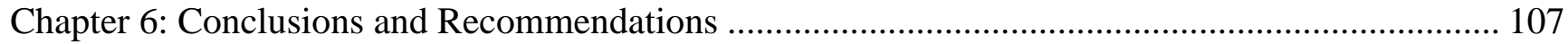

What does this study mean in the instructional context?............................................................... 108

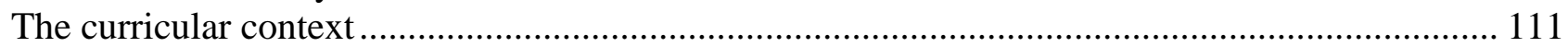

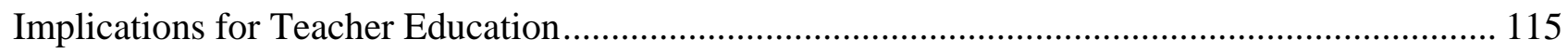

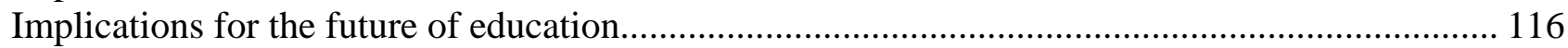

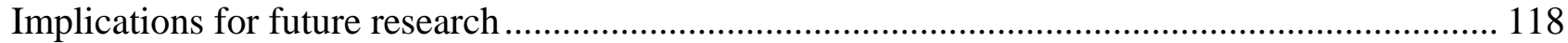

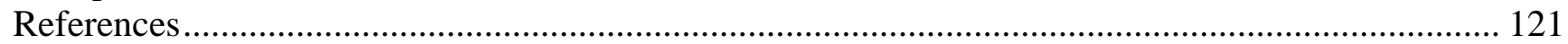

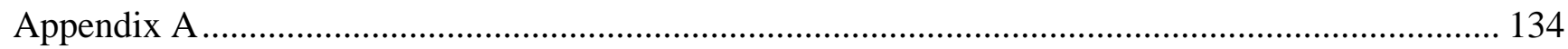

Table A1: Do's and Don'ts of Qualitative Early Childhood Educational Research............................ 134

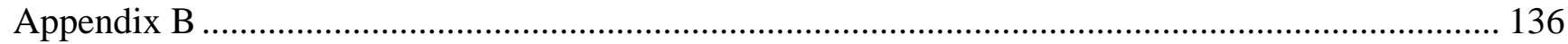

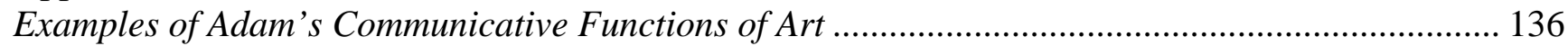

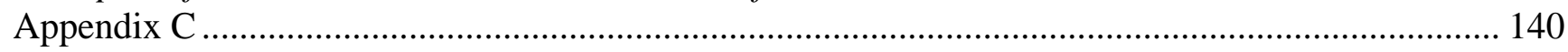

Examples of Alice's Communicative Functions of Art ……............................................................ 140

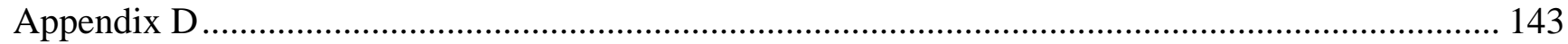

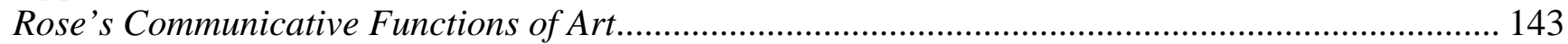

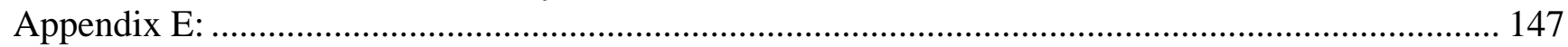

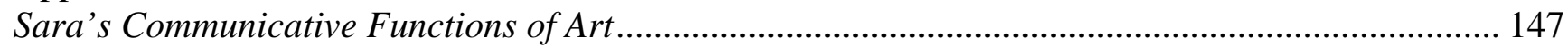

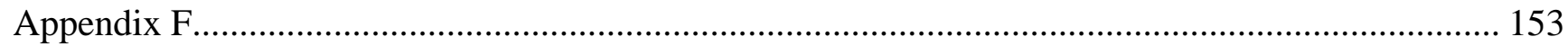

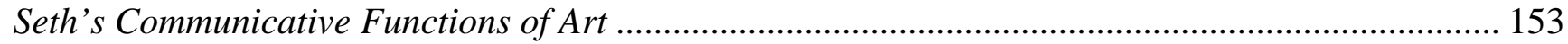

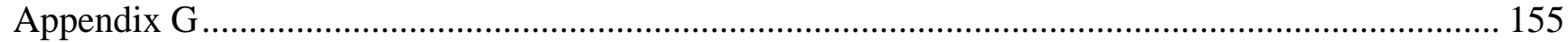

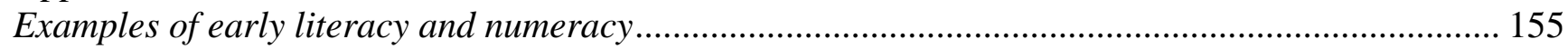

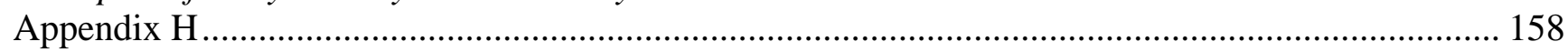

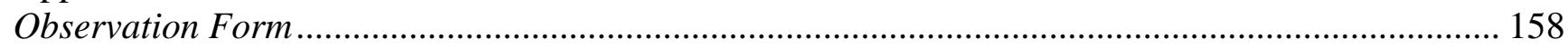

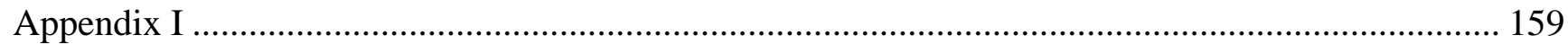

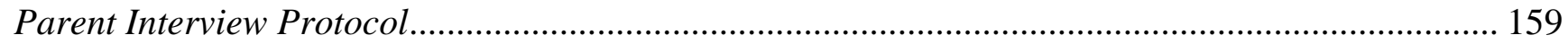




\section{Table of Tables}

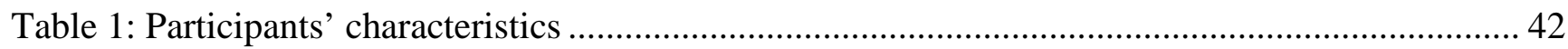

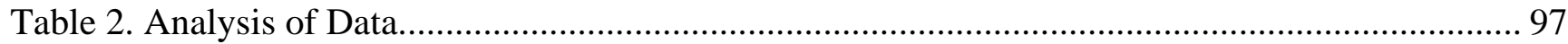

Table A1: Do’s and Don'ts of Qualitative Early Childhood Educational Research........................... 134 


\section{Table of Figures}

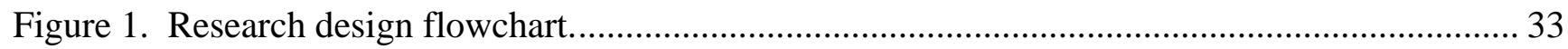

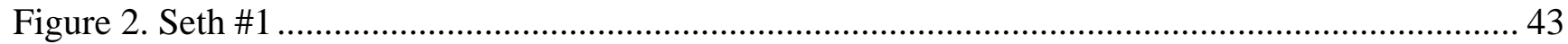

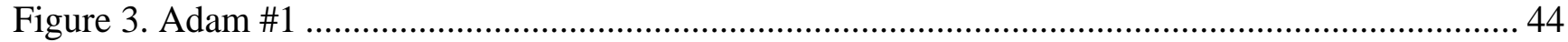

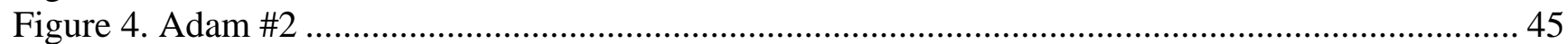

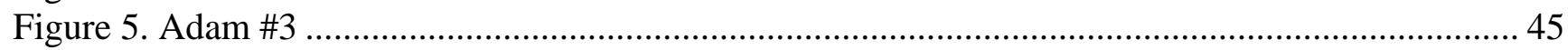

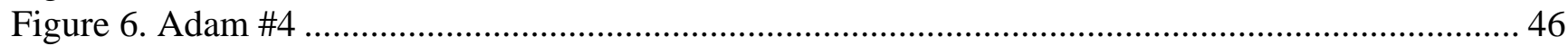

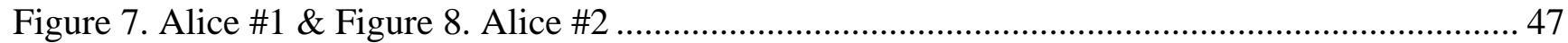

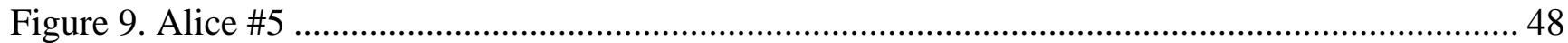

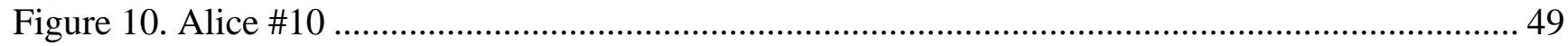

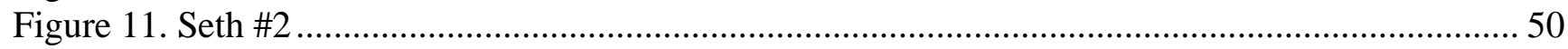

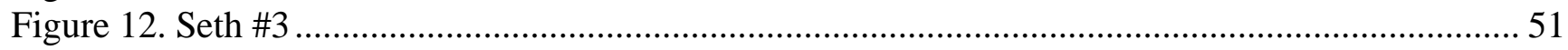

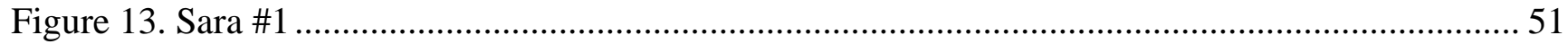

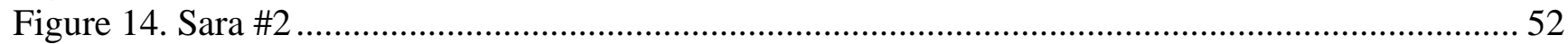

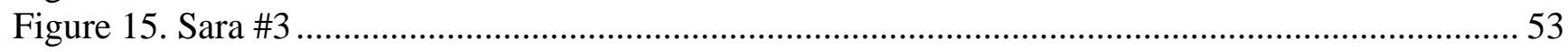

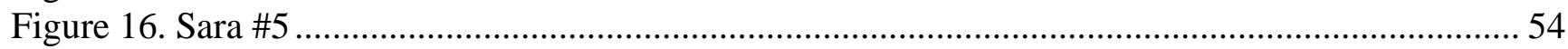

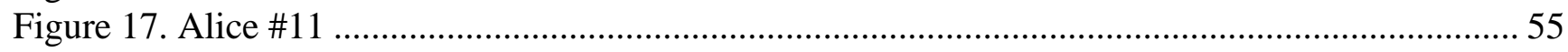

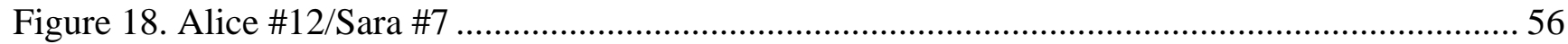

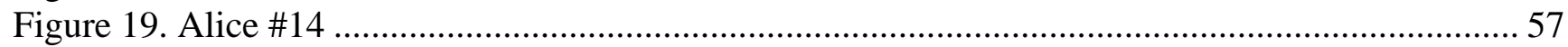

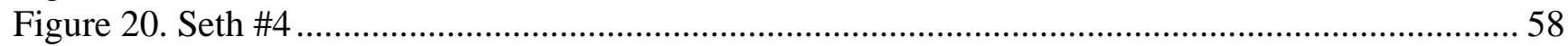

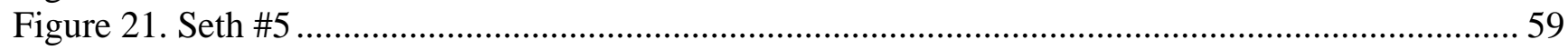

Figure 22. Alice \#15 (proper names omitted) \& Figure 23. Alice \# 16 (names omitted)...........................60

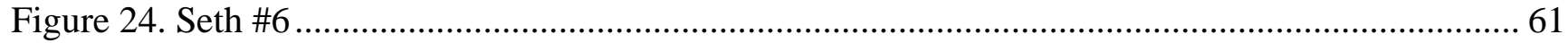

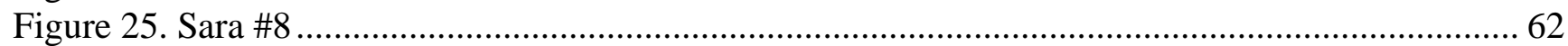

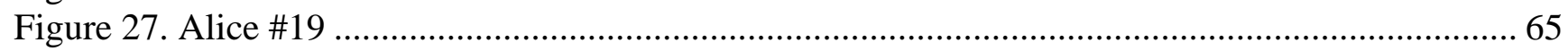

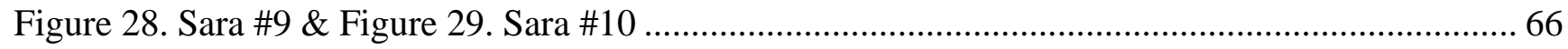

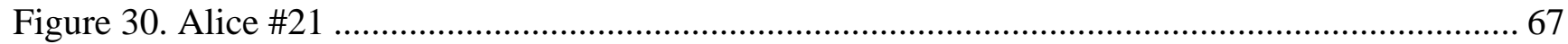

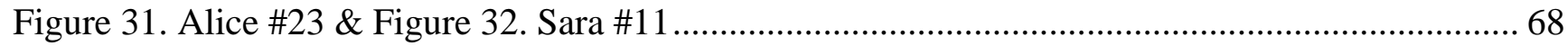

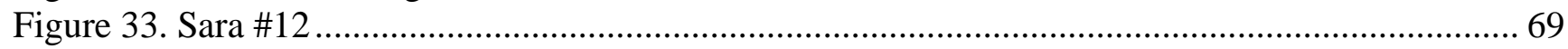

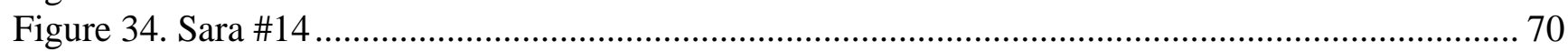

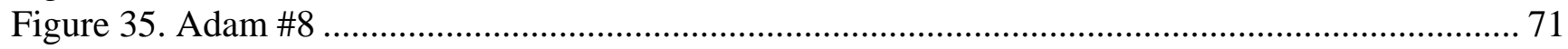

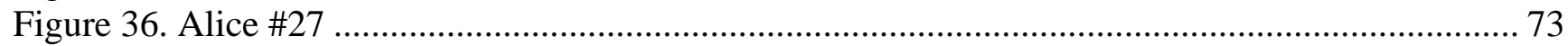

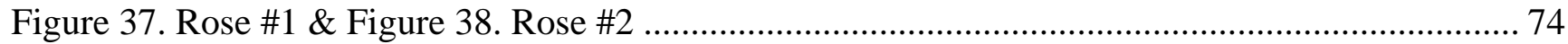

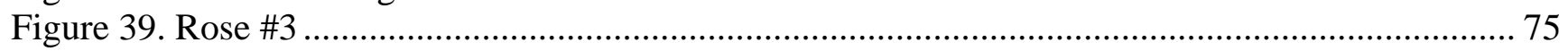

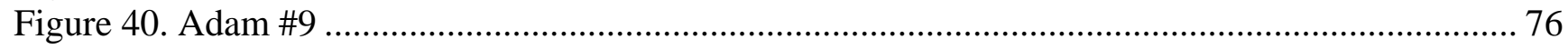

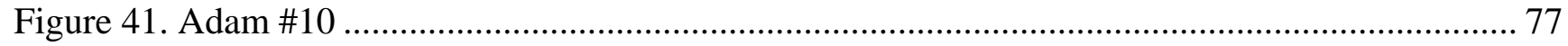

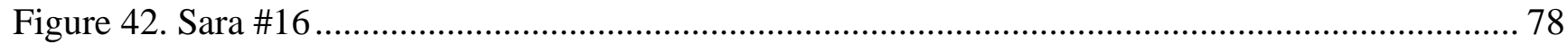

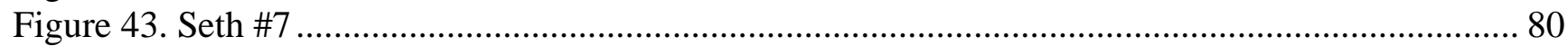

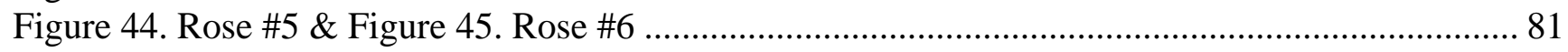

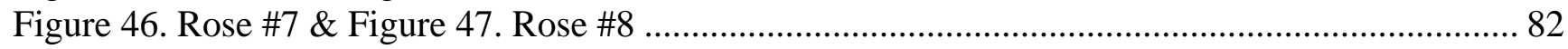

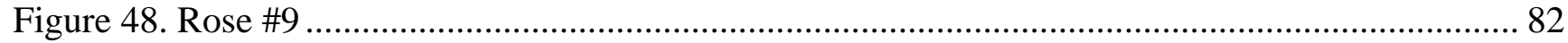

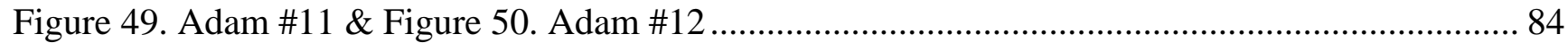

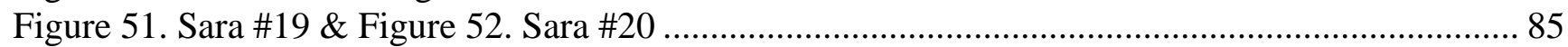

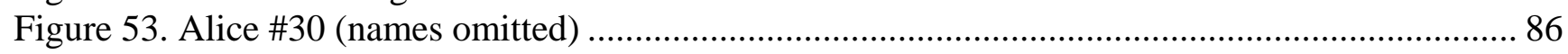

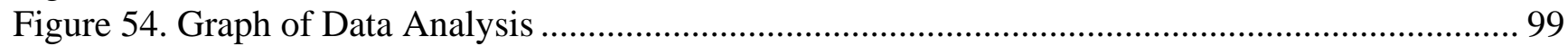

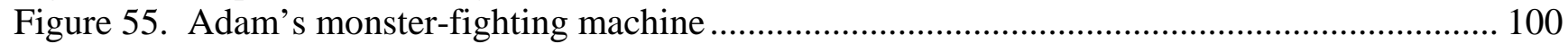




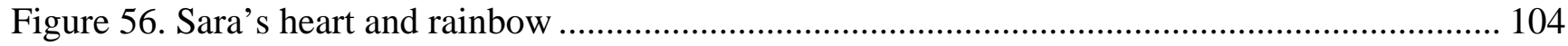

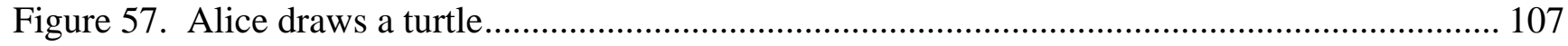

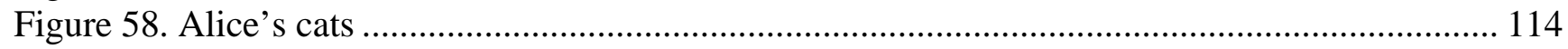




\section{Chapter One: Introduction}

What is the purpose of education in a multicultural democracy? As time brings changes in our understanding, expanding our knowledge and identity, it may be necessary to re-envision the objectives of education. Are we preparing the youngest citizens to embrace the challenges of a future we may not even be able to yet imagine? Are our young people being educated to achieve success in the $21^{\text {st }}$ century? What aims or intellectual habits will be valuable in the future? What shifts are required in our conception of curriculum?

Curriculum reconceptualists, such as William Pinar, believe that future scholarship and pedagogy will be characterized by "understanding”, rather than the traditional paradigm of curriculum development (Pinar, et. al., 2000). If our goal becomes understanding, how does that change the nature and structure of schooling?

Educational theorists answer that question in many ways. Dewey (1916) contextualized education as communication. Doll (1993) viewed curriculum as open systems of interaction, linking biological science with the science of education. Davis (2005) frames education as art. The diversity of these perspectives on learning seems promising in a pluralistic society like ours, one in which there are many cultures and kinds of learners.

In contrast, trends in today's education seem to be moving toward ever more rigidly structured curricula. Challenges today are numerous, and the way education is implemented does not seem to consider the needs of the learners. No Child Left Behind, the current administration's attempt to legislate success for all, high-stakes standardized testing starting in the early years, and learning benchmarks and expectations being pushed down to ever younger children are some of the most prominent and controversial ways measurement and analysis of student learning is currently being 
addressed (Rapp, Sloan \& Hostrup, 2006). These measures have led to much "teaching to the test”, which does not adequately address children's educational or developmental needs (Perrone, 1991, NAEYC-NAECS/SDE, 2001).

Some educators and policymakers believe that there is too much focus on standardized tests, and feel that this orientation shapes the design of instruction, more so than the way in which students actually learn (Bracey, 2000). Many popular types of assessments test students' recall of facts and skills in isolation, rather than application of what students know in real-life situations, which often leads to instruction that stresses narrow acquisition of knowledge and skills (Strickland \& RileyAyers, 2006, Poole, 1994, Perrone, 1991). The overemphasis on standardized testing has created what Pink called an "SAT-ocracy—a regime in which access to the good life depends on your ability to reason logically, sequentially, and speedily (Pink, 2005, 29).” This limited definition of academic success leaves out students whose intelligence may lie in more creative domains.

What changes in our orientation towards learning will positively impact instruction, and lead toward the engaged learning that will prepare students for the 21st century (Sternberg \& Grigorenko, 2004, Bond, 1995)? Quality early childhood education is one factor that points to increased likelihood of academic success for all students (Logue, 2007, Milne \& Plourde, 2006, Gormley, Gayer, Phillips, \& Dawson, 2005).

Current brain research indicates that the early childhood years are some of the most crucial ones for growth and development (Katz, 2003, Talay-Ongan, 2000, ECS 1996). These findings have led to a great deal of focus on preschool education, characterized by the movement in the public schools towards universal preschool (Scott-Little, Kagan, \& Frelow, 2003). Because the brain continues to develop and form throughout early childhood, more emphasis should be placed on enriching home and school environments (ECS, 1996). In other words, the learning capacities of each 
child seem to depend in some part on the learning opportunities offered to each child. How can we ensure that every child has a richness of opportunities to learn in multiple ways?

Racial disparities in school readiness among America's preschoolers are strong and persistent. ...Many aspects of childhood experience, including health, parenting, stress, violence, and access to resources, contribute to these disparities. Many of these same experiences, including chronic stress and cognitive stimulation, also affect brain development in both animals and humans, suggesting a possible pathway between experience and ability. (Noble, Tottenham, \& Casey, 2005, 72)

During the child's early years, rich experiences appear to be necessary to build brain circuitry (Lindsey, 1998). These may positively influence cognitive and socio-emotional development, and lead to better academic performance in school later on (Slaby, Loucks, \& Stelwagon, 2005). Because of the importance of early experience for brain growth, active learning in the arts is especially significant, since many areas of the brain are involved (Gellens, 2000). Novel and creative experiences help form unique brain connections that may have a significant effect on development (Elliott, 2005).

Howard Gardner's Theory of Multiple Intelligences (1983) has had a major impact on the way that educators think about intelligence (Beliavsky, 2006, Sternberg \& Grigorenko, 2004), yet a child’s intellectual capacities are still evaluated by tests administered at the beginning of schooling. "Typical measures of school readiness such as achievement tests or even IQ tests are quite imprecise from the perspective of brain science (Noble, Tottenham, \& Casey, 2005, 72).”

Although it is acknowledged by the American Psychological Association that there is a discrepancy between IQ test scores and actual academic achievement, IQ tests are still widely utilized to diagnose learning abilities and disabilities (Benson, 2003). Norm-referenced testing is also used to determine if a child is ready for kindergarten, although these tests are often culturally skewed, 
resulting in a gap between the readiness of white children compared to black children and to Hispanic children (Rock \& Stenner, 2005).

Young children have diverse ways of living, learning, and different types of intelligence, yet culture and individual variation seem to be overlooked by conventional measures of intellectual capacity, which address only certain types of intelligences, usually related to literacy and mathematical abilities (Rock \& Stenner, 2005, ECS, 1996). Because of the neurological evidence that suggests children’s learning capabilities are only limited by the way in which each child is taught, it seems even more important to find ways to engage all kinds of intelligence in an education system designed to maximize each child's learning opportunities (ECS, 1996). What limitations are placed on the child and on society if we institutionally validate only one or two types of intelligence, such as verbal or mathematical abilities?

There are some who believe that the role of the arts in the curriculum has been overlooked and undervalued. Maxine Greene, a prominent scholar in the field of education, is a champion of the arts, and of the role of imagination and creativity in reconceptualizing the possibilities of education. She writes, "Far too seldom are...young people looked upon as beings capable of imagining, of choosing, and of acting from their own vantage points on perceived possibility (Greene, 1995, 41).”

Inherent in Greene's ideas is the stance that honors the learner as the primary focus of education, and not as a blank slate, or clay to be molded. Freire described a banking model of education in which knowledge is bestowed by those who have it upon those who do not; this model leads to passive students who accept meekly the facts of the reality the teacher fills them with (Freire, 1970). Opposite of that is a more humanizing view of the learner as an agent of his own learning process, in which the learner actively constructs knowledge through direct interaction with the learning environment, including other learners. This constructivist view of learning is one that is 
shared by many researchers who are focusing on the role of arts in education (Rinaldi, 2006, Cadwell, 2003, Eisner, 2002, Edwards, Gandini, and Forman, 1998, Katz \& Cesarone, 1994).

There has recently been an increase in interest in the educational and cognitive potential of the arts, in particular visual art (Efland, 2002). As early childhood research shows, human development and learning is interconnected; art has begun to be recognized as a valid part of children’s early literacy learning (Corsaro \& Nelson, 2003).

We bring the arts into the curriculum of academic subjects because to experience or to construct a work of art requires careful interest in the parts of the piece and the ways they are combined...the arts require the lively presence of the learner. (Rabkin \& Redmond, 2004, 55)

There are some educators and theorists who understand that the arts can help learners construct knowledge; foremost amongst the examples of this orientation are the preprimary municipal schools of Reggio Emilia, Italy. Reggio Emilia’s preprimary schools and infant-toddler centers provide what have been recognized by many as the best preschool programs in the world (Hancock \& Wingert for Newsweek, 1991, Katz \& Cesarone, 1994, New, 2000).

The Reggio Emilia approach utilizes the arts embedded in project-based learning to teach young children. Reggio children are encouraged to express that which they are thinking, doing, feeling, learning, and experiencing through conversation and the arts. The teachers facilitate children's expression through direct instruction in art techniques to give them tools to express their ideas (Hertzog, 2001; Edwards, et al, 1998).

When art is contextualized by project work, as it is in the Reggio Emilia approach, it can be even more educationally meaningful. If the project is based on a group interest or experiences, art can 
become a social learning vehicle. Art activities which are rooted in interactions for negotiated understanding lead to problem finding and solving (Pitri, 2007).

A key component of the Reggio Emilia approach is the use of a studio to facilitate children's artistic expression. Known as the atelier, and staffed by an artist and teacher called the atelierista, this space functions as a workshop for ideas and explorations involving the arts. The graphic languages, the atelierista, and the atelier are all critical components of the philosophy and belief systems in Reggio Emilia (Rinaldi, 2006). Art is the medium by which the educators in Reggio Emilia encourage the children to communicate; it is the medium by which their teachers "listen" to the children (Hertzog, 2001).

Reggio Emilia’s philosopher, Loris Malaguzzi, whose concept of the “100 Languages” in which we are potentially fluent, inspires a view of art as language (Malaguzzi in Edwards, Gandini, \& Forman, 1998). Art has many characteristics of language: socially agreed upon meanings, symbolic representation, abstract and concrete concepts, and, most relevant to this research project, the goal of communication (Barroquierro, 2004).

The communicative functions of language were written about extensively by British linguistic theorist M.A.K. Halliday $(1973,1974)$. Halliday theorized that language is systematic and has communicative function (Halliday, 1974). There are, according to Halliday, seven kinds of communicative functions which young children utilize:

1) Instrumental: Language used as a means of satisfying material needs;

2) Regulatory: Language used to regulate the behavior of others;

3) Interactional: Language used to mediate and maintain relationships;

4) Personal: Language used to express self and form individual identity;

5) Heuristic: Language used as a means to investigate reality, to question; 
6) Imaginative: Language used to express creative thoughts, to play;

7) Representational or Informative: Language used to communicate content, to express what is known or understood (Halliday, 1973).

This research project assumes the orientation that young children's art shares many of the characteristics of language. Halliday himself wrote that language could be considered an "art medium” (Halliday, 1973, 1) For example, like language, art is acquired systematically, learned through use, with widely recognized stages of development (Gardner,1980, Malchiodi, 1998). While some research and writing exists about children's communication through art, there are still gaps to be filled. In this research project, I seek an answer to the questions: How can young children use visual art to communicate? Are Halliday's seven communicative functions of language relevant to young children's visual art?

To answer these questions, I observed and described the visual art of a small group of young children, focusing specifically on drawing. Through this data collection and subsequent analysis, I was able to discover that the communicative functions these particular young children were capable of utilizing through their art corresponded to Halliday's linguistic theories. Teacher, parent, and student interviews triangulated my observations; I paid attention to the instructional strategies and pedagogical orientations that facilitated young children's communication, art creation, and creative expression. In short, this research paints a picture which illuminates the process of young children’s learning, focusing on communication through art creation, in the early childhood learning environment.

This research is a voice of advocacy for the inclusion of creative arts as essentials in the early childhood curriculum. Further, it is a touchstone for consideration of artistic expression in measures of learning and intellectual capacity, evaluation, and assessment.

Our knowledge of the world, and our existence as human beings would be 
vastly different without art. It is art that sets us apart from other living things,

and it is art which can lift us to a higher plane, sometimes helping us to see, feel and express what words cannot say (McArdle, 2005, par. 4).

\section{Chapter Two: Literature Review}

\section{Art in the curricular context}

Art has an important place in democratic schools and curricula; the arts offer diverse learners more chances to succeed and learn. Dewey wrote almost a hundred years ago that, “...it is the office of the school environment to balance the various elements of the social environment, and to see to it that each individual gets an opportunity to escape from the limitations of the social group in which he was born, and come into living contact with a broader environment (Dewey, 1916, 20).”

The arts make possible direct and personal interactions with the ideas and experiences of other people from different places and periods of time than one's own, in ways unique. These interactions, when conducted skillfully and intentionally, are experiential and authentic ways to learn which can result in personal growth and knowledge construction (Efland, 2002). Further, focus on the arts allows diverse learning styles to flourish, because the arts draw on a range of intelligences and approaches (Beliavsky, 2006, Sidelnick and Svoboda, 2000, Darby \& Catterall, 1994).

The body of research supporting the importance of the arts in enhancing the quality of schooling for all students includes a variety of data that link school arts programs to higher academic achievement. The arts encourage students to stay in school, increase literacy, and build confidence to encourage students to take risks in other classes (Darby and Catterall, 1994). The arts can also afford success for linguistically diverse learners, rather than the more traditional teaching strategies of memorization and skill-and-drill. Some of the newer approaches to teaching a second language are 
based on a more holistic view of the learners that recognizes the importance of language as meaningful communication and the students' lived experience as the source for language development (Abramson, Ankenman, \& Robinson, 1995).

Additionally, art can provide a venue for academic success for special needs learners. “Aesthetic, narrative, and reflective inquiries using the arts help children attain new conceptual language to organize and express their learning, and serve as an instrument for acquiring knowledge (Sidelnick and Svoboda, 2000, 176).” Being able to express ideas in other modes or media may motivate students with challenges.

Opportunities to learn through art creation are developmentally appropriate for a wide range of ages and abilities. The arts can provide open-ended, creative opportunities, in which learners can try problem solving techniques and take risks. “...Developmentally appropriate practice shifts the focus of education toward a holistic view of the child—a child who creates an understanding of the world within the context of social interaction (Vakil, Freeman, and Swim, 2003, 187-188).” Although the produced work is important, it is the social, process-oriented nature of art creation that may offer the greatest educational benefit. For example, creative drawing, like writing, involves learning to express ideas, how to represent experiences, how to communicate, how to edit, and more (Clemens, 1999). Although art is recognized as a step towards early literacy, it is often considered an "extra" outside the real curriculum, and one of the first programs to be cut when funds run low (Meyer, 2005). Some theorists posit that art has been considered primarily as affective and emotional in content, rather than cognitive (Efland, 2002, Gardner, 1990). This view has influenced and limited how art is taught and researched in the past; currently there is a movement to appreciate art as academic necessity (Efland, 2002, Davis, 2005, Rabkin \& Redmond, 2004). 
The use of creative expression as a medium to explore the lived experience, draws on the notion that within human reality, there are phenomena which reach us so deeply that creative forms are the only adequate way through which to point to and make present a meaning (Kockelmans, 1987, in Brearley, 2004, 5)

\section{Art in early childhood education}

When researched at all, children's art has tended to be looked at as windows into the mind, revealing personality and affect or cognition and intelligence (Gardner \& Perkins, 1988), or as stages on the way to more formal operations (Davis, 2005). Attention has been paid to the ages and stages of children's development in art, and has traditionally focused on the deficiencies of each stage, i.e. what the child can not do yet, such as draw legs and arms on human figures. Rarely, children's abilities as constructors of symbol systems have been acknowledged by researchers (Gardner and Perkins, 1989). Much of our thinking is conceived and stored in symbols (Clark, 2006), and as such, creation of art is a cognitive activity, which involves mobilizing symbols to communicate visually. For example: many very young children use a circle with rays to represent the human form.

Children's art has been recognized as important to cognitive development by the National Association of Education for Young Children. They understand that “...Children are active constructors of knowledge and that development and learning are the result of interactive processes...Play gives children opportunities to understand the world, interact with others in social ways, express and control emotions, and develop their symbolic capabilities. (NAEYC position statement, 1997)” Further, through symbolic play, such as drawing, interactions between the learner and the materials, the learner and teachers, and the learner and peers, "scaffold" the learner's knowledge building, extending and building upon what was previously known (NAEYC, 1997). 
Research indicates that effective early childhood education is learner centered. Learnercentered education is defined as: the focus on individual learners (their culture, experiences, perspectives, interests, capacities, and needs) combined with a focus on how learning occurs, including the pedagogy which promotes motivation, learning, and achievement for all (Henson, 2003).

\section{Multiple intelligence theory and art}

Gardner's theory of multiple intelligences proposes that there are different ways to be intelligent (Gardner, 1990). Relying heavily on standardized IQ tests to assess students' potential success or failure in the school system, then tracking them accordingly, does not meet the challenge of success for all in a democracy. "Only if we expand and reformulate our view of what counts as human intellect will we be able to devise more appropriate ways of assessing it and more effective ways of educating it. (Gardner, 2004, 4)”

Of the eight intelligences Gardner defines_-linguistic, musical, logical-mathematical, spatial, bodily-kinesthetic, intrapersonal, interpersonal and naturalistic —only some are traditionally addressed in school curricula. What changes to curriculum and instruction does Gardner recommend? Foremost among his suggestions is a shift to focus on symbols and symbol systems (Gardner, 2004); every intelligence has an inherent set of symbols, the systems of which are worthy of study.

Symbols are a uniquely human phenomenon, and range from the rigorous, such as the symbols of math or physics, to the more creative and open-ended kinds of symbolism employed by artists. Gardner and colleague Nelson Goodman founded Harvard's Project Zero, designed to focus on the psychological and educational development of symbolic competence; of particular interest to them was the use of symbol in art (Gardner, 1990). Art has its own use of symbols, in every culture, which learners can "read" and use to communicate (Gardner, 1990). Additionally, art can be a bridge that 
connects diverse disciplines of human knowledge (Sidelnick \& Svoboda, 2000). The possibilities of art for connecting areas of knowledge and inquiry intrigued Gardner (1990), as well as Project Zero colleague David Perkins, who wrote that art engages our mechanisms of understanding (Gardner \& Perkins, 1988).

\section{Art as children's tool for understanding}

The arts can enhance learner-centered education when they are presented as process-oriented, and experiential, such as when they are contextualized within a larger project. Making project work an integral part of the curriculum promotes children's intellectual development by engaging them cognitively through observation and investigation of their experience and environment (Glassman \& Whaley, 2000, Katz \& Chard, 2000).

Art can play an important role in young children’s projects (Corsaro \& Nelson, 2003). A child's art can be perceived as his theory construction (Forman, 1994). Project work which involves art gives children the tools and opportunity to ask questions and investigate to find answers. In a sense it is inquiry-based research that even young children can direct.

For example, a child could construct his theory about the nature of water by painting a picture. The child will decide what colors represent water, as well as other physical characteristics: fluidity, shape, volume, and so on, based on his experiences with water. Not only is the child differentiating (Holt, 1967) between all the things that are-water and are-not-water, but s/he is adding shades of meaning and inference as well to the painting. His art is contributing to his understanding about what water is, as well as communicating his understanding.

Now, imagine there is a child next to him, looking on silently until this point, who speaks up. She tells him about an experience she had at the beach with her family, and asks if fish live in the 
water that he is painting. Previous to this conversation, the first child was thinking about water in the bathtub, and now he is thinking about the fact that water is in the ocean as well. He decides to add some fish to his painting. In this way the social interaction has changed the original theory. Because art creation is taking place in a social environment, interactions between learners extend and improve the knowledge being constructed (Barroquierro, 2004)

Forman (1994) adds to this discussion the extent to which a child's theory can be tested by translating the original ideas into another medium. In this example then, suppose the child decided that paint is not quite the best medium to represent all the qualities of water; clay will work much better. As the child works, perhaps struggling to translate the experience of water into clay sculpture, a teacher suggests a certain tool or technique. Assisted by peer or teacher interaction, or perhaps through his own trial-and-effort, the child changes some original hypotheses about the nature of water, due to the affordances of clay as a medium (Forman, 1994).

Art is one way that children can construct epistemology. A large part of knowing and understanding is the organization of our experience. Knowing and organizing what we know go on simultaneously, and can be reorganized in new ways. One of the most basic, first processes of learning is identifying something as meaningful, and separating it from the experience by drawing some type of boundary around it, figuratively and sometimes literally, as in art (Franklin, 1994).

Project work which involves the arts along with more traditional academic activities helps to show the interconnectivity of subjects. In post-modern curriculum, establishing relationships between the disciplines helps learners see larger patterns in human knowledge, and leads to understanding. “...The appreciation and making of works of art inevitably and profoundly involve the application of our apparatus of understanding in various modes and directions (Gardner and Perkins, 1989, 118).” 
Art is amenable to authentic assessment. Children's expression of knowledge through the arts provides adults with a powerful means for accessing children's perception and understanding of their world (Abramson, Ankenman, and Robinson, 1995). This can be illustrated in the project context:

Imagine that in the classroom where the child and his peer were discussing and representing water, the teacher had overheard that discussion and helped it become a group project. Imagine that the Water Project went on for weeks, with different children's representations of water in various media, until the group had decided to take a trip to the aquarium. Afterwards, they drew a giant class mural depicting life under and around the sea. The teacher was able to know more about what her students perceive and understand about water and its properties through their representations, and the discussions that surrounded their creation process. Then, imagine she displayed on the wall at the entrance to the preschool, a beautiful photographic sequence of the children at the aquarium, gazing in wonder, and then hard at work on the mural in various phases, and finally completing the mural. Any visitor or parent would be able to know the story of the mural, and the children's learning, especially if the teacher documented and narrated the ongoing project with captions next to the photos that recorded what the children said and did. In the process of documentation, the teacher has the opportunity to “unpack” the experience and learn about what and how her students learned, as well as tailor her curriculum and instruction to the needs and abilities of her students.

Including children's art in documentation can draw the children’s attention to their own thinking processes through reflection and metacognition, which are higher order thinking skills. Children tend to enjoy seeing what they have created, and to hear what they said as they learned; perhaps their own thinking might inspire future projects, like constructing a boat, or investigating how to swim. Reflecting as a group on projects and participating in ongoing conversations can strengthen the sense of community, and build strong relationships. Positive, supportive relationships, important 
during the earliest years of life, may be essential not only for cognitive development but also for healthy emotional development and social attachment (NAEYC, 1997).

Children involved in learning through group projects often find that there's more than one right answer to a problem. Educators can capitalize on this and increase children’s respect for and understanding of other ways of doing or seeing. The diversity of ideas and problem-solving strategies represented within the group strengthens the overall project and learning, as well as validating personal and group identity. Children’s learning, their knowledge, is constructed socially, as children become active agents in their learning process (Corsaro \& Nelson, 2003). "It is a view of children as meaning makers, but always in relationship with others, seeking an answer, rather than the answer. (Moss, 1999, p.149)”

\section{Art as early literacy}

Young children are aware, even at very young ages, that art is similar to, yet different from writing. There have been several studies which have shown that young children can differentiate between their drawing and writing (Karnowski, 1986). Looking across cultures, Ferrero and Teberosky’s (1982) research in Argentina with young children showed that children by the age of three were able to metacognitively distinguish between drawing and writing in their graphic communications. It is interesting to note that art as early graphic communication is a phenomenon witnessed in other countries and cultures.

Art is communicative (Dewey, 1916); through art, young children can express and respond to ideas and experiences. The artistic media are open-ended opportunities for children to broaden and deepen their knowledge, whereby children acquire knowledge through communication of and representation of their experiences in a variety of media such as drawing, painting, construction of 
models, dramatic play, and verbal expression (Katz, 1995, NAEYC, 1997). Symbolic representation grows in complexity as children gain experience expressing and revisiting ideas with different media (Forman, 1994). It seems reasonable to assume that what each child chooses to communicate to others is meaningful to her or him (Clark, 2006), and in that regard, art helps children construct their identity, and find his or her place in the larger world.

Social-constructive theories, such as those of Vygotsky and Bruner, advance the view that young children actively construct knowledge through communication and interaction with the people and environment around them, and extend the argument that because of these interactions, learning can precede the developmental stages that Piagetians perceive as limits for children’s cognitive abilities (NAEYC, 1997).

Even very young children are able to use various media to represent their understanding of concepts. Furthermore, through representation of their knowledge, the knowledge itself is enhanced (Edwards, Gandini, \& Forman, 1998; Forman, 1994). “... Meaning is formed, not simply expressed or communicated, in the process of giving shape to ideas in a medium... This view of symbolizing activity provides a powerful rationale for placing work with arts materials at the center...of educational curricula (Franklin, 1994).”

Art can be a path to discourse, communication of ideas, with even the youngest children. Art, like language, is a system of symbols designed to communicate. Expression of thought is endemic to all language (Chomsky, 1986). From a social-constructivist view, art and language are semiotic systems, ways of making meaning that are personal and agreed upon in one’s culture and/or community.

Language is for the child a rich and adaptable instrument for the realization of his intentions. ...The child's internal 'model' of language is a highly complex one. In fact, it may be more 
helpful ...to speak of the child's 'models' of language in the plural, in order to emphasize the many-sidedness of his linguistic experience. (Halliday, 1973, 2-3)

Communication is a socially situated act central to the construction of knowledge. Dewey believed that communication is education, as well as the relationships which contextualize communication (Dewey, 1920). When art is created in the social context of the early childhood classroom, it is a natural learning tool for young children to explore the properties of language. Language leads to art, which in turn leads to language, in an ongoing conversation. This concept is illustrated in the Water Project described earlier, in which the children's art sparked discussions, which led to revision and translation into different media. Language extends the learning that takes place through art.

The language instinct is the simplest form of the social expression of the child. Hence it is a great, perhaps the greatest of all educational resources. Then there is the instinct of makingthe constructive impulse. The child's impulse to do finds expression first in play, in movement, gesture, and make-believe, becomes more definite, and seeks outlet in shaping materials into tangible forms and permanent embodiment. The child has not much instinct for abstract inquiry. The instinct of investigation seems to grow out of the combination of the constructive impulse with the conversational. (Dewey, 1920, p. 43)

Language and communication are inextricably linked; it impossible to separate the communicative functions of language from the meaning of what is spoken (Ellis, 1999). Because of the complex nature of language, it really can not be taught; learning about language is therefore emergent, as the learner constructs his understanding of language through his use of it. Further, language learning is the basis of all learning, and as such is tremendously important to the education of young children. 
When children learn language, they are not simply engaging in one type of learning among many; rather, they are learning the foundations of learning itself. The distinctive characteristic of human learning is that it is a process of making meaning-a semiotic process; and the prototypical form of human semiotic is language. Hence the ontogenesis of language is at the same time the ontogenesis of learning. (Wells, 1994, p. 42, par. 1)

It is reasonable to assume that learning to create art, creating and using symbols, is a form of language learning. Learning how to express ideas through art, for young children, is a developmentally appropriate way to learn about the qualities of language and the communicative affordances of symbols (Dickinson \& Schaffer, 1991). Further, art offers a chance to communicate richly, especially if the children have a variety of media with which to work.

And so the expressive impulse of the children, the art instinct, grows also out of the communicating and constructive instincts. It is their refinement and full manifestation. Make the construction adequate, make it full, free, and flexible, give it a social motive, something to tell, and you have a work of art (Dewey, 1920, 44).

Art is made up of visual symbols, which are representations of socially, culturally, and individually constructed knowledge. When art is created, the artist is sharing his or her unique vision. When we create art, we externalize the internal; we reveal who we are by how we see things. "...Language is primarily a social thing, a means by which we give our experiences to others and get theirs again in return. (Dewey, 1920, p. 49)" This exchange of ideas shapes our own thinking and perceptions, and that of others. Thus our knowledge is constructed, not in a vacuum, but in a social context.

Vygotsky put forth the idea that language facilitates socialization, because it enables people to determine, execute, and reflect on their actions through speech; in addition, language is a medium in 
which those activities are symbolically represented, and it is a tool that can externalize the internal discourse of thought (Wells, 1994). As symbol systems which are constructed in a group setting, or mediated by translation in a social context, children's art acts as a social learning tool. Art offers a chance for cooperative learning which is in fact co-construction of knowledge.

\section{Art as a language in Reggio Emilia}

The theory of art as language has been put into practice in Reggio Emilia's preprimary schools, and in schools inspired by the Reggio Emilia approach. There, the teachers listen to children's art and use it to guide their curricular and instructional decisions, called "negotiated curriculum.” Theirs is a socio-constructivist perspective, “... where knowledge is seen as constituted in a context through a process of meaning making in continuous encounters with others and the world, and the child and teacher are understood as co-constructors of knowledge and culture. (Rinaldi, 2006, 6)”

Reggio educators contest the linear view of knowledge acquisition, and the project-based learning that takes place there can move in many directions. They challenge the separation of the disciplines and join other postmodern theorists in questioning the organization and compartmentalization of human knowledge (Rinaldi, 2006). Central to their concept of learning and educating is the forming of multiple connections and relationships, experimenting, and forming and resolving conflicts and problems.

Theirs is a pedagogy of listening (Rinaldi, 2006). Listening to children requires that teachers “...value the process of exploring children’s ideas, theories, questions and opinions. (Katz and Cesarone, 1994, 25).” This enables teachers to enter the child's world, rather than forcing the child to adapt to the adult world. The Reggio Emilia approach is learner-centered, and positions the teacher as learner, too. Teachers study and learn from the ideas expressed in children's art, conversation, and 
play (Katz \& Cesarone, 1994). Further, they use their observations and interactions with the children to arrive at a negotiated curriculum, which reflects the interests of the group.

Language is one way humans construct what they know as reality, and as identity, cultural and social and personal:

We are constituted through language which means that we cannot live outside of language: 'Life happens to us, experience happens to us, the worlds we live happen to us as we bring them forth in our explanations (Maturana, 1991, 49, in Rinaldi, 2006, 12).' A shift is proposed, from language as an abstract thing, a noun, to languaging as an act, a verb.

Languaging brings forth a world created with others in the act of coexistence which gives rise to what is human...(Rinaldi, 2006, 12)

In this study, I wanted to examine the languaging of young children through visual art. In particular I wished to look at their drawing, because of the graphic nature of the symbols; I sought to read the ideas of children in their drawings. The focus of this research was to explore the communicative functions children's drawings can fulfill in an educational environment in which the teacher is listening in the Reggio Emilia inspired sense.

\section{Halliday's Communicative Functions of Language}

Halliday defined seven communicative functions of language of which young children are capable in his landmark text Explorations in the Functions of Language (1973):

1) Instrumental: Language used as a means of satisfying material needs

2) Regulatory: Language used to regulate the behavior of others

3) Interactional: Language used to mediate and maintain relationships

4) Personal: Language used to express self and form individual identity

5) Heuristic: Language used as a means to investigate reality, to question 
6) Imaginative: Language used to express creative thoughts, to play

7) Representational or Informative: Language used to communicate content, to express what is known or understood.

Halliday felt strongly that language and learning are linked inextricably. "In order to be taught successfully, it is necessary to know how to use language to learn; and also how to use language to participate as an individual in the learning situation (Halliday, 1973, 10).” He wrote that a child's identity and ideas about reality are formed, and maintained through language. His perspective was similar to Malaguzzi’s “100 Languages” concept, as his theory proposes that a child’s concept of language is much larger, richer, and more multi-faceted than any adult can understand (Halliday, 1973); like Malaguzzi, Halliday felt that the capacities of children's language are underestimated.

Halliday's concepts about the communicative nature of language have been applied widely in various areas of research. Fields as diverse as social psychology, structural linguistics, speech and language pathology, journalism and mass media have used the idea of communicative function to frame language-related issues.

The educational research influenced by Halliday's theories has taken place in fields as diverse as developmental psychology, emergent literacy, language instruction, and often special education, in particular with deaf or disabled children. For example, a recent study entitled: "The Use of Communicative Functions among Pre-school Children with Multiple Disabilities in Two Different Setting Conditions: Group Versus Individual Patterns” determined that the relationship between disabled young children's environment and use of communicative function was stronger than the relationship between the individual specifics of their disabilities and use of communicative function (Olsson, 2005). 
Another study focused on the development of communicative functions from informative to heuristic in young children with and without hearing loss. This study concluded that the functions progress differently for hearing and hearing-deficient children, but that both groups correlate increase in complexity of communicative function with maturity and growth (Nicholas, 2000).

Of significance to my own research is the lack of recent application of Halliday's theory of communicative function of language in a) typical early childhood settings and b) to visual art. This gap in the research indicates a need for further study. Additionally, the proliferation of interest in communicative function, in particular for early childhood, suggested that the time was ripe for such study.

What might Halliday's communicative functions look like, if constructed through young children's art? The instrumental function might be something like a toddler drawing a round shape and pointing to it, saying, "Pizza.” In this way, his art could help him express his desire, and perhaps preference, for a specific food.

In my preschool classroom, the regulatory function was utilized by a four-year-old, who made a sign for the classroom "climber". She created a drawing to communicate that the climber was closed by visually portraying the climber with a black circle around it and an X through the middle. In this way, her art helped her affect the behavior of others, or so she hoped. The interactional function followed, as a classmate, a bit younger, sought to emulate her work by creating his own sign for the climber, using art to interact with the older child, perhaps hoping to build an alliance.

I have also witnessed the interactional function used by children creating art for each other, to communicate. One little boy drew furtively secret art on construction paper, using his arms and body to shield the contents from scrutiny; he next cut it up with a scissors, placed all the pieces in an envelope and sealed it, drew more on the outside of the envelope, applied some stickers, then slipped it 
into the hand of a favorite female friend of his. Later that day, they played "wedding” in the dramatic play area.

The representational or informative function is used by children all the time, as they draw to show what their houses look like, or their pets, or what their sister's mouth looked like with three missing teeth... Young children often use art to describe reality as they see and live it.

The personal function of language shares personal feelings and emotions; in art this could be a child drawing a picture of dog heaven, and explaining to you that her puppy went there, even though this made her sad. Barroquierro (2004) found this to be the least likely utilized function in her research.

The imaginative function of language is also frequently utilized by young children in their art. Many of the youngest children know that when they draw giant dragons, purple flying robots, or themselves as princesses, that these things are not really real. I put forth the idea that children's imaginations stretch when they express their imaginings though art. Maxine Greene wrote that, “...We must make the arts more central to the school curricula because encounters with the arts have a unique power to release imagination. (Greene, 1995, 27).”

The heuristic function can be used to question, test theories, or find out how things work. For example, how does a race car go? Really, really fast and around in circles, a former three-year-old student of mine determined, as he raced his marker in faster and faster circles around the edges of his paper, chanting “vroom...vroom...” softly to himself. His art explored the ideas of speed and circularity, rather than depicting a car, demonstrating what Forman refers to as theory construction (1998).

The heuristic function of art seems quite valuable, particularly in the educational context. This is the linguistic function I imagine Reggio Emilian, and similarly inspired teachers listen to. In 
this type of communication, children might draw what they want to know, what they wonder, or what they are in the process of learning, which is a form of inquiry. This could take the form of blueprints being drawn by the children after their class has gone to visit a construction site, or the ocean drawn by the child who has just seen it for the first time. It is a way of using art to ask questions, pose and solve problems, and construct knowledge.

\section{Another view of art and communicative function}

Barroquierro (2004) studied the problem of young children's communication in the process of art creation. As an early childhood art educator, her focus on this topic was slightly different from mine. She examined the form, content, and social aspects of children's art creation, using primarily the oral, but also visual functions of language to illuminate the artistic process. She asked, "How does language function in young children’s art making events? (Barroquierro, 2004)” Her research also took into account which pedagogical practices and activities would scaffold and facilitate children's art and social learning.

She utilized Dyson's five major functions of language, based on the theories of Halliday and Tough, in her study:

1. Representational language: language used to give information about events and situations, real and imaginary.

2. Directive language: language used to direct the actions of self and/or others.

3. Heuristic language: language used to seek information.

4. Personal language: language used to express one’s feelings and attitudes.

5. Interactional language: language used to initiate, maintain, and terminate social relationships. (Dyson as cited in Barroquierro, 2004) 
These categories were contextualized by Bruner’s three facets of language, syntax, semantics, and pragmatics; she also examined the realms of knowledge which children expressed through their art: factual, fictional, autobiographical, and affective (Barroquierro, 2004).

Barroquierro utilized an Artistic Research Design Model, based on La Pierre’s Continuum of Educational Research Methods and Possibilities (La Pierre and Zimmerman, 1997 in Barroquierro, 2004). This model involved settings, conditions, and ways of thinking which are domain-specific (Barroquierro, 2004). Some aspects of her methods were: qualitative, inductive and deductive, interpretive, subjective, idiosyncratic, illuminative, explorative, affective, and imaginative. She used a small sample size of a purposefully selected population to collect her data, which consisted primarily of sketchbook drawings by young children, video recordings, and transcripts of art-making and social interactions.

Barroquierro’s research yielded some very interesting and relevant results about how children combine social interaction with art, and language with imagery. She concluded that children’s knowledge expressed through art was most often fictional or autobiographical. As for the functions of language, she determined that Dyson's interactional function was most common in the children's communication, while expression of emotion was least common (Barroquierro, 2004).

\section{Research design. implications, limitations}

I propose to use Halliday's communicative functions as a guide to the language of art, and to help me answer the question: What can young children draw to communicate? I hope to address this question qualitatively, and phenomenologically.

This project is not designed to arrive at a broadly applicable conclusion; I do not seek to generalize from my data analysis, for example, the way that all children communicate through all their 
art. This phenomenological perspective on children's art will show a way to understand what some children can communicate through art.

Because the research involves young children, the emphasis is on the educative and explorative nature of art. I will attempt as much as possible to make the learner the center of the research, with the story of his/her learning as the main narrative. Illumination of the process of art creation is a main goal.

Another consideration is the interpretive subjectivity on the part of the researcher in the analysis of the children's art. “The act of constructive interpretation is a creative event of meaningmaking (Brearly, 2004, 5)” I do not seek to keep myself out of the narrative of my research. On the contrary, I hope to use my voice as a teacher, a learner, a participant and observer to illuminate and open up the learning processes of the young children I will study.

A defining aspect of qualitative research is the role of the researcher as the instrument used to collect and analyze data (Edwards, 2001). The validity and reliability of qualitative findings depend on the researcher's honest awareness of self as a lens through which the research is viewed.

Consequently, I feel it is important for the reader to share this awareness, to know whose voice s/he is listening to, and to be able to consider the lens and potential biases of the researcher.

\section{Personal and Research History}

In this case, I, the researcher, am a doctoral candidate at a land-grant university. I am a white, Jewish, middle-class woman who was born in the heart of the Appalachian Mountains. I am heterosexual, married, and have no children. Being a preschool teacher is a large part of my identity. I began teaching in the early childhood setting in 1996. I was employed at the time of this study as a 
Graduate Assistant, supervising student employees and working with children in an informal early childhood setting on the university campus.

Originally, I had intended to carry out this research project in a Reggio Emilia approach inspired setting, in which I was merely an observer. However, exposure to Barroquierro’s research (2004), which took place in a studio based on the Reggio Emilia model, conducted by an art specialist, changed my approach. Instead I decided to conduct this study in the child care setting in which I taught, as a participant-observer. I felt strongly that the phenomenon of communication through art could happen anywhere that children create art.

The setting in which I worked with children was a university drop-in setting, informal, which provided care for children, ages from 6 weeks to 12 years, while their parents utilized recreation facilities on-site. The center's physical location was in the Student Recreation Center on the university campus, and those whose children attended were students, faculty, and staff at the university. Of particular interest was the wide range of cultures and nationalities of the children in this particular setting; I worked with children from Italy, Sweden, Germany, France, Panama, Peru, India, Lebanon, China, Ethiopia, Bulgaria and other countries.

Some of the research suggests that bi- and multi-lingual children, because of their sensitivity to different contexts for using language, are likely to have a heightened awareness of the possible range of contexts for literacy and increased possibility of the range of communicative functions which written (or perhaps drawn) messages may convey (Wallace, 1987).

One aspect of drop-in care is that I did not have the consistency of a formal classroom; some children came the three days a week which we were open, or only one day, or perhaps only a few times a month. However, with my background and philosophy of early childhood education, I helped to design and evoke an environment that had many opportunities for creative expression. As a result 
the children enjoyed their time in the center, and tended to return frequently once they began to attend. Some children were "regulars", and it was from this group that I selected the participants in this research project.

Another limitation of this study was that the setting was not conducive to in-depth project work, such as would have been ideal for the study of communicative art in the Reggio Emilian sense. However, I did respond through curriculum and materials to the children's interests, and provided opportunities for them to revisit and extend ideas and experiences that capture and appeal to them. Also, I placed in a central location, a mini-atelier, or art center, with lots of creative materials in reach and sight of the children; for many children who attended the center, this was the place where they went first and most often within the center. Art was very popular with the children within this setting. My intent was to ensure that the art I observed and analyzed for communicative function was voluntary and authentic (Barroquierro, 2004). To this end, I provided the participants with their own sketchbooks, in which they were invited to draw whenever they were at the center. I selected a group of five children, of various ages and nationalities, who manifested the tendency to draw and create art voluntarily. This sampling method was purposive and fully intentional, so that I could study the phenomenon of young children's communication through art, paying particular attention to the differences of the participants. I attended closely to the artwork of these 5 children for a period of 6 weeks. This time frame allowed for the emergence of patterns, themes, and artistic expression in the children.

\section{Philosophy and pedagogical style}

My approach to teaching/learning with children is intuitive. Perhaps because my mother is a teacher, I find that I am maternal and informal with young children; because I want the best for them, I 
strive for the creation of an environment where children can be who they are, where children can determine the curriculum through their interests, play, and personalities. I perceive my role as teacher to involve much improvising, as I play with and learn from children in any setting in which I interact with them. I find that the natural interactions with children, as they go about their daily lives, offer a wide range of teaching/learning opportunities.

I was first schooled in a Montessori approach preschool, starting when I was 3. From Montessori's approach, I came to understand the value of solo play, or a bit of distance, to allow uninterrupted interaction between children and environment—-their world. This viewpoint strengthened as I first taught in a Waldorf-inspired preschool, as an undergraduate student. I began to think that the child's world/worlds, their particular reality deserved space, respect, and interest. There is a place for guidance and teaching, and also a place for observing and learning from young children, as they struggle and grow from learning new ideas and concepts.

As a teacher, the aspects of the environment that inspire, evoke, and support creativity— literally, the generation of ideas-has become my focus. I make sure to include the arts in every way possible. As a cultural outsider in the place where I grew up, the arts were my outlet for expression, my entertainment, and my construction of identity. I played and composed music, studied dance, acted and sang in plays and musicals, and wrote poetry, songs, plays, and short stories, many of which I illustrated with unskilled but enthusiastic art. When I began teaching, I naturally gravitated towards creative expression, and found young children respond with growth to the creative arts.

As a graduate student studying the Reggio Emilia approach for the first time, I found validation and confirmation of my beliefs and practice. The Reggio approach combines the rigor of science with the aesthetics of art, and this union is actually quite spiritual, humanizing in the Freirean sense. I felt awakened by exposure to this philosophy, to Loris Malaguzzi and recognized the importance of 
concept of the "100 languages of children” (Malaguzzi in Edwards, et al, 1998). Hence, I seek to apply many of these principles in the design and content of my dissertation, by consciously seeking to combine the methods of science with the creativity of art, just as I have always sought to do with my teaching.

My style of teaching, which has been influenced by the theories of Montessori and Waldorf, and particularly the Reggio Emilia approach to early childhood education, is validated by recent research. Edwards (2002) pointed out that these three approaches share a perspective that children “....are the active authors of their own development, strongly influenced by natural, dynamic, selfrighting forces within themselves, opening the way toward growth and learning (Edwards, 2002, par. 7).”

In the last few years more research has come to show that this arts-rich, play based, socialconstructivist perspective that I embrace is actually best practice (Walsh \& Gardner, 2005). "Further, findings are accumulating that suggest potential negative consequences associated with highly structured, academic preschool programs (Goffin, 2000, par. 13).” This makes researching children’s communication through art, and other creative expressive forms, a timely act.

\section{Chapter Three: Methodology}

The literature of early childhood education is filled with reports of studies in which children have been the objects of inquiry. Given the amount of work focused on children, it is surprising how little we know about their lives. Little if any attention is paid to the contexts in which children live. Where are those young ones whose actions change so much from home to school to playground? Where is the understanding of, or even interest in, children's lived experiences? 
It is ironic that a field that takes great pride in its attention to young children has been dominated by research methodologies that are, in practice, quite distanced from children themselves (Hatch, 1995, 136).

\section{Research Overview}

The goal of my research was to construct understanding of a view of children's visual art as communication. This study was conducted by me, in the early childhood program in which I was employed as a teacher and supervisor. In the setting of this drop-in center, I observed 5 children as they created visual art over a 6 week period. I took notes on this process, conducted interviews with the participants, their families, and other educational stakeholders. I collected the children's artwork in sketchbooks, folders, and photographs. My aim was to study children creating art in a real context, to pay close and systematic attention to children's interactions with the environment, with each other, and with the art they created. I attended to the "concrete particulars" of their lives, and recorded those particulars in painstaking detail (Hatch, 1995, 139). Depth and richness were my goals for data collection.

The results for my research took the form of a series of narratives. These narratives revealed the details of each child's artistic process, and the interactions which contextualized the art they created. My interpretations were balanced by interviews with students and parents, and others in the setting.

I coded these results by communicative function, as well as by other behaviors and characteristics which seemed significant to the artistic and communicative process, such as verbal statements, social interactions, and discrepancies between what I saw and what the participants described. These led the analysis of the data, as I noted emergent themes and patterns, as well as 
differences between children. However, my aim was not to judge, score, or evaluate. I simply wanted to illuminate the communicative functions of children's art in a particular early childhood educational setting with an eye towards understanding children's meaning-making. Illuminative research provides information which challenges assumptions and offers novel and creative ways of interpreting familiar events (Edwards, 2001). The information that my research has generated may be helpful for rethinking assumptions about early childhood and how we teach and interact with young children. 

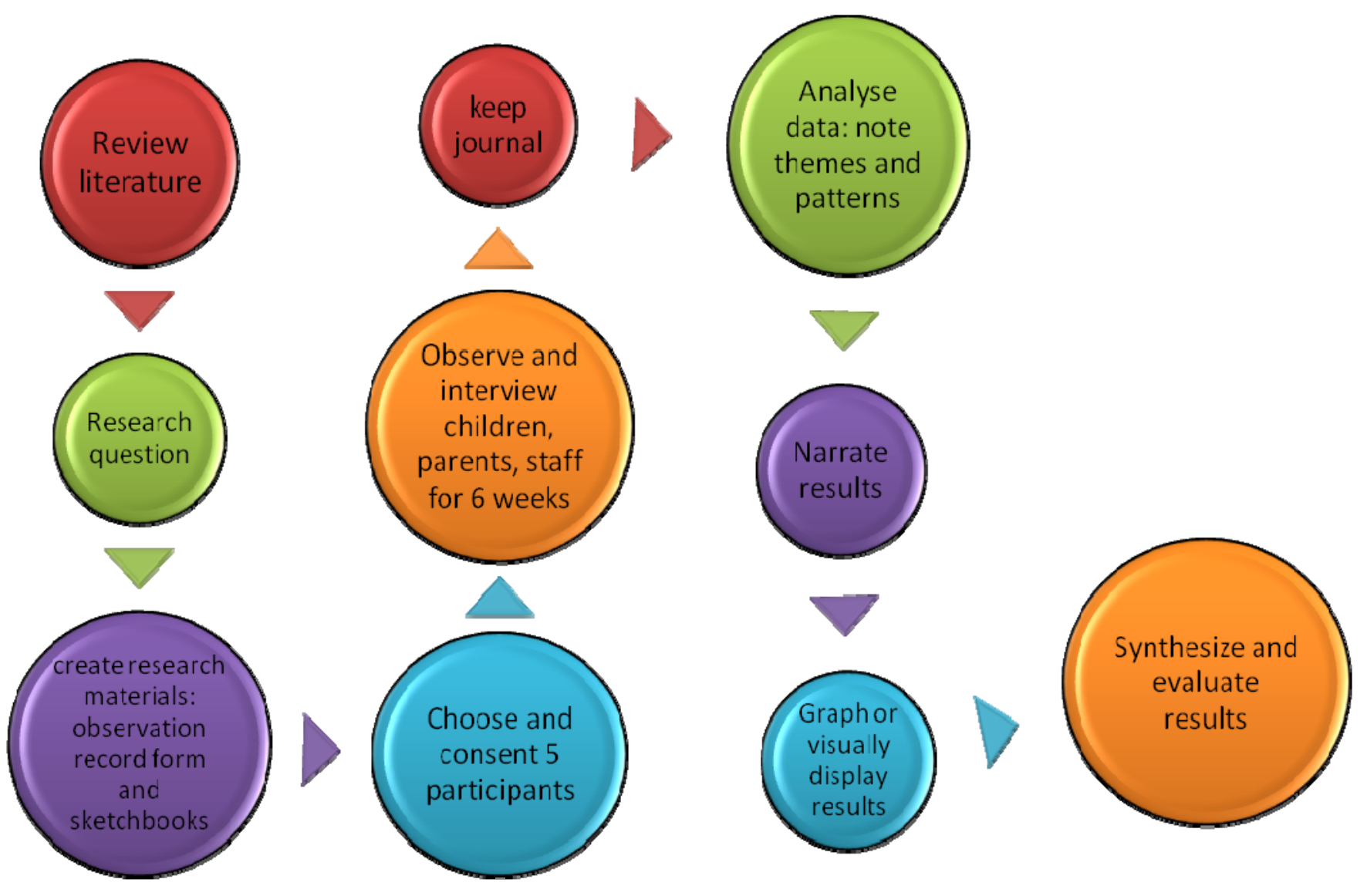

Figure 1. Research design flowchart.

\section{Research Design}

...The notion that the quality of learning environments can only be assessed in terms of outcomes, context, and teaching style has been challenged. Instead...the quality of an early years setting is principally determined by the way in which the learning and developmental needs of the main stakeholders — that is, the children—are met. (Walsh and Gardner, 2005, par.13) 
This study involved an interpretive research design. "Interpretivists argue that rather than simply perceiving our particular...circumstances, each person continually makes sense of them within a cultural framework of socially constructed and shared meanings, and that our interpretations of the world influence our behaviour in it (Hughes, 2001, 35).” I felt that this methodology and orientation accurately represented the topic of children's communication through art and represented well my role as teacher.

I chose to undertake the research for this topic phenomenologically. I was interested in the phenomena of each child's process of learning to communicate in a wide variety of ways. Because of the wide range of variety in human development and interactions, to which I wanted to stay open and flexible, and in order to incorporate a broader, richer array of information, the design of this project was flexible.

This research design incorporated aspects of phenomenology, social constructivism, heuristic inquiry, and hermeneutic interpretation. "The hermeneutic act of interpretation involves in its most elementary articulation making sense of what has been observed in a way that communicates understanding. Not only is all knowledge production merely an act of interpretation, but, hermeneutics contends, perception itself is an act of interpretation (Kincheloe, 2001, 245).”

From hermeneutics, I adopted the stance that understanding children’s art required interpretation; this interpretation was subjective, shaped by my identity, experiences, and role as researcher. Because I could only interpret, there was no absolute or correct truth at which I can arrive (Patton, 2002). However, this deep, rich look at young children's art garnered information that should be useful to teachers, researchers, and other educational stakeholders.

This research was contextualized by a recent surge of interest in art as a research method for studying aspects of education and children's development. Researchers have combined participant 
observation, structured and informal interviews, drawings, and narratives with photographs as multiple means to access children's views, experience, and knowledge construction (Haney, Russell \& Bebell, 2004, Klein, 2001). There was a range of reliability and validity evidence to show that children's drawings could be used as documentation of learning (Haney, et al, 2004).

\section{Sampling}

For this study, I selected five children from the 140 children that attended the center where I taught. I picked these five because they were foremost among the children who always chose to draw while at the center. I wanted to select participants that had a passion for visual art. This sampling method was fully intentional, so that I could study the phenomenon of young children's communication through art.

The child care setting where I worked was informal, but provided the opportunities for visual art necessary to the study. Key was my ideological orientation as an educator in this environment towards art as one of the "100 languages" (Edwards, Gandini, and Forman, 1998). I focused on the participants' art creation processes for a period of six weeks. This time frame allowed me to perceive the emergence of patterns, themes, and artistic expression in the children.

My intent was to ensure that the art I observed and analyzed for communicative function was voluntary and authentic (Barroquierro, 2004). To this end, I provided the participants with their own sketchbooks, in which they were invited to draw whenever they were at the center. Because I knew these children so well already, I knew that they would enjoy and even benefit from the extra attention to their art. 


\section{Participants}

The participants were given pseudonyms, so I could protect their identity. Adam was three years old. He liked to draw when he was at the center, particularly with an adult. He was halfEgyptian culturally, but he was raised in the U.S., and did not speak the language. Adam lived with his mother primarily, although he sometimes stayed with his father; he had no siblings. He was small for his age with a quiet intensity in his actions and interactions. He could be a very literal person; once I called him "sweetie” when he was two years old, and Adam corrected me. "I'm not sweetie; I'm Adam,” he informed me.

Alice was three years old. She drew constantly when at the center; art was her favorite activity. She was also amazingly good at puzzles; at 2 she could solve a 45 -piece jigsaw puzzle alone. Alice loved anything to do with animals, particularly dogs and cats. She was half-Vietnamese, and spoke some of the language. Her mother was from Vietnam, and gave Alice words in her home language when she requested them. Alice had an older brother who was six years old, whom she adored. She lived with her mother, father, and brother.

Rose was three years old. She liked to draw and paint, and chose these activities first when at the center. Prior to this study, she was an only child. However her parents were expecting another child, so this research was conducted in the time period before she was to have a sibling. Rose loved dramatic play, and was often in head to toe costume the whole time she was at the center. She lived with her mother and father, with a new family member on the way. They did not identify themselves culturally.

Sara was five years old, and turned six shortly after the study concluded. She was an avid artist, and primarily chose to draw or paint when she was at the center. Sara had with no siblings. She lived with her mother and her grandparents. Sara easily engaged with other children as well as adults, 
quietly but on her own terms. She had a calm way about her that seemed to particularly draw younger children to her. She liked to volunteer to help out the staff in the infant room, and was very gentle with the babies. She could read and write, and was the only child known to do so in this study. Sara’s family did not identify themselves culturally.

Seth was four years old. His family identified culturally as Persian, and he was an English language learner. He liked to draw, particularly with a familiar adult. He had a younger brother who was not quite two years old. He would follow Seth around sometimes and imitate his actions, which annoyed Seth greatly. I had several talks with him about strategies he could use with his brother to get some space. He seemed to need the words or the permission to verbalize his frustration. Seth enjoyed music so much, that he would sing every day that he was at the center; he even took requests from the staff. He and his brother lived with their mother and father.

All of the participants’ parents were students, faculty, or staff at the University where this research was conducted. All of the participants’ families utilized the University’s recreation facility where the child care center was located.

\section{Data Collection}

The collection of data centered on observation. I created an observation record, a sample of which is included in the appendix. The observation record included the following elements: date, time, participant name, artwork number, setting, if the child created the art solo/in group/pair, if the art was created as part of play, if art led to any social interaction, materials or media chosen, verbal communication—questions/statements, what I see in the art work, participant description of art created, communicative function/s: instrumental, regulatory, interactional, personal, heuristic, 
imaginative, representational/informative, and any notes I had, including parent interviews, which shed light on the child's communication or meaning.

This form guided my observations by keeping me focused on the details of what happened in the child's drawing process. If play or social interaction preceded the drawing, I noted what it was. If the child communicated verbally during the process, I wrote down what was said by everyone in the conversation. I wrote my own description of the artwork when needed, especially if the child's description of the drawing seemed at odds with what the drawing appeared to be. I also noted the communicative function(s) that initially seemed evident in the art, even if I later changed my mind about how to categorize the art.

The art observed had to meet the following criteria: it had to be child initiated, not teacher directed, had to be a drawing, and had to be created in the classroom setting. Collection of artifacts stemmed from the preceding conditions. I obtained the child's and parents' permission to either photograph the artwork or keep the original.

To aid data collection, I provided sketchbooks to the children in the setting. These were available to the children at all times, so that they could draw when they felt inclined. However, I did not limit the art I studied to the sketchbooks alone, as Barroquierro did (2004), because I would have missed opportunities of communicative art that occurred in different contexts. For example, when a participant decided to get a piece of construction paper and make a card for a family member, I included that in my observation, photographed the art, and interviewed the child about the intention of the artwork.

Validation was determined by the triangulation of artifact analysis, documentation of observations, interviews with children, and parent interviews, as well as by referencing any relevant research. Artifact analysis was framed by Halliday's communicative functions of language. I also 
looked at the content of the artwork, the context in which it was created, and any information other than the drawing itself which helped to illuminate the child's communicative intent.

To understand the children's lived experiences more fully, I continued to interact freely with the children during and after the course of the study, so that the relationships with them that I had already established could continue. As a participant-observer, I aimed to be close to the Reggio Emilian idea of "teacher-researcher" (Rinaldi, 2006), someone who is invested in the processes of the children's learning, not merely the outcome of my study.

This research stance is established and well regarded in the field of early childhood education (Barroquierro, 2004). Maintaining an “objective” stance, in which I imagined myself outside and removed from the situation in which I observed would have been an illusion. Young children are naturally curious and inquisitive, and seek interactions with those in their learning environment. Further, the genuine relationships which I established with the children I studied and observed helped me gain valuable insight as I recorded and interpreted their creation of art.

\section{Interview Protocol}

Interview protocol was primarily unstructured and conversational. Mainly I asked participants the questions that lent clarity to my interpretations and understandings of artistic elements and communicative intent(s). I interviewed participants, parents and other adults in the setting as was relevant to each situation of art creation. I relied on each child to teach me which questions are most important to ask (Hatch, 1995).

From my years as a preschool teacher, I knew that certain questions would yield more fruitful responses. For example, a common question I asked was, "What can you tell me about your picture?” I recorded the response faithfully. 
I interviewed parents informally, as situations of art creation arose which required further illumination. For example, when a participant drew something that I could not understand, I asked a parent for clarification. Also, if a participant would have given a verbal description that included words in another language, I would have asked the parents for translation.

I also had a more structured interview protocol, a copy of which is included in the appendix, which I used for a one-time interview with the parents of the participants. In this interview, I asked four questions which addressed the child's patterns of art creation, family response to art, family communication style, and cultural or language considerations of which I should be aware. The purpose of this interview was to help me with the data analysis.

\section{Data Analysis}

I used an emergent approach to data analysis, sometimes called data-driven analysis (Edwards, 2001). This involved the development of a coding system based on my observations about how the children communicated through their art. First, I read over each observation record and interview transcript multiple times to gain an overall impression of the gist of the participants' experiences with art and language.

Next, each interview/observation was analyzed as a whole, combined with the child's work of art and triangulated by any notes shedding light process of art creation and communication, such as parent interviews or my research notes. Third, I looked at each child's art over the six week period which I coded and grouped by communicative function, as well as other significant characteristics. Finally, I integrated and synthesized the visual art, the child's words and experience of creation, any relevant information from participants in the setting, the communicative function or functions utilized 
by this child in this particular work of art, and my own response to the communication as teacherresearcher.

\section{Results and Conclusions}

I have arrived at five interwoven sets of narratives, each describing in-depth how a particular young child created art and communicated visually over a specific period of time. My overall goal for this research is to contribute to the body of knowledge about young children's learning. In particular I wish to inform future pedagogy and curriculum design in order to maximize children’s creative opportunities for knowledge construction through meaning-making and communication. I hope to create a foundation upon which I, and others, can conduct further research.

My recommendations include concrete suggestions for early childhood research, theory and practice that result from my research process. I have kept a personal research journal, upon which I will draw while determining my results. I will keep track of any additional enlightening insights and include these in my conclusions and recommendations.

\section{Research Timeline}

My dissertation committee approved the prospectus for this study in early October, 2007. Because of a new institutional review system, it was late April before I was approved to begin my data collection. I began the six week period of data collection on Monday, May 19, 2008, and ended it Saturday, June 29, 2008. 


\section{Chapter Four: Data Collection}

\section{Participants}

There were five participants in this research project. Three of the children were three years old: Adam, Alice, and Rose. Seth was four years old at the time of the study. He spoke English as a second language; his family spoke Persian in the home, as they were from Iran. Sara was five years old; she turned six two weeks after the study concluded.

\begin{tabular}{llllcc}
\hline Participant: & Adam & Alice & Rose & Sara & Seth \\
\hline Age: & 3 & 3 & 3 & 5 & 4 \\
\hline Family: & Mother & Mother, & Mother & Mother & Mother, \\
(who child & or & Father, & Father & Grandfather, & Father, \\
lives with) & Father & older Brother & Baby & Grandmother & younger \\
& & & sibling on & & brother \\
& & & the way & & \\
& & & US & US & Persian \\
\hline Culture: & US/Egyptian & US/Vietnamese & US & Female & Male \\
\hline Gender: & Male & Female & Female & Femglish \\
\hline Other: & & Bi-lingual, & & & language \\
& & knows some & & & learner \\
\hline
\end{tabular}

Table 1: Participants' characteristics 
Monday May 19, 2008

Seth. Seth arrived at 4:30. As he was one of the first children to arrive, the room was mainly empty, so he chose to come to the art table where I was seated. I offered him a sketchbook of his own to draw in. He sat down, and picked the colors of marker I should write his name on the cover with. "Red and green are my favorite colors," he informed me. Then he turned the page and began to draw. He started with a large round shape, then traced that shape with a second line in another color. Finally, he added other colors in a section of the round shape.

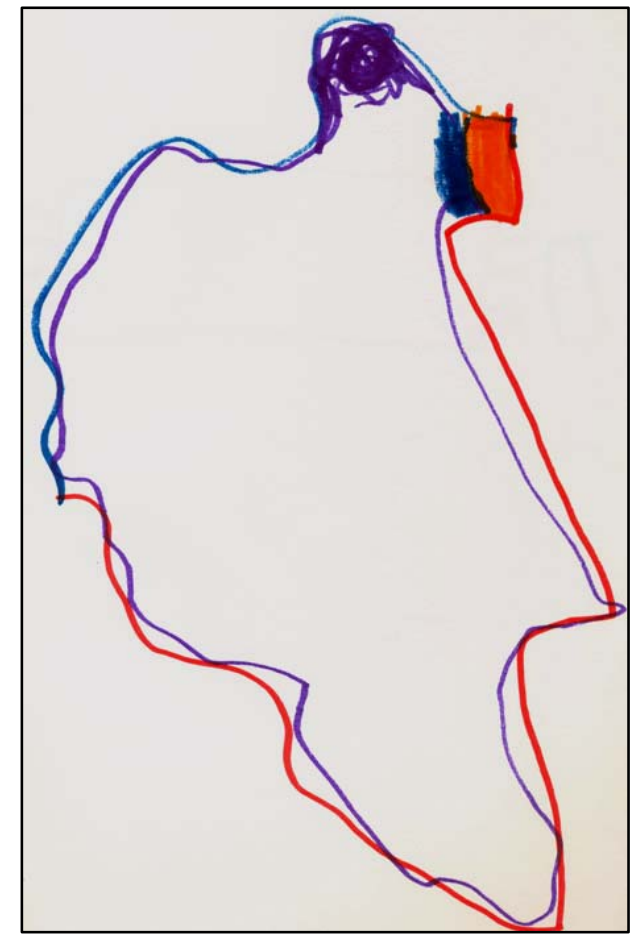

Figure 2. Seth \#1

Seth told me when he was done with his drawing that it was a "cool rainbow". I asked him if he had ever seen a rainbow. He had only seen one on TV, he told me, but he did not hesitate to name what he had drawn. I knew that his drawing seemed to communicate something that he felt was real, so the function of language closest to this effort is representational/informative. There was also an element of imagination involved, as he showed something he had never seen in real life. 
Adam. Adam was having separation problems. His father brought him into the center, and Adam was very clingy, climbing on and hiding his face in his father's body. I greeted him, and offered him the sketchbook. Seth was already seated and drawing, so I suggested that maybe Adam would want to join him at the art table. His dad brought Adam to the table to begin drawing.

Adam's father sat by him, and interacted verbally with his son, talking with him about the color names of the markers he chose and the contents of his drawings. Adam wanted his father to draw with him, but I brought his dad a separate piece of paper to draw on. Adam drew quickly, dashing off the first drawing while I was sitting with Seth. So I had to run over to Adam, turn back the page, as he was already on to the next one drawing in a different color, in order to ask him about the first drawing. He named the parts of the picture that I pointed to, in a tone of voice that suggested it was obvious what they were. Because he could not verbalize an overall concept or theme to picture 1 , it seemed to me to be instrumental, as he was drawing to communicate basic concepts such as color and line, as well as exploring the media.

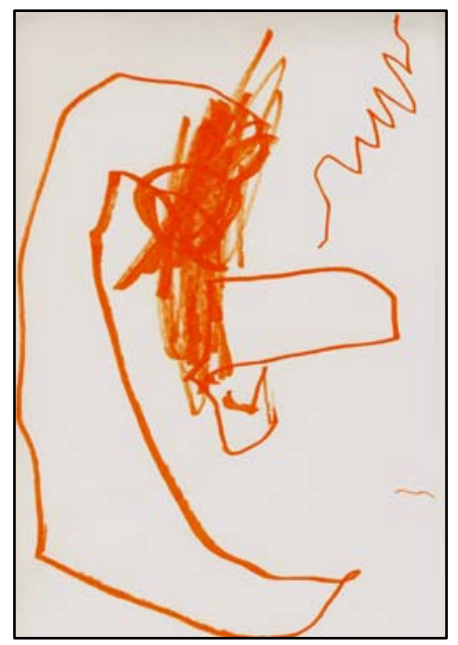

Figure 3. Adam \#1

While I talked briefly with Seth, Adam began explaining to his dad about his drawing 2, so that I missed the beginning of that conversation. I ran back to them, and was able to catch Adam making 
the "sroosh, sroosh" noise that his machine in the drawing apparently made while it was working. Then he pointed out the tiny "toy" on the side of his picture. After I questioned him about its function in the machine, and he explained that the machine made the toy. "Only one toy?” I asked. He considered, then began adding more toys to the drawing. I hoped that that was his idea, not one I fed him with my question, but it was too late to take it back.

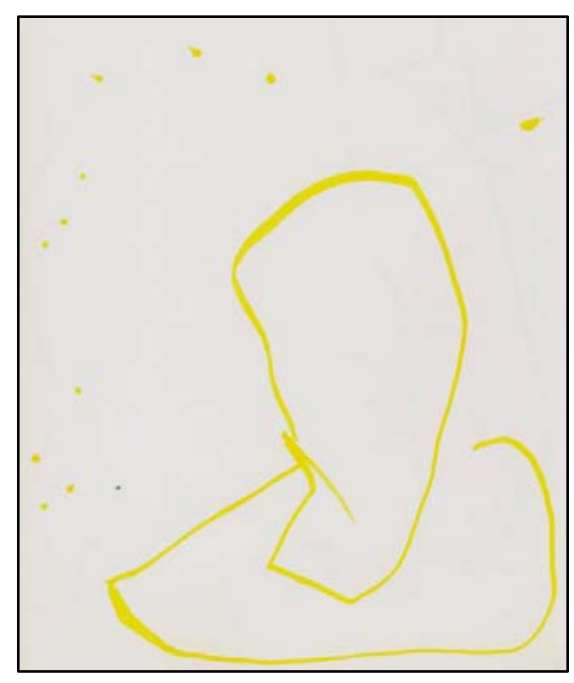

Figure 4. Adam \#2

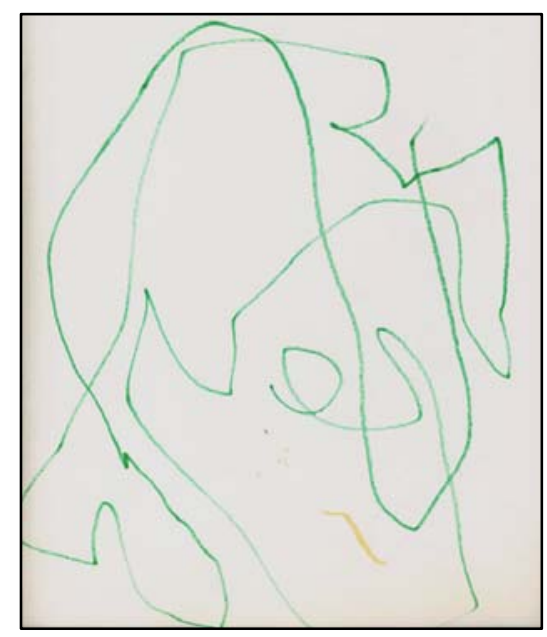

Figure 5. Adam \#3

Adam went on to draw a "crazy waterfall” on the next page, with lots of movement and swirling lines. He told me he had seen a waterfall in "West Merginia", where we live. This led me to 
think it was representational, especially when he talked about what it does, squirt water, and described how people can drink from it. Then he added a peach colored "giant" to the waterfall, so it was imaginative, too.

Adam made a $4^{\text {th }}$ drawing sometime later on orange construction paper. It was primarily kinetic, with letter-like shapes. As he worked, he exclaimed, “Look Clover, I made an N!” When finished he told me, "It’s a rainbow." This drawing seemed representational/informative, since he based his drawing on things that he knew: a rainbow and a letter. Adam usually chose primarily one color to do his drawings, but \#4 had five colors involved. Perhaps that is why he called it a rainbow.

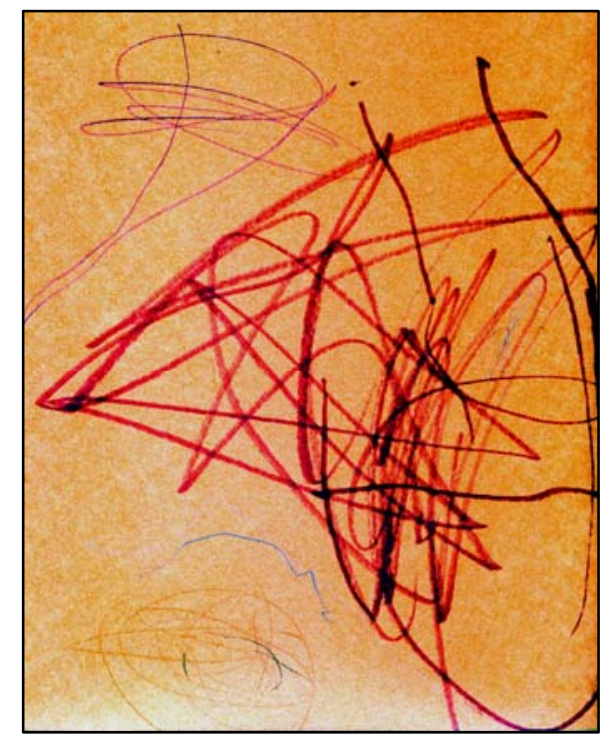

Figure 6. Adam \#4

Alice. Alice arrived at 6, and immediately sat down to draw in her new sketchbook. She drew in her sketch book for the entire hour she was there. Tuning out my presence and other distractions, which were numerous—rainy day, no outside play, a screaming 3 year old with separation anxiety, a 3 year old daredevil trying to leap off of tables and shelving, and lots of shouting and chase games going on all around her—she calmly drew 7 pictures. “Too loud,” she told me, but kept working. 
After her initial request for me to draw the body of a dog, she not only drew it herself, but narrated each shape as she did so. "I make an oval," she said, and did. She drew a dog, then a cat, then a dog, then a cat on 4 successive pages.

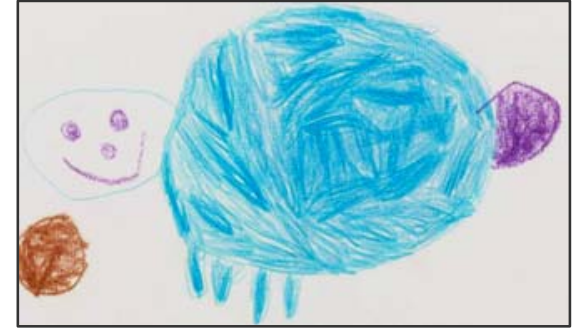

Figure 7. Alice \#1

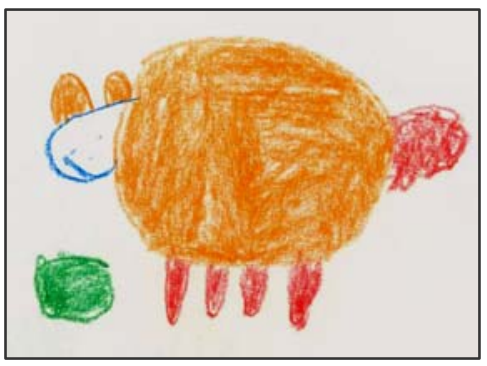

Figure 8. Alice \#2

She used the same technique for each: oval body, 4 skinny oval legs, a round head with eyes, nose, and smile, and a round tail. Cats got two pointy ears on top of the head; dogs got no ears. On drawing 2, a cat, she began thinking about what cats eat, and decided whatever it was it was in a bowl. I talked with her about bowls, and what shape they might be; she wanted to make it right. She agreed that bowls are round, then drew a circle for the bowl and colored it in. She grinned at me afterwards, obviously pleased with the addition to the picture. Then she went back to drawing 1 , and added a bowl for the dog. "Dog like bones,” she told me, but chose not to draw one, "they're hard.” Each animal thereafter had a bowl of food drawn with them. I felt that these drawings were very representational / informative, almost textbook cases of that function. She seemed very concerned with what was real, and getting things right. 


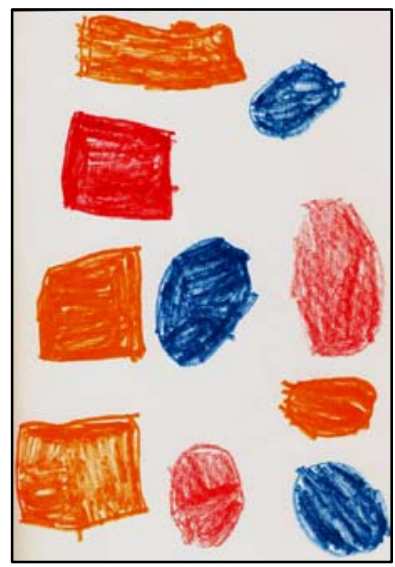

Figure 9. Alice \#5

Drawing 5 was all about shapes. Alice drew and narrated each shape, then colored it, as if she was teaching me. She had trouble with the triangle, so she made a square instead. She drew ovals, circles, squares, and rectangles. Drawing 6 and 7 were tracings of her hands, left and right. Alice wrote her name carefully inside one of the hands. I think she was showing something of herself, very proud that these were her hands.

Researcher's note: After one day of attempting to tape record the interviews and conversations with my participants, I had to give up on that particular effort. It was so impossible to hear the child's words, given the amount of background noise, that the effort seemed wasted. I decided instead to focus on note-taking to record the questions and answers taking place. Also, I decided to let the child speak or not through the art creation process, as my questions were leading or distracting the children's efforts. As long as I wrote careful notes, and expanded upon them in my research journal immediately after the art creation, I decided the information was intact, or as good as it could get given the circumstances. 
Thursday, May 22, 2008

Alice. Alice was the first to arrive at 4:30, and was drawn to the art table, where I had set up an egg carton filled with 12 bright colors of paint. In the paint were q-tips, instead of brushes, for the children to explore the paint with. She eagerly began to paint.

Alice announced, “I’m drawing a dog.” She proceeded just as before: a big oval body, then 4 legs, a round head. Then she told me, "I'm making a cat", and began to paint a cat above the dog. Her sleeves went in the paint, and she looked distressed and stopped. I showed her how to rotate the paper so the top part was nearer. Then she went on to paint the cat, face and all. These were representational, much like the dogs and cats from the previous day's art.

Alice began her drawing 10 with a red marker. "I gonna make a big rectangle," she told me. She did, and colored it very carefully, taking a long time to get even coverage. Next to it she drew a tiny rectangle and a little circle. All were red, colored in. "A big rectangle, a little rectangle, a circle," she told me about her drawing. Then told me, "I gonna save this now," signaling the end of her drawing for the day. This again seemed to me to be purely representational; she functioned as a little teacher, showing me through her art how to draw these shapes and what to call them.

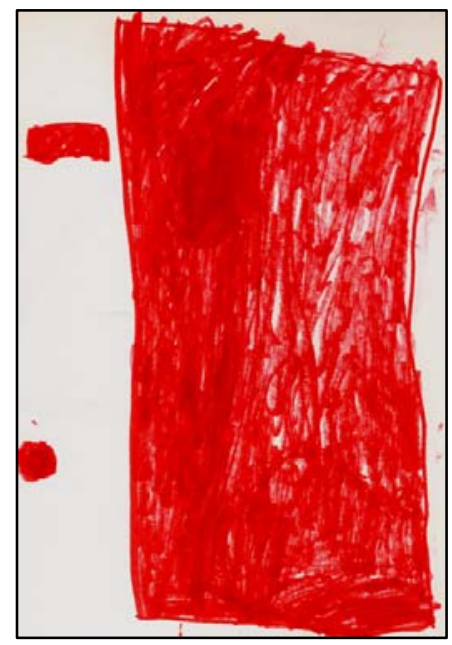

Figure 10. Alice \#10 
Seth. Seth painted at the same time as Alice, seated across from her, yet there were no interactions between them. He picked up a q-tip, dipped it in the peach paint, and swabbed it on his paper. "What's this?” he asked me. "Peach,” I told him. "No, this," he said holding up the q-tip. "It's a q-tip,” I answered. "For your ears?” Seth asked, laughing. He continued to giggle, as he used the qtip to draw lines, and blend the paint. "What?” I asked him. "It’s funny.” he said, but when I asked him why he didn’t explain. “This is from the rainbow,” he said, as he painted. “This?” I asked pointing to the line he had just drawn. "All the colors," he answered. At another point in his painting he pointed out "a big giant leg” he had made. After he was done, he told me about his picture: “The rainbow is dead and all of them (gesturing over the whole paper).” Obviously, I thought, this was the imaginative function, but it was representational too; rainbows are real and he has tried to draw one before. This seemed to be a theme for Seth.

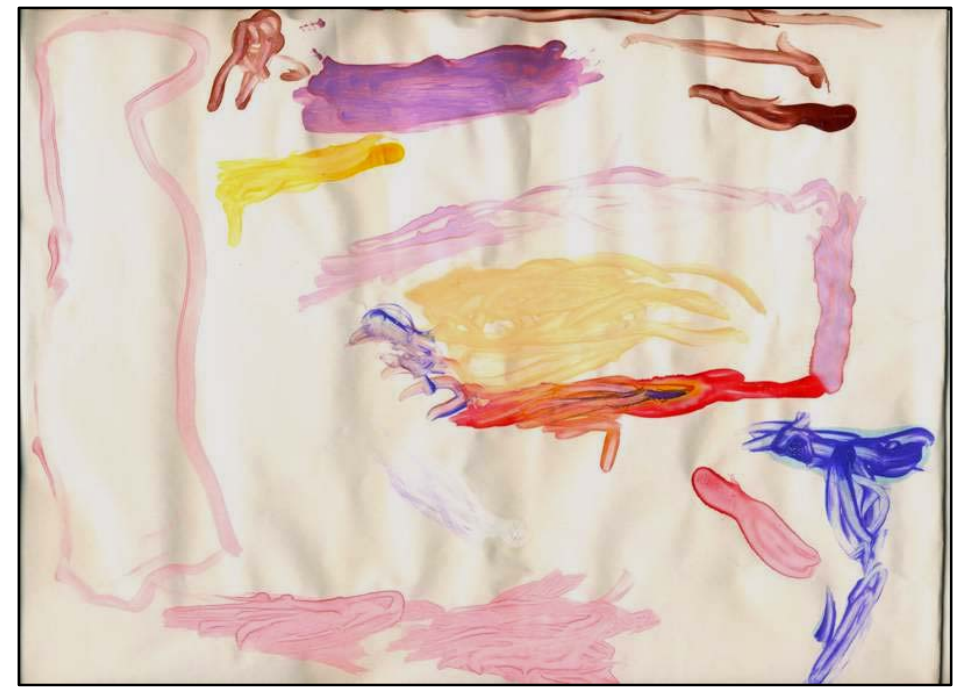

Figure 11. Seth \#2

He asked for his sketch book, and began to draw \#3 with markers. Seth drew a pink rectangle with fringes on two ends. "This is blanket," then a little rectangle next to it, "and pillow, too.” When he was done he told me, “It’s bed.” “Are you tired?” I asked. "No, this is my bed, my Wiggles 
blanket,” Seth patiently explained to me. I believe this drawing was primarily representational/informative, because it showed very representationally real things from Seth’s world. It is also a little bit personal, since he was showing me his things.

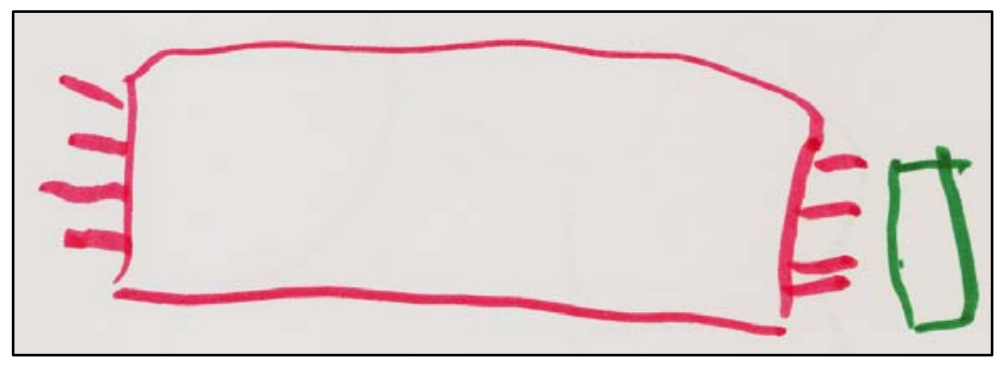

Figure 12. Seth \#3

Sara. Sara came at 5:30. She chose to paint first. Silently, she worked on drawing \#1, a big heart, then filled it with bright colorful dots of every color. When she was finished I asked what she had made, and she told me, "A heart. A colorful heart.” At first I assumed this was imaginative, because she was not making a "real" heart. On reflection I thought this was representational, because she was representing what a heart stands for with a symbol.

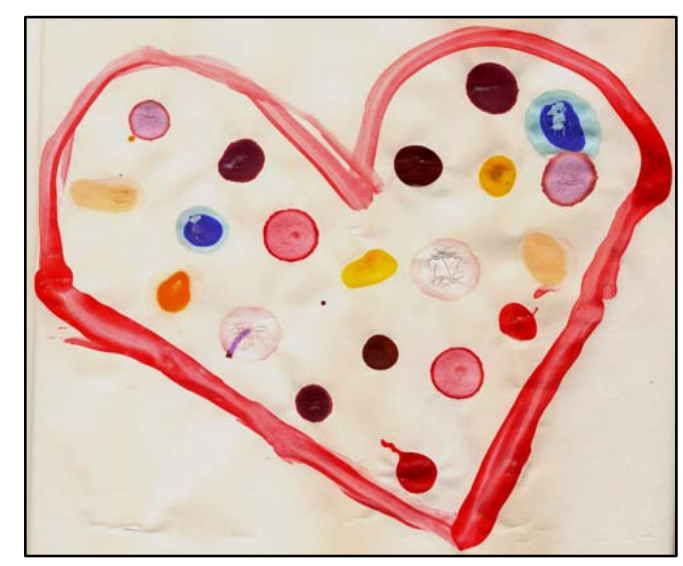

Figure 13. Sara \#1

I gave her a sketchbook, and explained what it was. She wrote her name very neatly on the cover, coloring in different letters with different colors. Then she made large handwriting lines: 
baseline, top line, and a dotted midline. In these she wrote her initials. Then she opened to the first page and drew \#2. She made a rainbow, with colors in ROY G BIV order, in a classic arch shape, using the whole paper. I asked her if she ever had seen a rainbow, and she said yes, at her house. This part was representational. Then she made a pot with a handle, colored in yellow. "I made a pot of gold” she told me, smiling. "What would you do with a pot of gold?” I asked curiously. "If I had a pot of gold, I would buy a hundred things," she responded, with a note of longing in her voice. This part of the drawing was imaginative in function. Although the representational and imaginative were the primary functions, it would be easy to see how the pot of gold could express the instrumental function in the sense that she wanted "100 things".

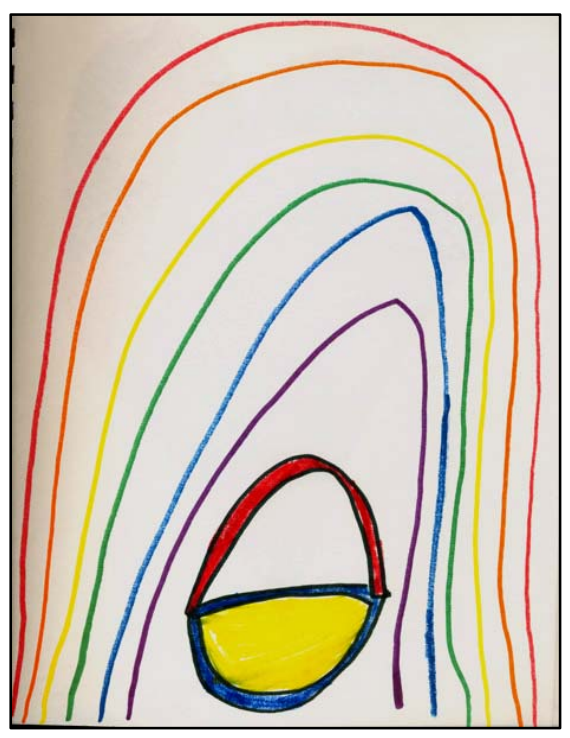

Figure 14. Sara \#2 


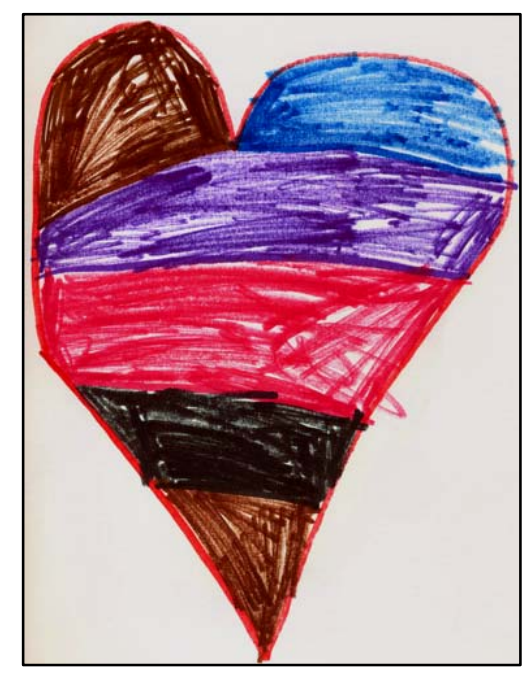

Figure 15. Sara \#3

Drawing 3 was a heart again. This one had wide stripes of different colors. “A striped heart,” she told me. "Why do you like to draw hearts?” I asked. “Because I like everybody,” Sara said, with a smile. “Aha!” I thought. This made her drawing an example of personal function of language. So it probably was with the other heart she drew. Hearts for Sara were a symbol of liking everyone.

Drawing 4 was done in chalk on construction paper. She drew hearts inside hearts, all different colors. “Different colored hearts," was how she described her drawing. I was in awe of her generosity in her affection; heart after heart meant she was giving her "like" to everyone around her. I felt honored to know this and to know her.

Saturday, May 31, 2008

Sara. Sara was the first participant to arrive, with wet hair from the powerful thunderstorms that morning. I asked her if she wanted her sketchbook and she said yes with a smile. Her drawing, \#5, was made with marker. She created a drawing of a "pot of gold” much like the first one, but without the rainbow this time. The outlines of the pot itself were in 6 different colors, and had detail she described as “swirlies.” When she finished, she asked if I could help her draw a bicycle. I explained that I was interested in her drawing of a bicycle, so I couldn't draw it for her. But I would 
help her figure out the shapes of a bike; together we discussed that the wheels look like circles, and the other lines are straight. “So,” I asked, "how many wheels are you going to draw?” "Four,” she told me. She went on to draw these four round wheels on lavender tissue paper, cut them out, and carefully glued them to the bottom and sides of her pot of gold. "Now what have you made?” I asked her. She considered, and then answered, "A wheel pot of gold.” This combines representational function with the imaginative, but also heuristic function since she had questioned, designed, tested a theory, and applied it to her original design.

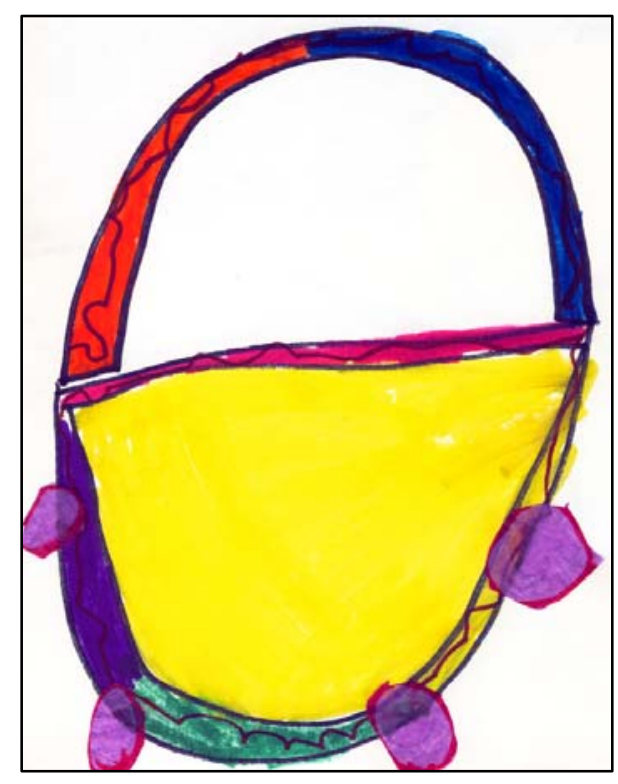

Figure 16. Sara \#5

Sara went to the easel to paint her artwork \#6 at 10:30, while she waited for her glued on wheels to dry. "I made a sun!” she announced when she was finished; the sun had red outlines, gold center and red rays. This seemed to be representational/informative.

Alice. While Sara was working on her wheels, Alice arrived and sat down next to her at the art table. She asked for her 'book.' When I gave it to her, and opened it to the next blank page, she announced, “I want to draw just like Sara.” Then, considering Sara’s pot of gold, “I need help.” I 
discussed with her the shapes that Sara had used, and reassured her that she could draw these: a big circle, with a line that cut it in half. Alice proceeded to do just that and more; for this drawing, \#11, she used a double outline like Sara which she colored in black, then when she bisected the circle, she colored in the bottom half green, not gold. Throughout, she kept checking her work against Sara's. When she was finished she told me, "I make this for my mommy.” This was the first interactional function I have seen with Alice.

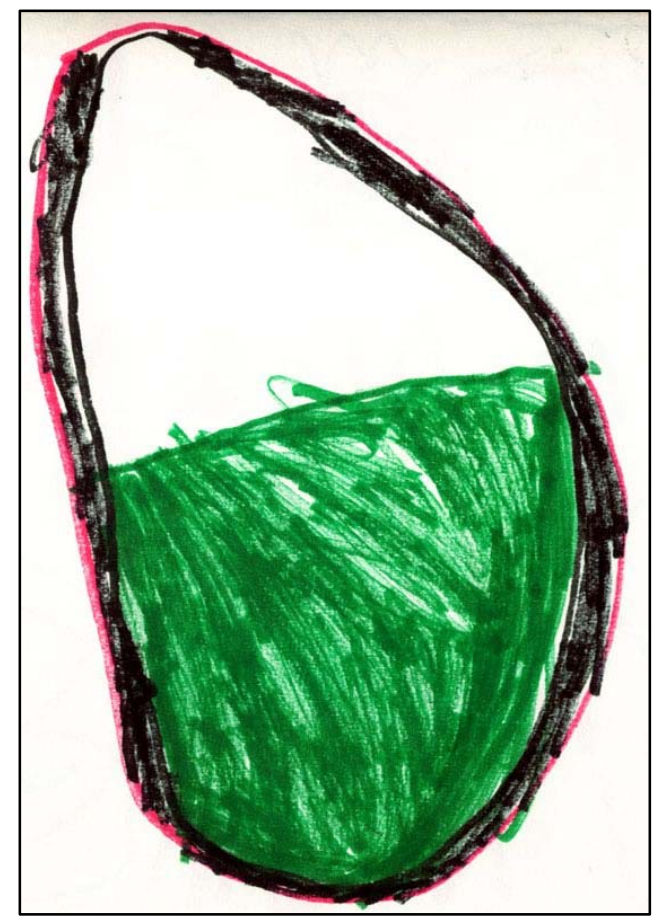

Figure 17. Alice \#11

Alice said, "I make a snake now." I asked her if she would make it in her sketch book or on separate paper. She picked a piece of orange construction paper at 10:43. I was called away to another part of the room; one of the infants was crying loudly and a new employee needed help to calm her. (I realize this is another limit of my study; I am still a supervisor and I may have to respond to situations in order to support my coworkers and ensure a harmonious environment.) 


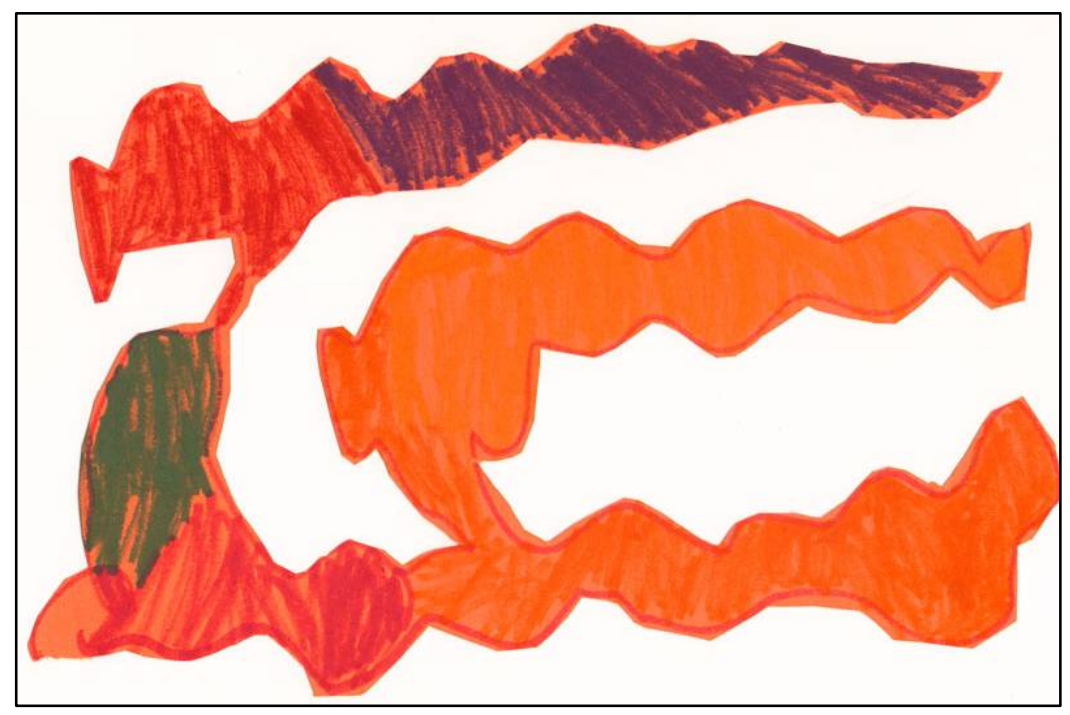

Figure 18. Alice \#12/Sara \#7

While I dealt with this, Sara helped Alice with her snake drawing, making this \# 12 for Alice and \#7 for Sara. Alice told me, “Sara helped me make a snake.” On her paper was a long wiggly shape that curved all around the paper. Alice was engaged in coloring in the outline that Sara had drawn. Then she cut it out, by herself although she asked for help. Alice explained the drawing was: “A snake_all one body.” This was not only interactional but truly collaborative, as well as representational. 
Alice drew \#13 and 14 on the same paper at 11:08. She picked a piece of construction paper, blue. As she brought it to the table, she looked at the blank paper and told me in a happy tone of voice, “There’s enough room on here for 10 dogs.” As she drew with marker she narrated, “I’m coloring the dog. It's a pink dog.” When she finished with the pink dog, complete with a big smile on its face, she turned the paper over. On the other side she drew a cat and a dog. She also wrote the letter $\mathrm{S}$ and the numbers 223 3. This may be because she just turned from 2 years old to 3 in the last couple of months. I think this is representational.

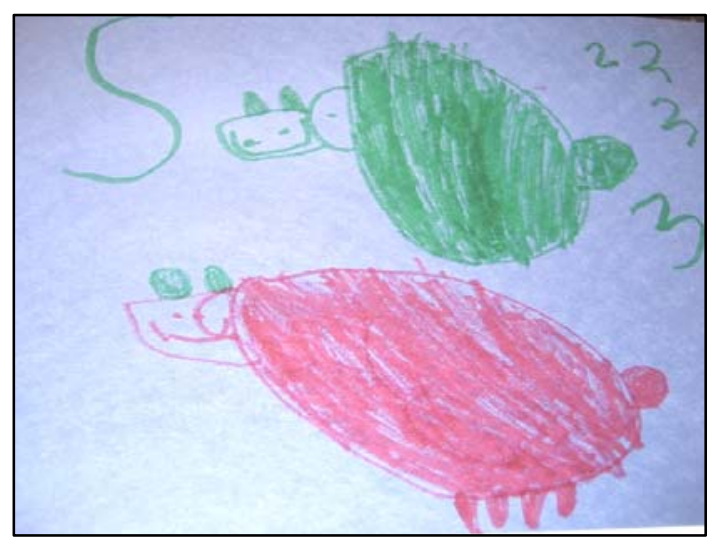

Figure 19. Alice \#14 
Seth. At 11:01 Seth came to the art table and wanted his sketchbook. As he drew, he kept up a steady stream of verbal communication. "A big, big monster," he announced as he began drawing \#4. “There’s a giant in there,” he said, “in his belly!” He giggled, “Pretty silly, huh.” Then later, "Rarrrrrr!" Seth roared, either as the monster or the giant. Then he began to sing a song. "Is that a song about the monster?” I asked. “No, it’s a Wiggles song,” he answered impatiently. He continued to sing until he announced he was finished. His drawing showed a big dark shape with a large blocky person-shaped figure in its center. This artwork obviously is the imaginative function of language.

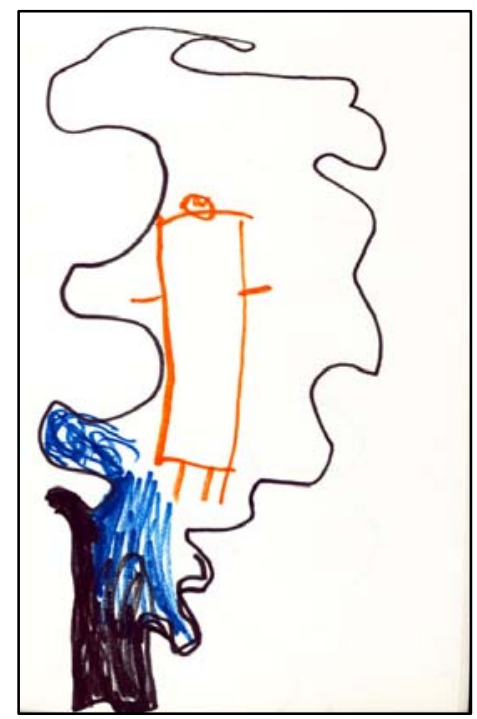

Figure 20. Seth \#4 


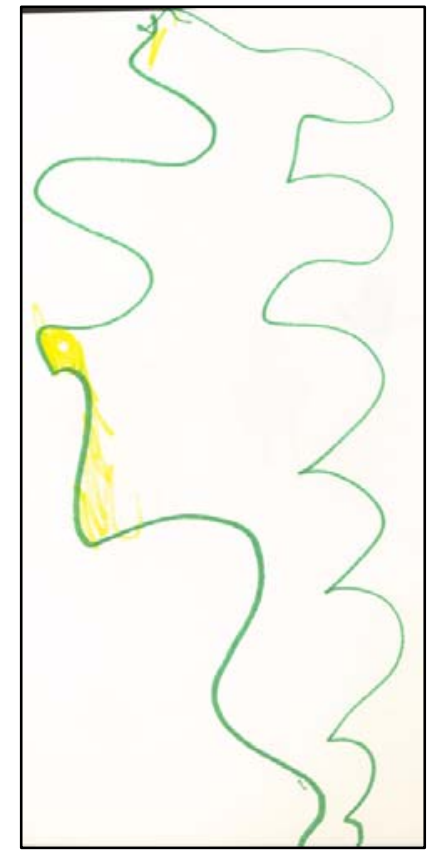

Figure 21. Seth \#5

Monday, June 2, 2008

Seth. Seth was the first participant to the art table at 5:09. He wanted his sketchbook, and he looked over the drawing he did of the monster and giant the last time he drew. After turning to the next page, he began drawing \#5 by fluidly drawing a long, green, complex squiggly line that looped around at the bottom of the page and came back up to meet at the top. "It's a clown," he explained to me as he worked. Then, gesturing to the bottom of the shape, “This is like a bone.” Selecting another color, yellow, he marked two areas, one larger and one smaller, inside the clown-shape. "This is a part where he eats.” "What do clowns eat?” I asked. “Birds! (giggle)” replied Seth. Then he dashed off to see if it was his turn on the computer.

I intuitively think this is imaginative, not representative, because I have seen Seth draw human figures quite accurately. This was an abstract shape that very closely resembled the shape of his giant (\#4) and his rainbow (\#1). I started to wonder if this shape was a theme for Seth, or a symbol he can 
use to express something about his identity or experience. If so, this would make it personal in function, too.

Alice. Alice came at 6:30. She asked for her 'book', as she called it. Her drawing \#15 was dominated by letters and letter-like shapes. Carefully, in silence, she wrote: ABCBD33... and continued with the letters of her name, her brother's name, numbers 3 and 5, then began tracing the letters with a contrasting color, adding little squiggles and swirls in between the letters and in the margins until the whole paper was filled. She told me this picture was her name, her brother's name and "mommy name". This drawing seemed representational/informative and interactional. It was also the most decorative of Alice's art works thus far. I was intrigued by the shift from animals, to shapes, now to letters and numbers.

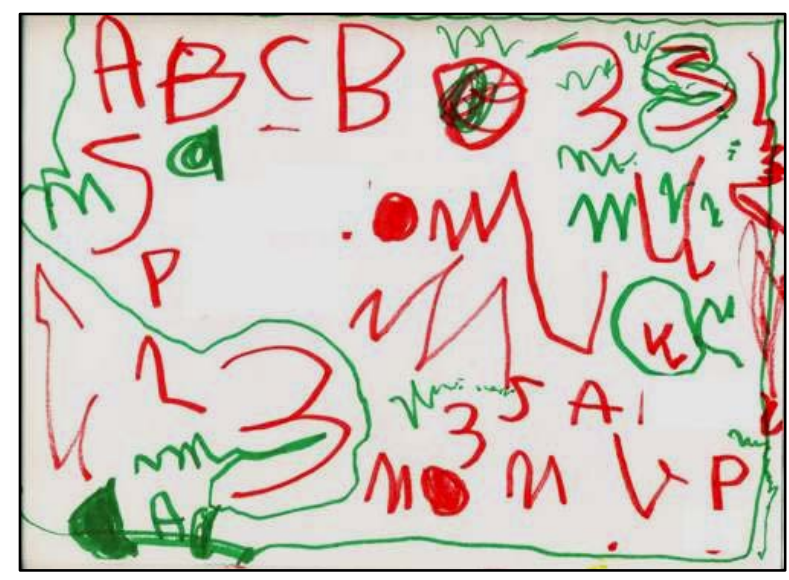

Figure 22. Alice \#15 (proper names omitted)

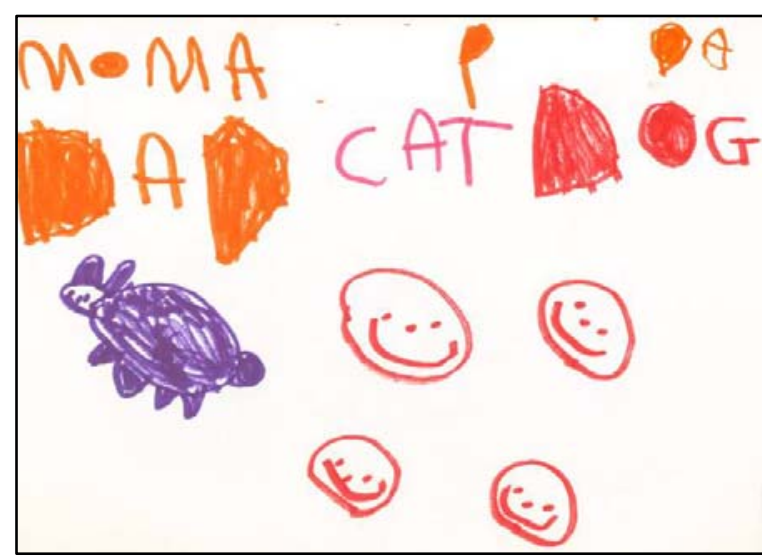

Figure 23. Alice \# 16 (names omitted)

Alice’s drawing \#16 also started with writing: “mom,” her name, brother’s name, “dad, cat, dog.” All in left to right order on two lines. She stopped as if to think about what to do next; I asked her if she was going to draw about what she wrote. She nodded. She went on and drew four smiley faces, hers and mom's were the biggest, to represent her family. Then she moved on to the cat, which was purple with long ears, round tail, and 4 legs. I am sure she was about to draw the dog when her 
father arrived to take her home. "Save this for me," she instructed as she prepared to go. I think this is a similar blend of linguistic functions as drawing \#14: representational and interactional.

Thursday, June 5, 2008

Seth. Seth was my first participant in attendance today. At 4:56 he arrived looking flushed from the 88 degree heat. I asked him if he would like to sit at the art table and draw to cool off, and he replied, “yes!” with a big smile. As he drew he kept up a steady stream of conversation: "I want to draw the Wiggles. This is the Wiggles. I want to put this in my mailbox. This is the yellow Wiggle. Red Wiggle (as he drew them)—eyes, nose mouth! Higgletytown hero! (As he drew, he started to run out of room on the right hand side of his paper, causing him to make the blue Wiggle very small.) This is hard. Blue Wiggle. (Then he moved to the bottom of his paper for the last one.) Purple Wiggle. (When he was done, he counted them) One, two, three, four.”

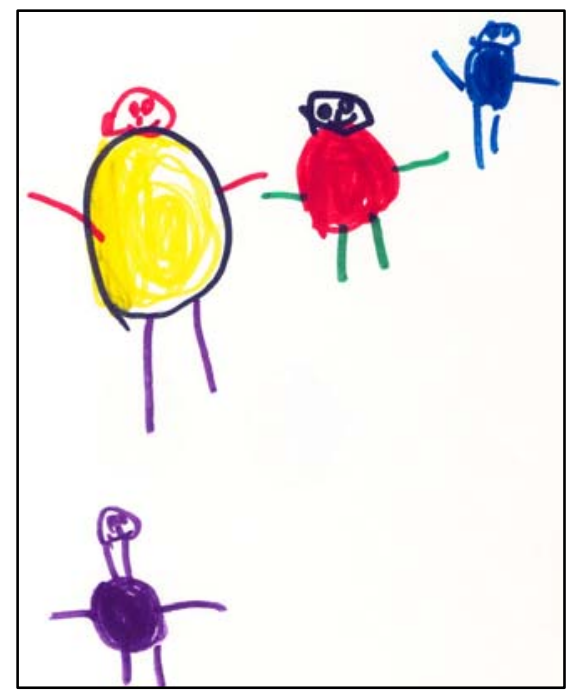

Figure 24. Seth \#6

“What are they doing in your picture?” I asked. “They’re walking into the Wiggle house!” Seth exclaimed happily. This drawing was representational/informative. 


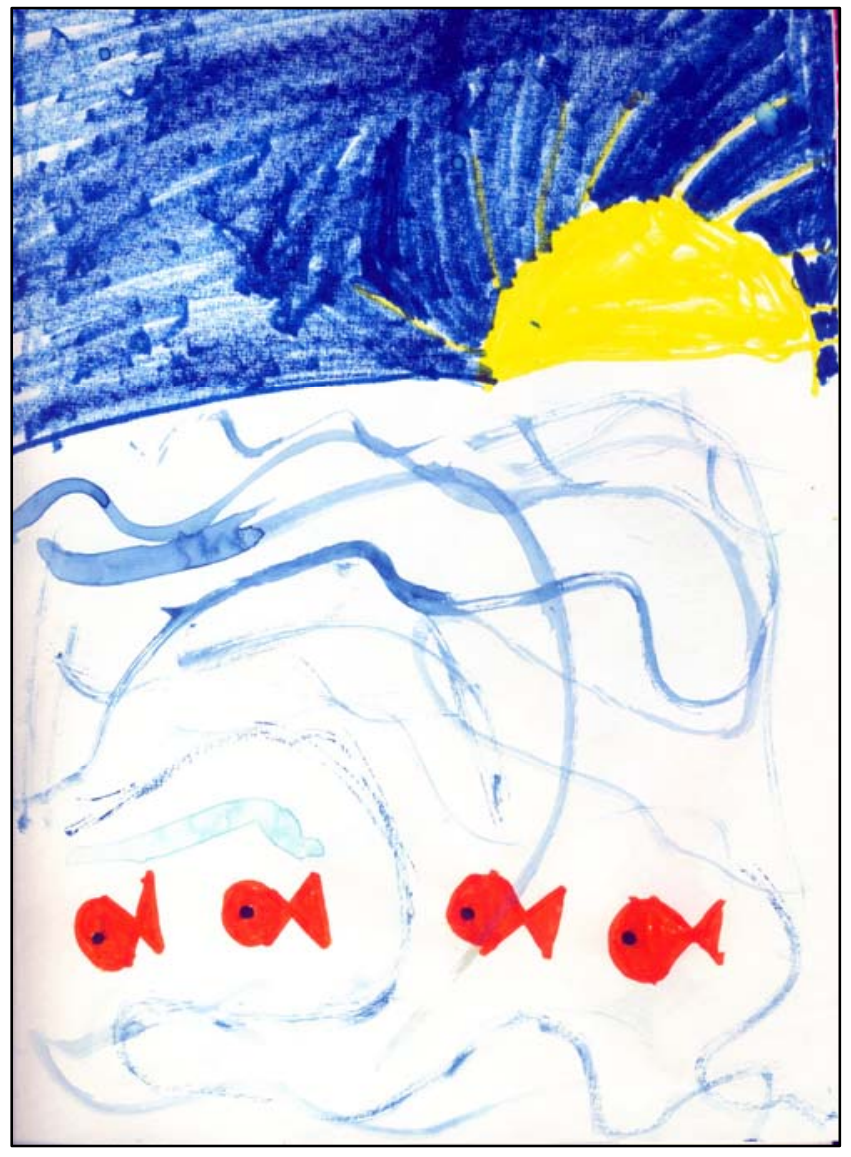

Figure 25. Sara \#8

Sara. Sara arrived and sat down to draw at 5:20. She started her drawing \#8 with little orange "x"s. Then she connected one end with a straight line, and drew a round shape at the other end - they were fish! She made four little orange fish, each with one black eye, in profile. Then she moved to the top of her paper and made a yellow half circle with rays - the sun. She began coloring the sky blue, in between the yellow sun rays, and continued across the whole top of her paper. As she worked I had asked her if she would prefer watercolors to color the sky, but she told me, "No, but I'll use them for the ocean." She painted the ocean with thin, wavy lines that resembled waves, and also swirls that looked like currents and eddies. When she was finished she told me she had drawn "fish in the ocean.” "Have you been to the ocean?” I asked her. “No, I’ve been to the beach.” I said to her that 
the beach is the ocean, and she agreed. But I think what she was trying to say was that she hasn't been out in the ocean where the fish are swimming. Because of this, there was an element of the imaginative function, but it was primarily representational.

Saturday, June 7, 2008

Adam. Adam arrived first today. He wanted to paint, and chose orange. He made several lines with the paint, and announced that he was finished. He told me he had made a "shtruckshun place” “A construction place?” I asked. "Yes,” he replied, and then repeated it the way he had said it. I record that here, as it seemed important to him. When his mother picked him up later, I asked her if there were any construction sites he had seen recently, and she told me that there was one near their house. “Are the machines orange?” I asked. She said that they were. This makes his drawing representational, to the best of his 3 year old ability. 


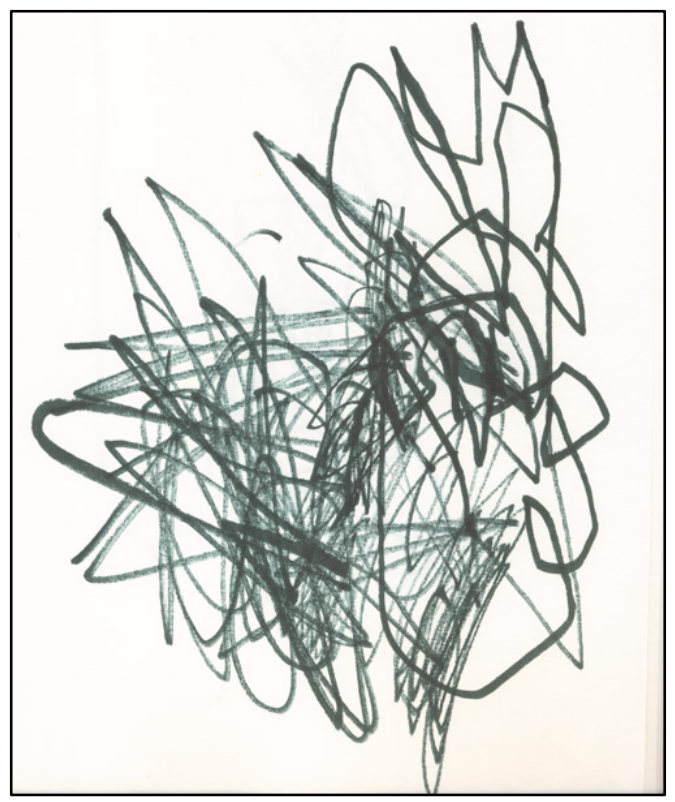

Figure 26. Adam \# 6

Adam's $6^{\text {th }}$ drawing was made right after his painting. He wanted to draw in his sketchbook, and this picture was a black complex shape, with lots of sharp angles and intersecting lines. He told me, “It’s a machine; it makes bubbles.” I asked him where the bubbles were, and he gestured vaguely to the center of the drawing, where there were no round shapes. He knows what bubbles look like. So, this was imaginative. He had also drawn a toy machine previously that was from his imagination, not real life. I think he is fascinated by machines of all types. His favorite book is nonfiction about types of trains. Because he knows machines are real, these drawings are also informative/representational.

Alice. Alice arrived next. At 10:39, she began drawing \#17 right after her older brother drew his favorite animal, a turtle. She announced, “I want to draw a turtle.” And on a piece of green construction paper, she did so. The shape was much like her dog and cat drawings, but the body was slightly different and had spots. Drawings 18 and 19 also featured the turtle. 19 additionally had a circle, and letters: D, C, A B, r, s, s. When I asked her why she drew turtles she told me, "Because I 
like turtles.” But I think it was mainly because her brother likes turtles. That makes these drawings interactional and representational.

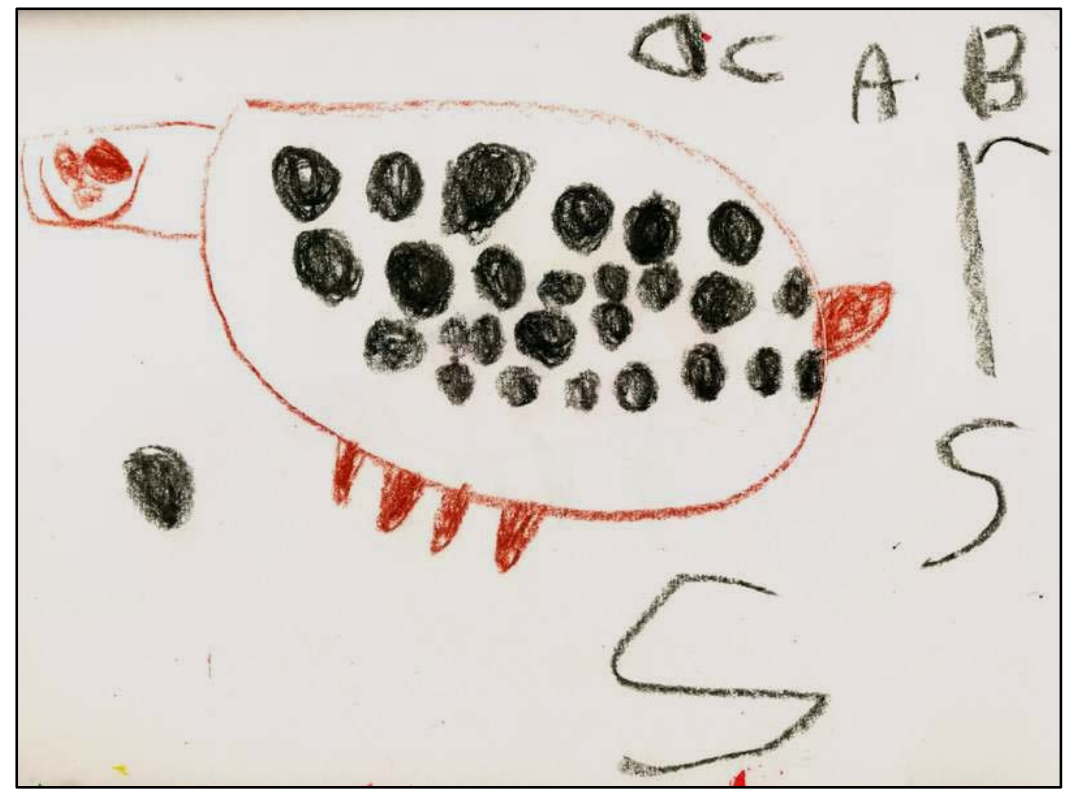

Figure 27. Alice \#19

Alice's mom came to pick her up, and sat down on the other side of her daughter to observe.

She saw her daughter's name on the front of the sketchbook, and asked her if she could write her last name too, which she did. Alice became aware of Sara drawing a snake, and announced she wanted to draw a snake. Her mom interacted verbally with her daughter, asking what letter snake started with, which she knew. Alice drew a large c-shaped snake. Mom asked if she wanted to draw eyes and mouth, which Alice did, even adding a nose. Mom asked what a snake mouth looked like, and Alice drew it instead of responding verbally, making a line with a split end. Alice then said, "I want to draw a little snake,” and did so, then added a third snake to the drawing. When she was finished she told me, "It's a mama snake, a baby snake, and a brother snake.” This drawing was interactional, as well as representational. 
Sara. Sara arrived, and started drawing at the art table next to Alice as she made the third turtle. Sara began to draw a snake. The shape she chose to make shows the snake curled on top of its body with the head facing the viewer. This looked realistic, and so I asked if she had ever seen a snake. No, Sara told me, not ever. Not in a zoo, not in a book, not in her yard, and not on TV in answer to my questions. The colors Sara chose were very vivid: blue, pink, purple, orange, brown, yellow, green, and black. These are not realistic colors for a snake, so combined with her interview answers I have to assume that this is the imaginative function. However she included details that were factual, like the shape of the body and tongue, so it is also representational.

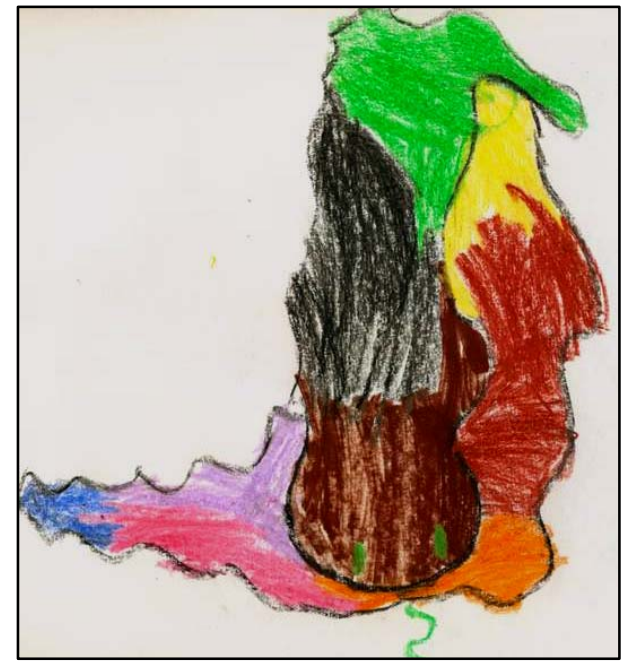

Figure 28. Sara \#9

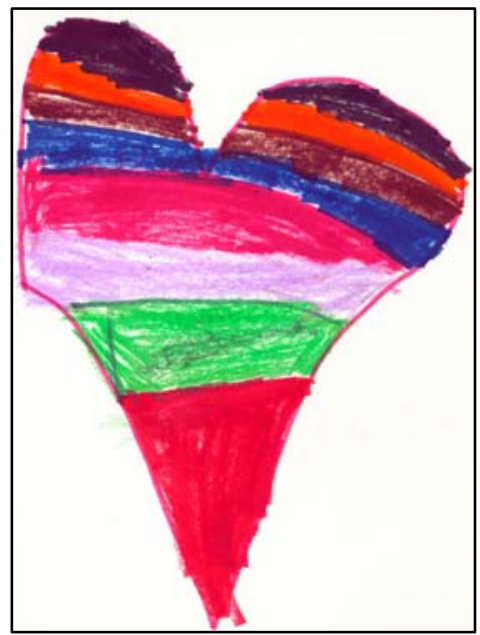

Figure 29. Sara \#10

Sara then drew a heart with stripes of various colors. She told me, "It's a rainbow heart.” I think this is from her imagination, since her rainbows are usually in color order and this heart had randomly chosen color stripes. Sara's mother arrived to take her home, so I was unable to question her further about the drawing's meaning.

\section{Monday, June 9, 2008}

Adam. Adam was the first participant to arrive. He painted at the easel with dot painters, something like bingo markers. His drawing \#7 he described as: “This is a wall. A funny wall. I saw it 
in a movie. It's in a far, far away land.” That was the end of his discussion. He was anxious to play in the sensory table, so he moved on. I think he was representing something he saw, so I will categorize this as representational.

Alice. Alice came to the art table and requested her sketchbook, telling me, "I want to make a snake.” She did so, in drawing \#21, using the c-shape she used the last time, all in black marker. I asked her if she had ever seen a snake in real life, and she told me no. "On TV?" "No." "Maybe in a book?” "No.” Then, on a hunch, I asked if she had seen a snake in her (reptile obsessed) brother's book; she smiled and said yes, making this representational. She then said, "I want to make a turtle." And she drew one right next to the snake. This turtle was all green with green spots, legs, tail, eyes, nose, and smile. But then she added a pink spot, an orange spot, and a purple spot to its shell—there may be a bit of imaginative function too.

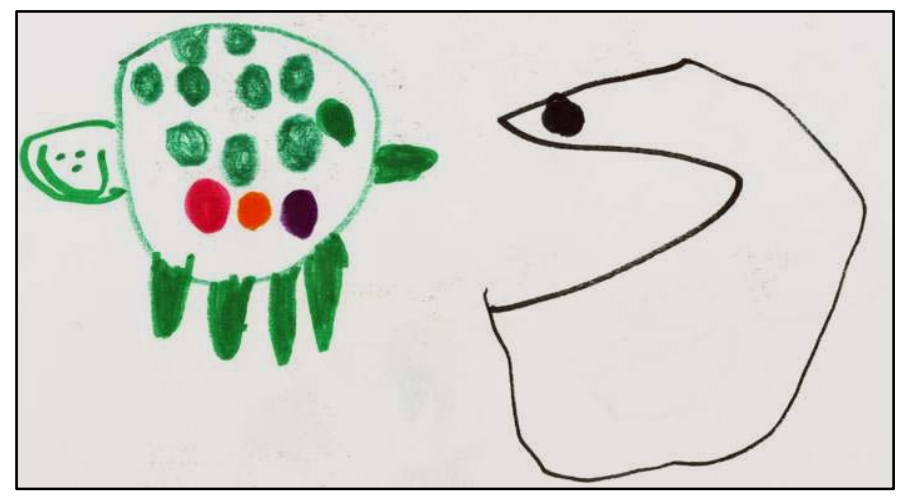

Figure 30. Alice \#21

On the next page, in drawing 22, all in purple marker, she wrote across the top: ABCDEEFGHIJ. Under that, she wrote the number 3. "I make a three," she said, then, "I make a little snake.” Alice went on to make three little snakes, next to the number 3, illustrating the numeric principal. She went on to write the number 2. "I make a dog," she said, and drew two-although they looked more like her cats, with pointy ears. "Now I make cats. Green.” And she traded the purple 
marker for a green one. She wrote the number 3 and drew 3 cats, with no ears. She smiled proudly at her paper, then at me, and quickly turned the page, saying "Number four." As she worked on drawing 23, she said to herself, 'Eyes, eyes...Four snakes (maybe for snakes).” She wrote the number 4 and drew 4 snakes, only one she colored in. Then she said, "Five dogs by number five.” And she drew five dog figures, again with no ears; one had a snake tongue, which made her giggle as she drew itmaybe a little joke. These drawings seem to be straightforwardly representative/informative, with the exception of the dog with a snake tongue. As she worked on this drawing, Sara arrived.

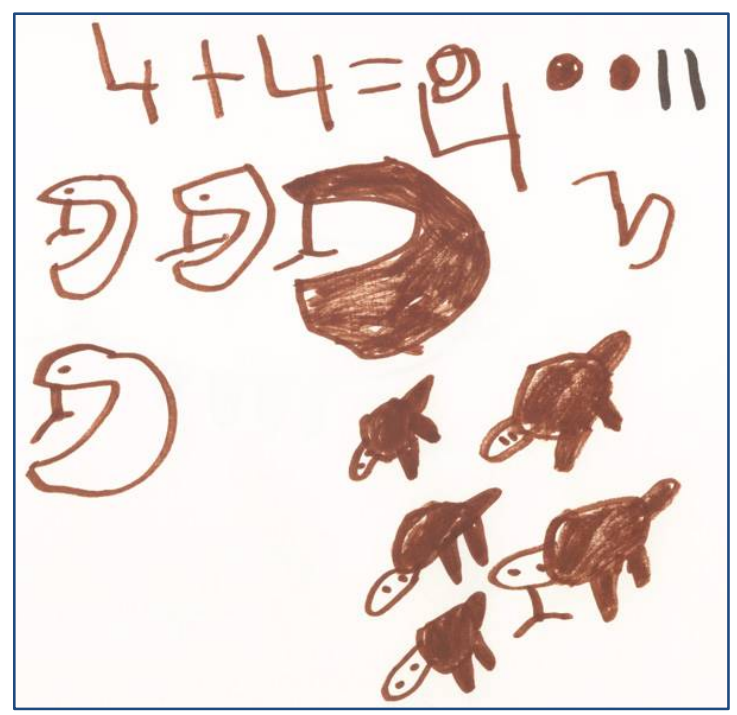

Figure 31. Alice \#23

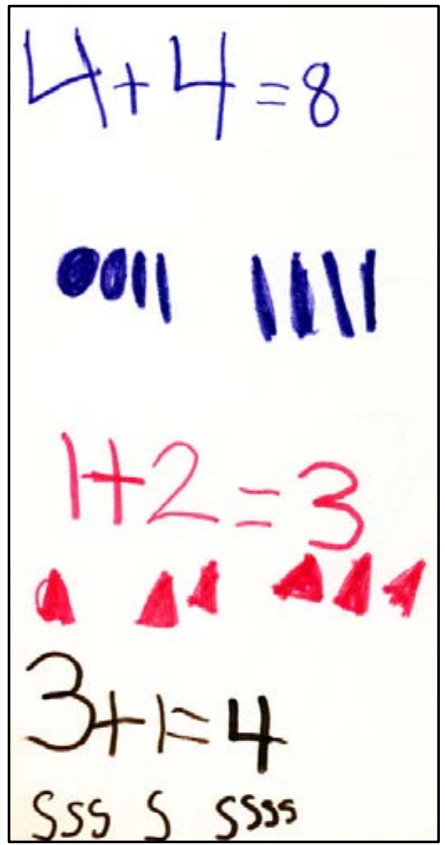

Figure 32. Sara \#11

Sara. Sara asked for her sketchbook right away, and sat down next to Alice, looking over to see what the younger girl was drawing. I explained to Sara that Alice was doing a kind of number drawing. Sara nodded her understanding, and then began on her own artwork \#11. She wrote the equation $4+4=8$, then illustrated with 8 shapes, in 2 groups of 4 under the numbers. Alice stopped her work to see what Sara was doing, and then added to the top of her paper: $4+4=8$. She next copied Sara's shapes, four of them, doing so exactly as Sara had. Sara initially made two round shapes, but 
then switched to long skinny line shapes for the other 6 shapes. Alice also made 2 round circles, then 2 lines to illustrate 4. At this point Alice's father arrived to take her home, so she left. These girls were definitely interacting through their art; although they did not speak to each other, their work shows the influence of the other. Sara went on with her equations, adding $1+2=3$, illustrated with triangles. She also wrote $3+1=4$ illustrated with "s"s. On the latter equations, she illustrated not only the first two numbers, but also the sum number. These are plainly representational, and also interactional.

Sara's next drawing, \#12, she made a rainbow, but with the ends curled upward. I asked her why she drew the rainbow, and she told me it is because she likes rainbows. The colors are all in color order. She tends towards very representational artwork, accurate and straight forward.

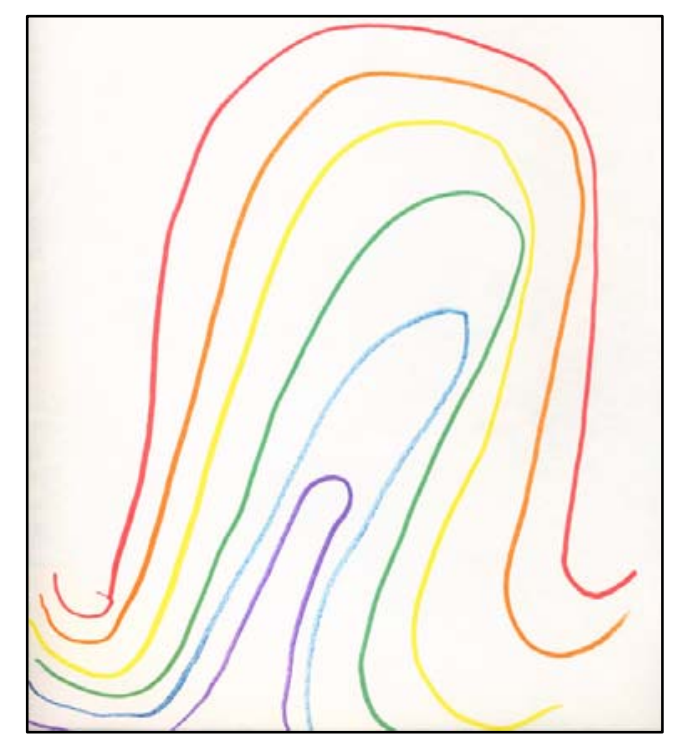

Figure 33. Sara \#12

Her $13^{\text {th }}$ drawing she did at the easel with dot paint markers. Sara drew a triangle tree shape, with a rectangular trunk. At the center of the triangle she wrote an S (her initial), and around the triangle she drew a flower shape. All of this was very colorful: blue, pink, orange, purple. When she had finished she described her painting: "It's a Christmas tree. This part is like a flower. The S is for 
me!” When I asked her if her Christmas tree ever looked like that, she said no and laughed. I think this was imaginative, because she could draw a representational tree if she chose to. This was the first time this usually serious girl drew something that was silly or humorous.

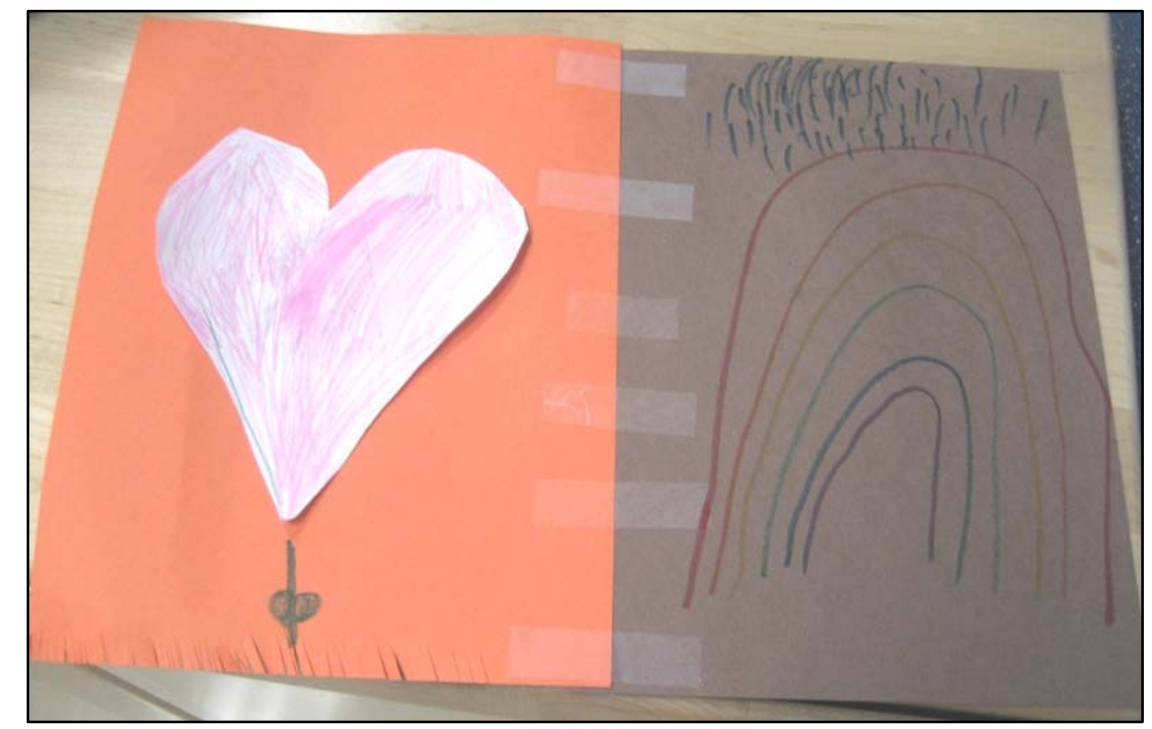

Figure 34. Sara \#14

Sara’s last drawing of the day, \#14, was complex. First, she taped together two pieces of construction paper. Then, she drew and colored a pink heart on white drawing paper. Next, she cut out and taped the heart to the middle of one of the construction papers. Under it, she carefully cut fringes in the bottom of the construction paper. "This is grass." She told me, otherwise working in silence. Under the heart, she drew a stem down into the grass. She added leaves to the stem. On the other construction paper she drew a rainbow. "I'm going to make rain," she decided, drawing blue raindrops only above the rainbow. When she was finished, she told me this about her artwork: "The heart grows and the rainbow comes.” This seemed to be a blend of imaginative and representational language/art. I did not feel that the heart was "saying" the same thing in this context as before when the heart was the only figure in the art work. In this piece, the heart did not seem like the personal function of "like", but was used to represent growth or life in the form of a flower. Sara used this 
symbol in a new way; perhaps she is scaffolding her own knowledge construction by applying something known into a new context in which it is unknown.

Thursday, June 12, 2008

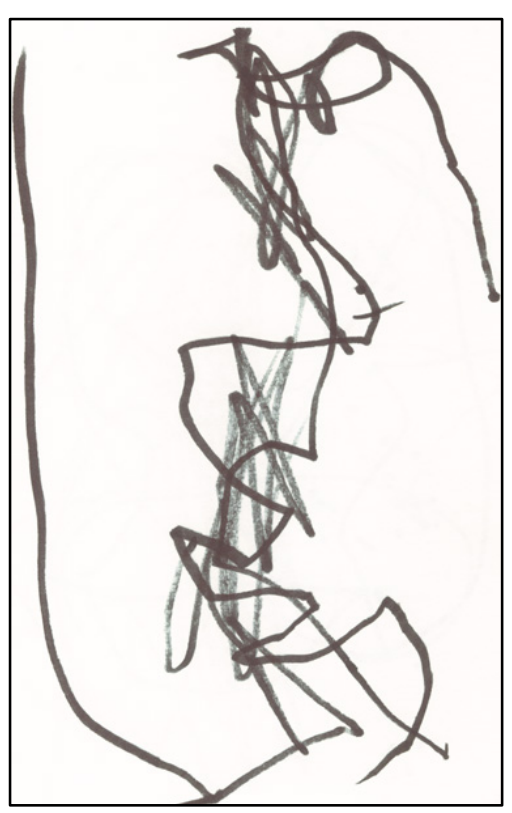

Figure 35. Adam \#8

Adam. Adam arrived at 4:45, and came right to the art table. He said he wanted to draw, and nodded yes when I asked him if he wanted his book. Using only black marker, he created a long vertical line, then a series of angular loops and zig-zags. Finally he scrawled a hasty scribble to color in a central part of the picture. While he was drawing I asked him, “What are you making?” He replied, "I'll tell you when I'm finished.” When he decided he was done, he told me, "It's a funny light pool. It turns lights off.” “Like a machine?” I asked; he nodded. “Have you seen a light pool before?” “At my dad’s house. Inside.” “Can you swim in a light pool?” He shook his head no. "Just look at it?” He nodded. What is this supposed to be? Later, when I talked to his mother, I asked her about it. She didn’t know what it was either, and phoned Adam's dad to ask him. He did not know either. Then she put Adam on the phone about it, but all Adam would say to his dad to illuminate his idea was, “It’s the funny one.” I intuitively believe a light pool is representational of something real 
he has seen, based on his previous drawings and interests. Adam's mom also felt that it must be something he has seen.

Alice. Alice was my next participant to arrive. She immediately picked a piece of orange construction paper, and began drawing \#24, as she announced, "I want to make a snake.” She drew two snakes, and then filled the space around them and the rest of the paper with large lines and swirls, shapes and loops. This was rather abstract for Alice's typical style. Then she wrote her name and the number 4. When she had finished I asked her to tell me about the drawing, and she said, "Two snakes. 4,” as she was pointing to these elements. Those elements were representational; maybe she was unsure about the abstract parts, as she just smiled at me when I asked her about them.

She turned the paper over and said, "Now I'm going to make another dog." She went on to draw a big dog and three little dogs, and wrote the number 4 next to them. Then she wrote the number 3 and surrounded it with three snakes. Finally she drew and colored in a small circle, wrote the letter R and finished by writing her brother's name, her name, and "mom". I asked her to tell me about her drawing. “A dog,” she said, “1, 2, 3,” (counting snakes), “4” (pointing to the number 4), “4 dogs. Little dogs (points them out), a big dog.” Because of her family’s names, I must include interactional as a function here, but mainly this is representational/informative.

Alice then asked for her sketchbook and drew \#26. "I’m going to make a turtle,” she said. She drew it quickly, in blue with a raspberry-pink tail. This turtle has a large smile on its face, and none of her usual spots. She did not want to discuss her drawing, just told me it was, "a turtle.” Then she went to look at books.

I did not have any other participants in attendance at the time, so I joined her in the book area. Seeking to capitalize upon her interest in animals, I picked a thick encyclopedia of animals off the shelf, and began to show her pictures of the different animals and talk about them. When we came to 
the page with the turtles, she grew very interested. There were photos of snake-necked turtles, snapping turtles, giant tortoises, and more, but the photo of the sea turtle really got her attention. She and I discussed that these turtles could swim, and lived in the ocean.

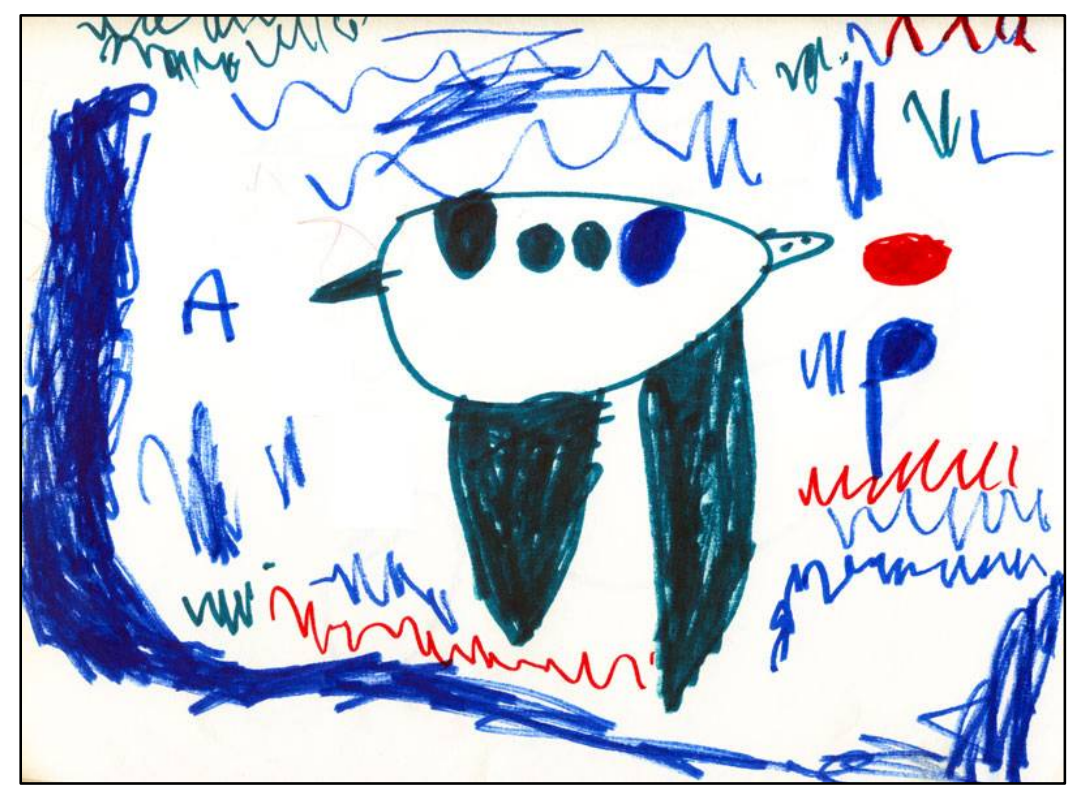

Figure 36. Alice \#27

"I want to make a swimming turtle," she told me, then added, mournfully, "I don’t know how." I reminded her that she could draw turtles, and that sea turtles simply have much bigger, flatter feet that push the water when they swim. She nodded and began to draw \#27. She drew her standard oval body, with a small head and eyes, and added a tail. Then, as the turtle was drawn in profile, she drew two enormous flipper-shaped feet. "He have big feet!" she exclaimed. "I want to make water. Is water blue?” I replied that sometimes water looked blue. She colored a blue semi-circle of water around the turtle. Then she began adding blue, green, even pink "waves" to the drawing. "I make an oval," she said as she added a pink oval in front of the turtle. Then she added her name and her brother's name-turtles are his favorite animal. This part may be interactional. When she was done she told me, "He in water." "It's a wave," she said, pointing out the waves. This drawing was 
definitely representational, but also was heuristic, as she questioned, constructed and tested her ideas through the drawing process. This drawing represented a leap forward for Alice, as she usually drew animals without context, and this one was shown in its habitat.

Alice’s last drawing of the day, \#28, she began in silence. After she drew a snake, she said, “A snake. A big one.” Then she said, "I'll make a little snake.” She drew 3 more little snakes, and wrote the number 3 above all four snakes. When she was finished, I asked her to tell me about the drawing. She said, "Snakes. 3.” "What do snakes do?” I asked. "They just fly like that,” she told me, giggling, as she traced the "s" shape with her finger. The drawing is representational and also bit imaginative.

\section{Saturday, June 14, 2008}

Rose. A half-hour before the center closed in walked Rose, the long-lost participant whom I had not gotten to observe since the start of this study. It turned out that her mother was in early pregnancy over the last couple of months, and has been too ill to go out much. Her father had been working long, irregular hours, and had no time to bring Rose to the center. So, mystery solved, Rose sat down with her sketchbook for the first time today.

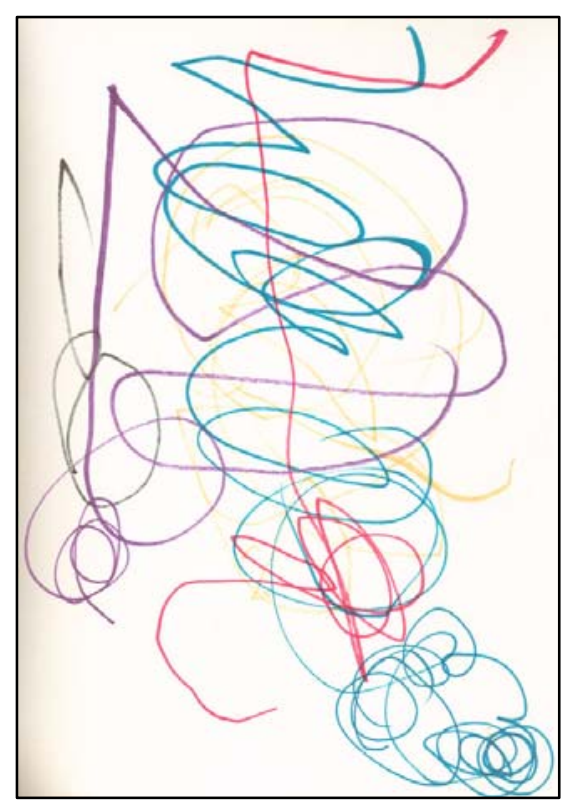

Figure 37. Rose \#1

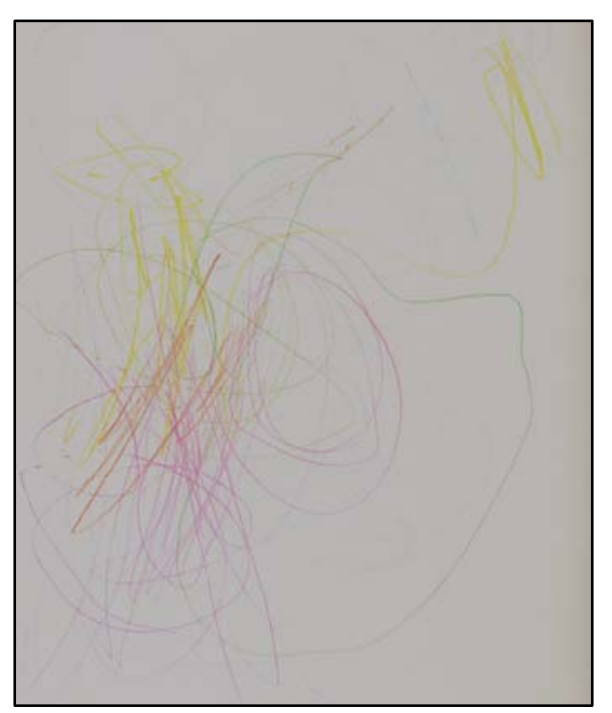

Figure 38. Rose \#2 
With four different colors of marker, she drew swirls all over the first page. "What have you drawn?” I asked. “It’s big of colors!” She replied, excitedly. I thought this could be instrumental—a sort of fundamental communication of size and color. She needed to draw to express this idea; therefore it is instrumental.

Drawing \#2 she chose to do in colored pencil. Rose focused more on the colors than on the form of the drawing. "It’s just light!" she told me, as she tried a pink pencil, "Light pink like the other one.” Later, as she picked a yellow pencil, she noticed, “These two match! (She held up two yellow pencils.)" Her voice is very animated, and most sentences sound like an exclamation. She scribbles most of this drawing scarcely looking at the paper as she does so. Finally she picks a green pencil, and makes a sort of round shape which encompasses much of the "scribbles". What can she tell me about the drawing? "A big octopus," she says. Has she ever seen an octopus? No. On tv? No. In a book? No. I wonder how she knows what an octopus is, but do not ask this young 3 year old such an abstract question. I will assume that this drawing is an imaginative/representational blend, with a splash of instrumental in her expression of "light."

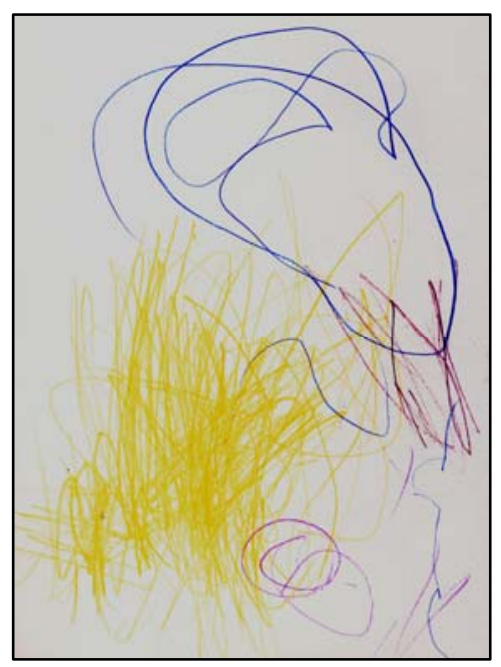

Figure 39. Rose \#3

Drawing \#3 started with an intention; “It’s a fence!” Rose told me as she scribbled a vertical yellow patch, with a yellow pencil in each hand. "Do you have a fence at your house?” I asked. “A 
big fence in my yard,” she answered. "Is it yellow?” I asked. “No, it’s brown.” On this note she picked up a brown pencil and added a brown zig-zag. Then she decided, "This is going to be a fire (pointing to the yellow “fence”).” She added, "You can’t touch the fire or you get an ouchie.” She demonstrated by pretending to touch the fire, and pulling her hand away as if singed. She offered the page toward me, so I followed her example, touching the fire, and pulling away, saying, “ow!" "Do you want a band aid?” she asked, and pretended to put one on my finger, then on her finger, too. Then she pretended to get hurt by the point of a pencil, and put another pretend band-aid on herself. She drew a big blue circular shape, saying, "This is going to be the shape." That concluded this drawing. I think some parts of this drawing were representational, some were interactional.

Rose's $4^{\text {th }}$ drawing was very simple. She drew a long rose-colored shape the length of the paper, with another smaller oblong shape beside it. "It’s a big diamond!” she told me. "What does a diamond do?” I asked. "It's a shape,” she answered. This is representational/informative.

Monday, June 16, 2008

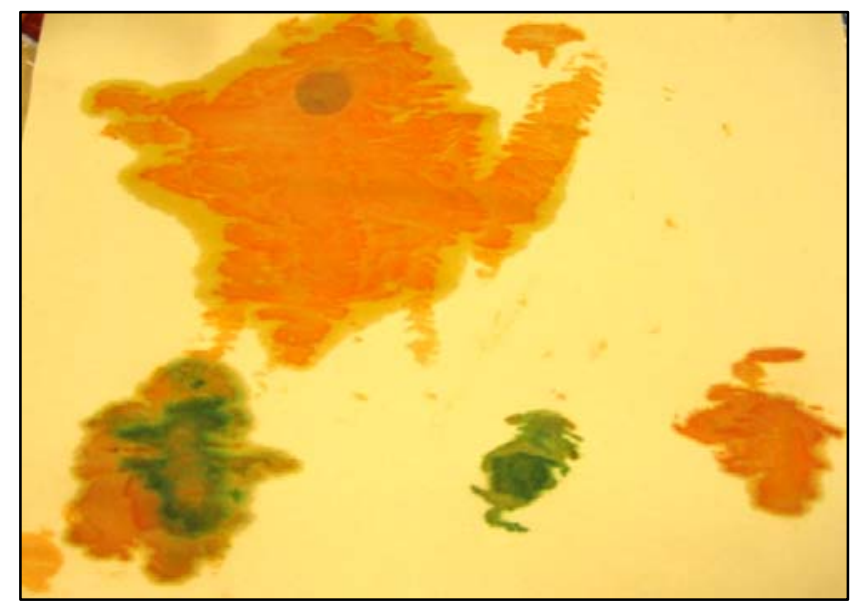

Figure 40. Adam \#9

Adam. Adam was my only participant today. He only created one piece of art, \#9. He utilized a piece of tissue paper, water, and a paintbrush. He told me, "I want to make a picture for my mom." Adam mounted the orange tissue paper on a piece of manila drawing paper, and as he painted, the 
water caused the orange dye to bleed through to the drawing paper in the design he created. When he was finished he told me, “It is a machine.” "What does it do?” I asked. "It fights monsters.” “Is your mom scared of monsters?” I asked. “Just pretend monsters. She’s not scared.” Adam told me. This drawing is interactional and imaginative.

Thursday, June 19, 2008

Adam. Adam was the first participant to arrive. At 5:00, he chose to draw in his sketchbook, creating \#10. For this drawing, he picked brown marker, and started slowly and carefully to create a long, curly, zig-zag shape that looped back around to where it began. As he drew, he picked up speed, drawing faster and faster, adding a long "tail” down to the bottom of the paper, along with a scribble of color in the center of the shape. Finally he ended with lots of dots all over and around the shape he created. "It’s a funny dog,” he told me. “It eats bones! It has one.” I asked about the dots, but he just shrugged. I believe this is a representational drawing, to the best of his ability to represent a dog. I wonder if perhaps this is why he calls things “funny” because he knows it doesn't look exactly like what it is supposed to be...

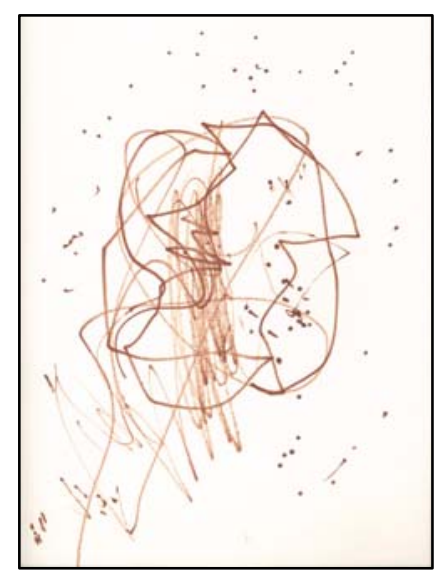

Figure 41. Adam \#10 
Sara. Sara was my next participant to arrive. She wanted her sketchbook, and at 5:38 began her drawing \# 15. She began by drawing a black line below the top of the paper, and then colored in the space above it pink. She continued to draw lines below that one, and color in the space above each with a different color, until she had covered the whole paper that way. Sara, usually silent when she draws, spoke up to say, “This is a pretty blue." "This is a pretty yellow," she added later in her process. When finished she told me this drawing was, "Rainbow stripes, and I made it with different colors.” Not sure how categorize this - it may be instrumental, because it seems to be all about the exploration and application of color. Yet she is representing the concept of a rainbow, and imagining a new application of that concept, so probably those functions could apply as well.

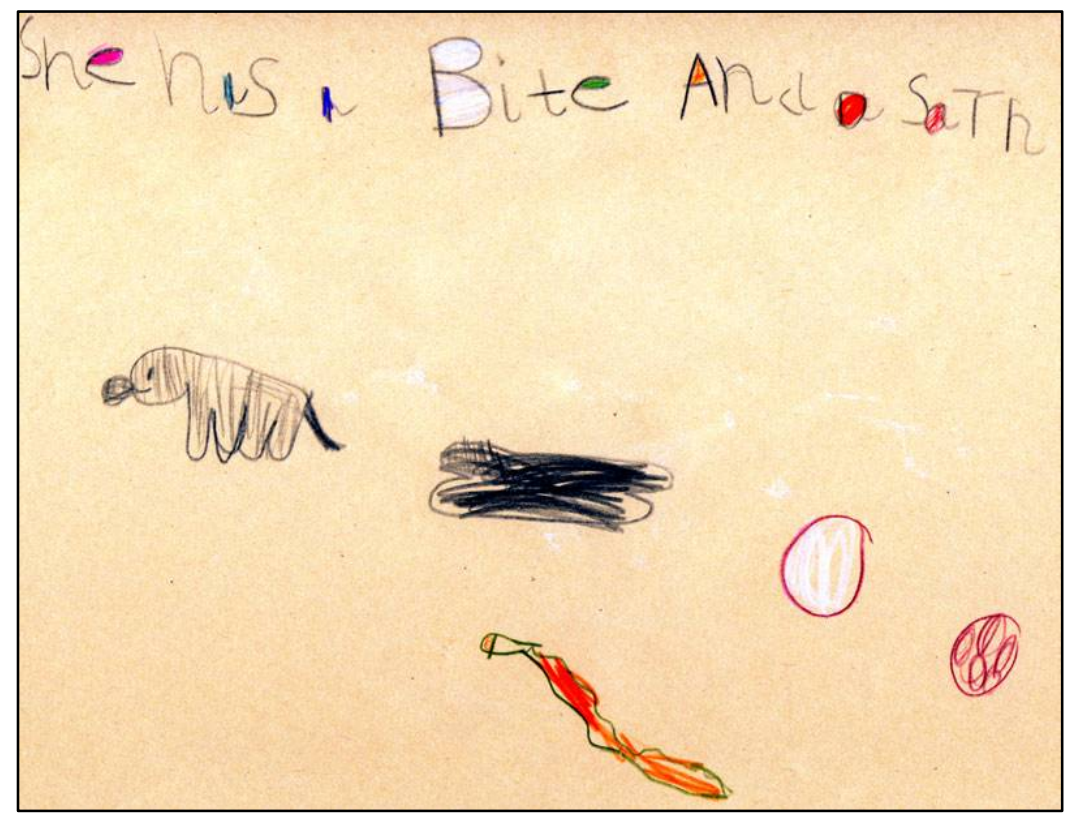

Figure 42. Sara \#16

Alice and Sara. A very interesting play scenario evolved when Alice arrived around 6. She wanted to play with Sara. I had set the stage in the dramatic play area for a veterinarian scenario. There were a vet's coat and hat, a toy puppy and dog bed, and paper and colored pencils. I told the girls that the puppy was not feeling well and asked if they wanted to help. Sara decided she would be 
the vet, and I helped her dress up as such. Alice was to be the puppy’s owner. I suggested to Sara that she could use the paper and pencils to write or draw what was wrong with the puppy. I was called away to another part of the room, and B., a student employee stepped in to support the girls’ play. I overheard Sara asking her how to spell words that she was writing. Then B. stepped back and just observed.

Sara wrote at the top of her paper, "She has a Bite And a Sath," which she later read to me as, "She has a bite and a scratch." Under the words was her $16^{\text {th }}$ drawing, which depicted a dog with a round shape in its mouth, a bone, a bowl of food, a bowl of water, and an orange leash. These were the things that she thought Alice should use to help the puppy get better-this is regulatory function. Alice watched Sara, and then took a sheet of paper and drew \#29, her own version of a dog, with three legs, and a large bone. At the top of her paper she carefully wrote "DOG”, but completely backwards so that it read “GOD”. Alice's mother had arrived to see the end of the play scenario, and watched her daughter write this and was confused by the word. I explained to her that letter or word reversal is extremely common in beginning writers, and not to worry about it. She then observed Alice and Sara as they went into the book area together, and Sara began to read to Alice. When Sara's mother arrived, Alice’s mother spoke to her about setting up a play date for the girls, which she agreed to do. I feel that art was instrumental in initiating and maintaining this budding friendship. This time, as with other times the girls have drawn together, the drawings were interactional as well as representational. 
Saturday, June 21, 2008

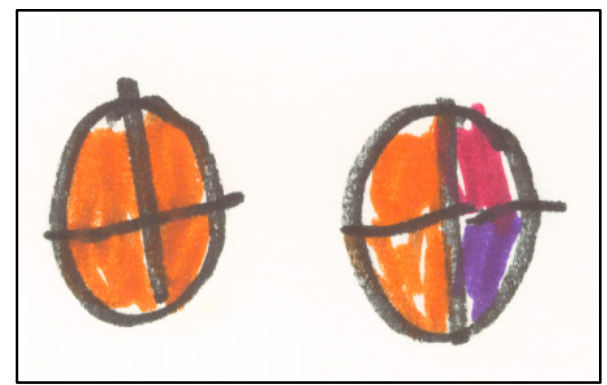

Figure 43. Seth \#7

Seth. Seth was my first participant to arrive, and at 10:21 he came to the art table to draw \#7 in his sketchbook. Using black marker he drew two small circles on the lower part of the paper. Then he used straight lines to divide each circle into quarters. Finally he used orange, pink and purple marker to color in the quarters of the circles. When he was finished he told me, "These are the wheels from a big red car.” I asked him if he wanted to draw the car too, but he shook his head no. This is representational, as they certainly look like wheels.

Rose. Rose arrived next, at 11:05. She eagerly nodded yes when I asked her if she would like to draw in her sketchbook. She opened to the first blank page and quickly drew a series of round shapes interlocking. Pointing to a tiny squiggle in part of the picture she remarked, "That's really small!” 


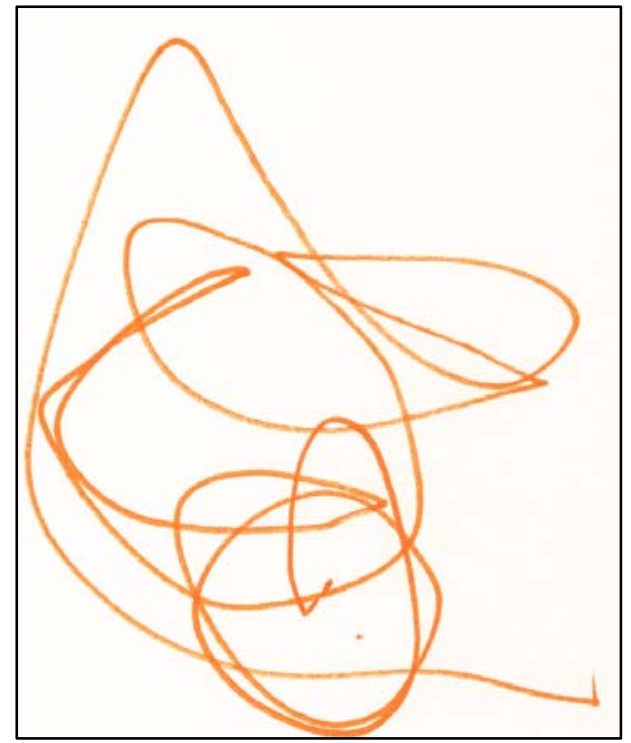

Figure 44. Rose \#5

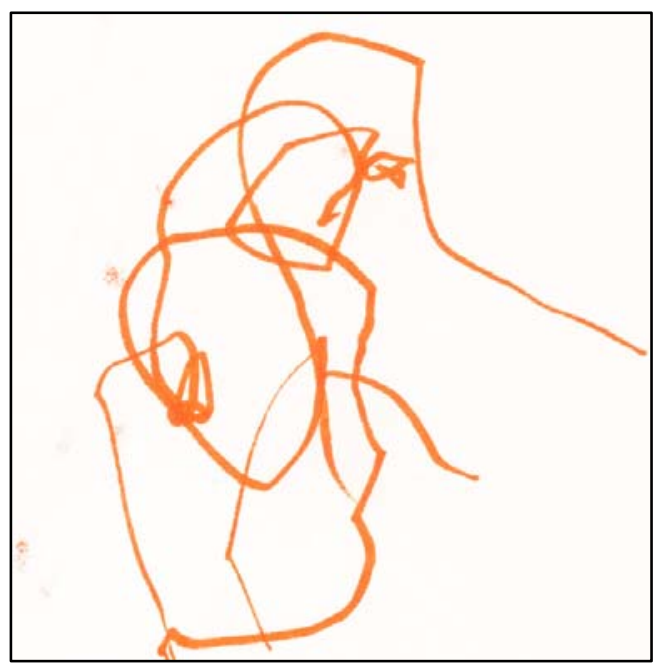

Figure 45. Rose \#6

Then without pause she began drawing on the preceding page, on the left hand side of the sketchbook. She dashed off a swirly drawing, and began to turn the page. "Wait, wait,” I said, "Could you tell me about these drawings first before you go on?” She sighed, and pointed to the first (\#5) and said, “It's a vacuum," in a tone of voice that suggested that this should have been obvious. Then she pointed to the other page (\#6) and said, “That’s its nest.” The picture of the vacuum nest was definitely imaginative in function; I was tickled by her juxtaposition of a nest with a tool like a vacuum cleaner.

She turned to the next page and drew a light zigzag scribble and some dots. Then on the opposite page she drew a round curly shape next to a heavy zigzag scribble. “That's a shape,” she said pointing to \#7, and pointing to \#8, said “And that's a necklace.” 


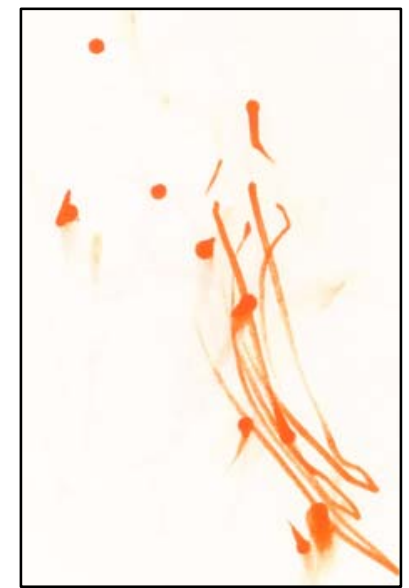

Figure 46. Rose \#7

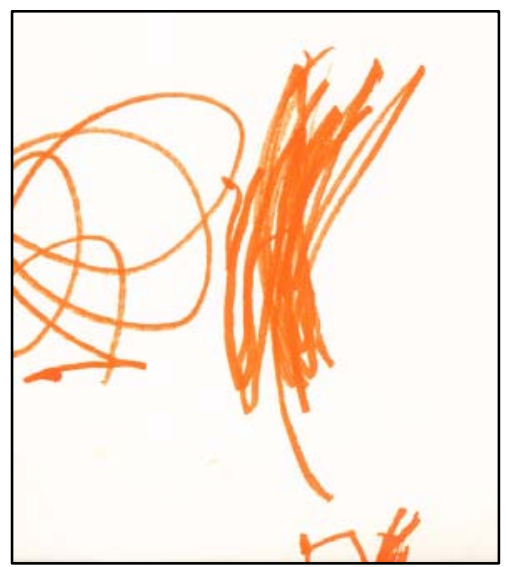

Figure 47. Rose \#8

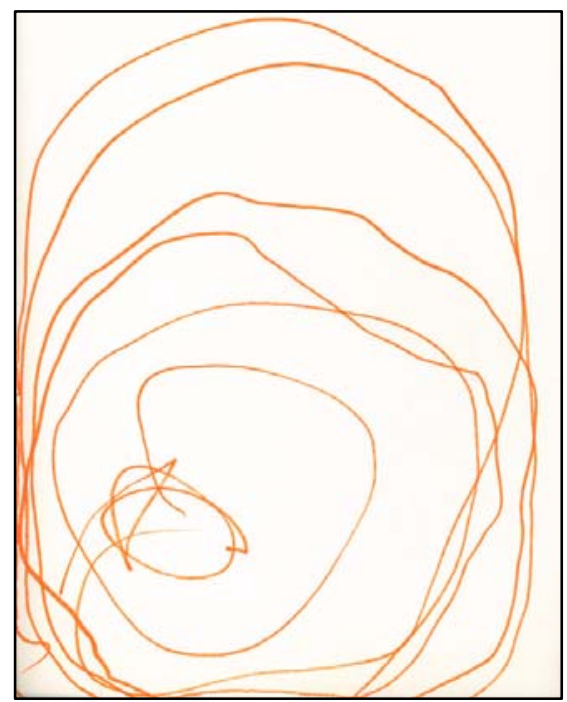

Figure 48. Rose \#9

Turning to the next page, she drew \#9, a large spiral that grew outward from a central circle. “What have you drawn here?” I asked. “A round of circles!” Rose explained. On the next page she drew a complex tangle of spirals and zigzags, ending with a zigzag up at the very top of the paper. “It’s a stairs,” Rose told me. “How do you go up the stairs?” I asked. “Up, up, up,” she chanted, hopping a finger up the "stairs" at the top of her drawing \#10. Drawing 11 began with orange marker like the others, but after several squiggles, she chose a teal marker to complete the drawing. She made a large shape at the bottom of the paper, then added a long interesting line going up to the top of the 
paper. “It's a big teeth. They go in your mouth,” Rose explained about this drawing. Then she announced she was finished and went off to play in the dramatic play kitchen.

About Rose's art: she completed all 7 drawings in about 7 minutes. She dashed through each so quickly that it was difficult to truly interview her about each. Most were representational—since she told me what they were-and it is her interpretation of her art that matters most in this study. She knew what she was trying to communicate with each drawing.

\section{Monday, June 23, 2008}

Sara. Sara was my first participant to arrive, shortly before 6:00. She chose to paint at the art table, where I had set out some tempera paint pads and paper. I was unable to observe her process, but I did see her finished product. She made a large brown circular shape on the left hand side of the paper, which she had painted so thoroughly that she had worn a hole through the paper, and on the right was a heart within hearts that was rainbow colors. When I asked her to tell me about the picture she said she didn’t know what the brown part was, but the rest was a “colorful heart.” (\#17)

Alice. Alice arrived after Sara, and also chose to paint at the art table. She sat across from S., another 3-year-old girl, but they did not interact, just painted in parallel to each other. Alice painted “a dog” on her paper, using her usual method. (\#30) Then she chose to join Sara who was working on a jigsaw puzzle in a quiet area of the room. I was able to ask both girls about their artwork when I came into the room briefly to see if they had drawn anything. D., a student employee, was able to fill in the details about how they painted. Both girls’ work seemed to be representational.

Adam. Adam arrived at 6:30. I asked him if he would like to sit in the reception area and draw with me for a little while before he went into the main room, or if he just wanted to go right in. He chose to sit with me and draw. The only writing/drawing utensils I had were two pens, one black and one red. He chose the red pen. “This time I'm going to draw a monster," Adam said. "Here is his eye 
and his other eye. And this is his smile," he narrated as he drew a large rounded shape, with facial details. “Is he a scary monster?” I asked. “No. He’s nice.” This was imaginative.

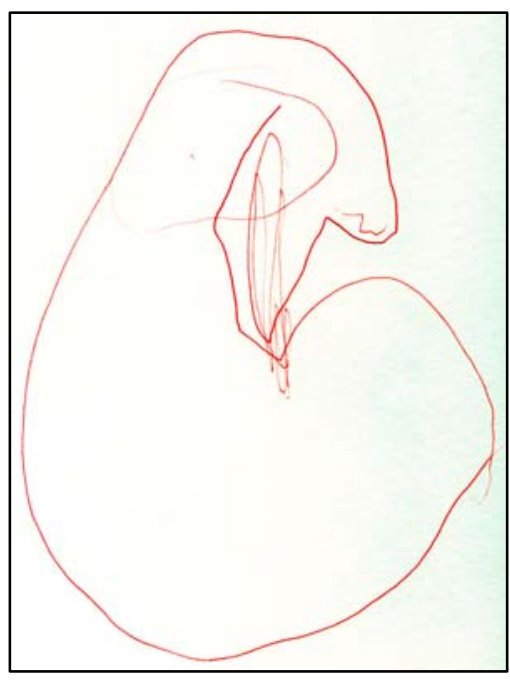

Figure 49. Adam \#11

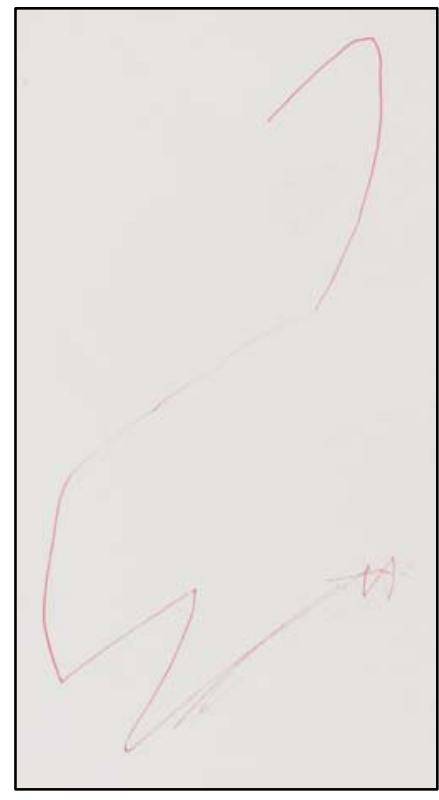

Figure 50. Adam \#12

Adam wanted to draw another picture, so he turned the page. “This time I'm going to draw a snake like on my shirt. It's going to be a bad snake. It's going to bite people!” He grinned at me as he spoke. I gasped, as if scared. "Not you. Only all the other teachers else," he reassured me. As he drew he narrated, "This is his tongue. And this is his tail.” This representational drawing looked very snake-like, and was also interactional.

\section{Thursday, June 26, 2008}

Sara. Sara was my first participant in attendance. She arrived late, at 6:15. She chose to go right away to the easel, where she requested the dot painters. She drew "a pot of gold", which was \#18. This resembled very closely the other pots of gold she has created. I consider this as before to be a blend of imaginative and representational. 
Later in her sketchbook, Sara created a large pink spiral, which opened out from the center of the paper. Around the outside edge, she switched colors, adding blue, orange, and green. Each time she used a new color, she took care to connect the new line exactly where the last line had stopped. Finished, she told me, "It's a big, big seashell.” We had seashells in the sensory table, and some have spirals on them, so I think this is representational.

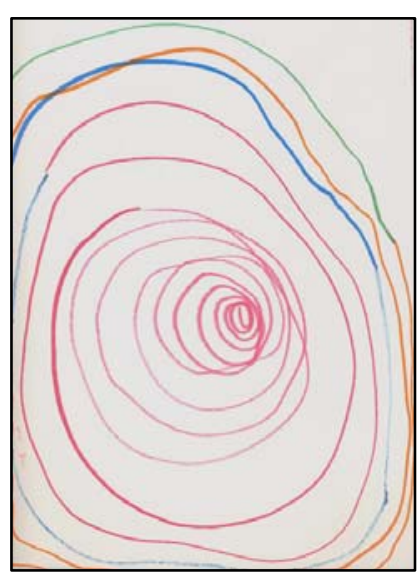

Figure 51. Sara \#19

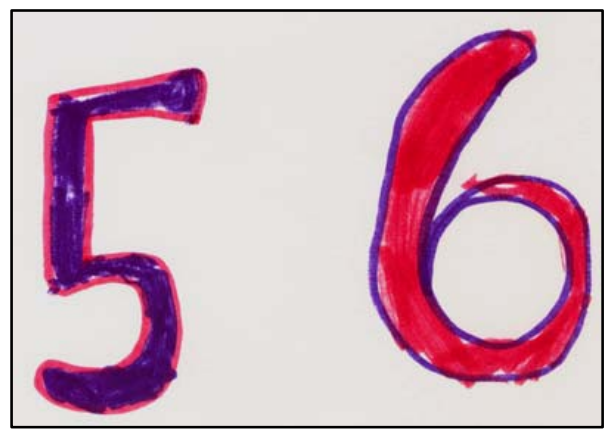

Figure 52. Sara \#20

Sara turned the page, and began another drawing. She drew a number 5, purple with a pink outline, and a number 6 , pink with a purple outline. She told me she made, “A 5 and a 6 . Because now I'm 5 and soon I'm gonna be 6.” This was also representational/informative.

Alice. Alice began drawing at the same time as Sara. She began with the number 3, and then drew three snakes. Switching to a pink marker, she began to decorate around these elements, adding letters, words, letter-like shapes, lines, swirls, and creature-like shapes. One of these latter looked like a dog or turtle shape, but she colored it in, and drew no face or legs. Another shape had eyes in a head, but no body. When I asked her about the drawing, she told me she had made, "3, snakes, (her name), (her brother's name)." She wrote the letters for the words "mom” and "dad”, although she did not read these back to me. 
“What about the rest?”I asked, indicating the elaborate decorations. "I don't know," she told me, smiling. I believe that these decorations may be aesthetic, but Alice is typically such a representational artist, that she may not have the words for that concept yet. The elements she identified could be categorized as representational and interactional.

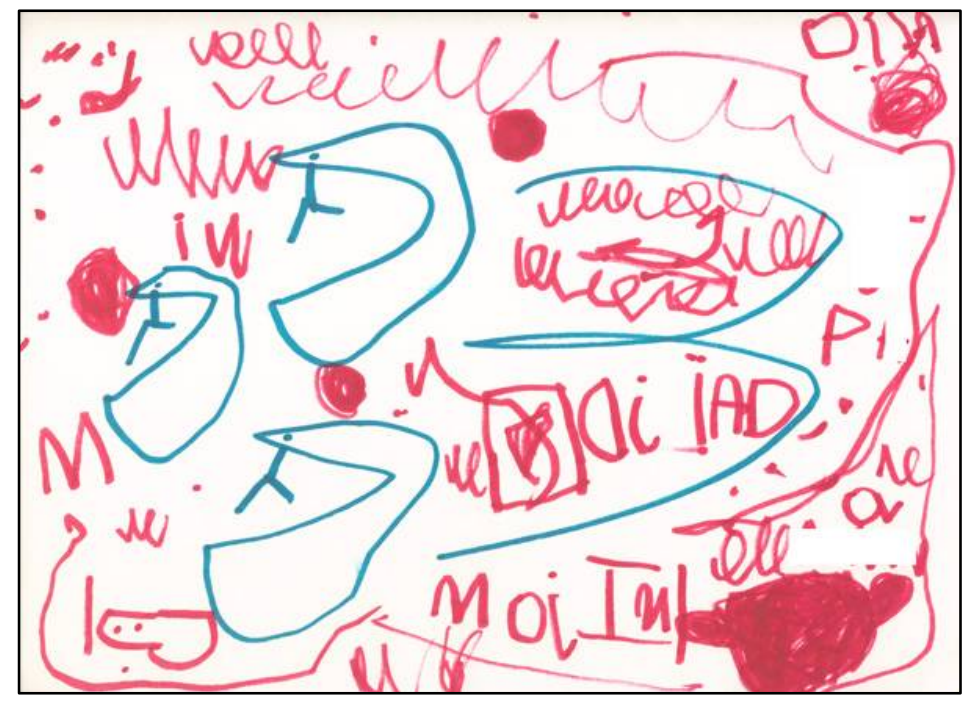

Figure 53. Alice \#30 (names omitted)

\section{Parent interviews}

Many of my interviews with parents of participants were informal and directly related to the art work their child had created. At times, the parents were present while the participant was drawing in his or her sketchbook. During these times, I tended to hold my breath, hoping that the parents would not steer their children's art too much. As the study progressed I decided to relax and observe these interactions, and note what they were, as well as what each parent and participant said and did. These interactions gave me some insight about the participants' culture, home life, and values, aiding my interpretation of their communication.

I include here narratives of significant parent interviews and interactions. Interactions with parents are daily and routine in the early childhood setting, therefore I sought to describe some of 
these to include in the overall picture of each child's art and communication. Also included are the results of one structured interview that I conducted with one parent of each participant. The interview protocol is included in the appendix.

\section{Adam's parents}

May 19, 2008. Adam's father brought him to the center today. He was aware that the study was starting and seemed excited about it. He let me know that he would like to see my results at the conclusion of the study. As he tried to transition Adam from "dad time” to "center time”, he smiled apologetically at me, as if his son was not cooperating. I assured him that Adam would come and draw when he was ready and only if he wanted to.

Adam's dad got down on his son's level and tried to say goodbye, but Adam foiled that attempt by climbing onto his father's knees and hiding his head under his arm. I overheard Adam tell him, "I don’t want you to go.” Adam's father decided that he would stay for a little while and watch his son draw. He was present for the first three drawings. Adam's father asked his son about the colors he was choosing, about the names of these colors; when Adam did not know the color name, his dad would tell him what it was, like brown, for example. At one point Adam wanted his father to draw in his sketchbook, but I came over with a separate piece of paper for him to use. Adam’s father drew a humorous face for his son, while Adam watched. Later, when Adam's mother came to pick him up, he made sure to take his father's drawing home with him.

June 7, 2008. Today, Adam drew an orange picture all about a "shtruckshun" place. I asked him if he meant construction place and he nodded at me in assent. When his mother came to pick him up, I pulled her aside and asked her about it. She laughed at his pronunciation. I asked her if there was any construction near where they lived. "Yes," she told me, "We drive past it every day.” "Are the construction machines orange?” I asked. "I think some of them are," she responded. I thanked her 
and let her know that her information had shown me that this drawing was representational/informative.

June 12, 2008. Adam had drawn a "light pool”, but he could not really answer my questions fully about what that meant. He told me that the light pool was at his dad's house, that it was inside, that you could not swim in it, and that it turned lights off. I was mystified.

I asked Adam's mother about it, and she was confused about what it was as well. She got down on Adam's level and questioned him about it. He told her the same things he had told me. She asked him if he was sure it was inside, and he nodded yes. "Let’s call your Dad,” she suggested, “Maybe he knows what you mean.” She dialed, and spoke with him first, describing the situation. Apparently Adam's father did not know what it was either, and asked to speak with his son. Adam held his mom's cell phone to his ear while his dad spoke to him. "It’s the funny one,” was all I heard Adam say. Adam's mother apologized to me for not being able to solve the mystery. She agreed that it seemed like it was something real that Adam had seen.

Formal interview with Adam's mother, June 25, 2008

1) Talk about what/how your child usually draws. (Any themes, recurring patterns, etc.) He goes through phases. Monsters, machines, trains... (trails off)

2) Discuss the kinds of things you do in response to your child's art.

I like to give them as gifts, sometimes. There's also a bulletin board in the basement where I hang things up.

3) What can you tell me about your family's communication style?

I encourage him to talk a lot. I try to take the time to listen. He tells me I don't (smiles).

4) Any cultural/language considerations I should be aware of?

He's half Egyptian. Doesn't speak a word of it. His dad was born here. 


\section{Alice’s parents}

May 19, 2008. Alice’s father dropped her off at the center with a hug, and told her, "I love you. Be good.” He was training for a half-marathon, so he let me know that he would be running while Alice was at the center. When he returned, flushed and sweaty, he asked if he could see her work. I showed him all seven drawings, and he knew what they were without me having to tell him. He recognized Alice's cats and dogs, and told me how much she loved animals, especially pets. I asked him if they had dogs and cats at their house. "No,” he told me, "but our neighbors have a dog that's out in their yard a lot.” I told him Alice had told me she had two cats. He laughed and said that maybe she had meant her stuffed toys. He asked his children, Alice and her brother, if they had thanked their teachers, as he did every day. They turned at the door and called out, in unison, “Thank you!”

June 7, 2008. When Alice's mother came to pick her up, Alice was not done drawing in her sketchbook. So she sat down to observe. She saw her daughter's name on the front of the sketchbook, and asked her if she could write her last name too, which she did. Next to Alice, Sara was drawing a snake in her sketchbook. Alice announced that she wanted to draw a snake. Her mom agreed to stay a little longer so she could do so. Alice’s mother talked with her daughter while she drew, asking questions from time to time. “What letter snake start with?” She asked. Alice did not respond verbally, but drew an S on her paper. Then she turned the S into a drawing of a snake by connecting the two ends with a line like the letter C. Her mother asked if she wanted to draw eyes and mouth; Alice did, even adding a nose. Her mother asked what a snake mouth looked like, and Alice drew it, making a line with a split end. Alice said, “I want to draw a little snake,” and did so, then added a third snake to the drawing. When she was finished she told me, "It's a mama snake, a baby snake, and a brother snake.” 
Formal interview with Alice's mother, June 25, 2008

1) Talk about what/how your child usually draws. (Any themes, recurring patterns, etc.) Dogs and cats. Usually pets. Especially dogs and cats. Sometimes she's interested in flowers.

2) Discuss the kinds of things you do in response to your child's art.

Do lots of painting. She likes to color. She's into just about everything: cut, glue, watercolor. Lately write letter and number. Most of them I keep it. She has so much of them I have to pick and choose (laughs). We have a bulletin board.

3) What can you tell me about your family's communication style?

We talk. The kids, we talk openly, out loud.

4) Any cultural/language considerations I should be aware of?

(Alice's mother is from Vietnam.)

I teach [Alice] not a lot, but here and there-say words in Vietnamese. She's interested, will ask me, "What's the word for this, Mom?"

\section{Rose's parents}

June 10, 2008. I had not seen Rose in over a month, since her father had signed the consent form for his daughter's participation in the study. Concerned, I phoned their home and left a message wondering if they were still interested in participating in the study. Her father rang me back a short while later. He apologized about their absence, and assured me that they indeed wanted Rose to be able to participate in the study. He explained that he had been working long and irregular hours at the emergency room. Rose's mother had been feeling ill, and unable to exercise, so that was why Rose had not been coming to the center. He said that they would bring her that week. I reassured him that whenever she came it would be fine, that this study was naturalistic, conducted in a real environment 
with real children who had real lives; it was not being conducted in a lab with perfect control of variables. He laughed and said it would not be a problem to bring her; her mother was starting to feel better.

June 14, 2008. Rose's mother brought her to the center, accompanied by a friend. She looked pale and tired. I asked her how she was feeling, and explained that her husband had told me that she was feeling ill. She pulled me to the side, and told me in a very quiet voice, "I'm pregnant. I've been having really bad morning sickness.” She had not been ready to tell Rose yet; she felt that Rose would understand better when it was nearer to the time she was due. I congratulated her and inquired about the due date. Later, when she came to pick Rose up, she asked to look at her drawings, and nodded approvingly. She seemed proud of her daughter's art.

Formal interview with Rose's father, July 2, 2008 (by telephone)

1) Talk about what/how your child usually draws. (Any themes, recurring patterns, etc.) A lot of circles lately. Not complete, she'll start, it'll turn into a spiral, then she'll try to close it.

2) Discuss the kinds of things you do in response to your child's art.

Obviously we encourage her. Hang it up on the wall or refrigerator.

3) What can you tell me about your family's communication style?

We more or less try not to do baby talk. We try to talk to her like an adult. We communicate a lot during dinner. She gets attention when she's talking. Lately, when her mother and I talk, she talks louder and louder so we can hear her.

4) Any cultural/language considerations I should be aware of? No. 


\section{Sara's mother}

June 9, 2008. Sara's mother was the only family member who brought Sara and picked her up. Since Sara was almost six years old, there was no need for her to linger, or to ease the transition. Her arrivals and departures were usually brief and relaxed. I stopped her on their way out, and asked her to look at Sara's amazing painting of fish in the ocean. Sara's mother marveled at the blue water, the neat line of little, orange fish, and all the details her daughter included. "Good job, Sis," she told Sara (perhaps a family nickname); “This is beautiful!”

June 19, 2008. Sara's mother arrived at the same time as Alice’s mother. The two girls were still playing veterinarian with the toy puppy in the dramatic play area. The mothers were amused, especially Sara's mother, who saw Sara in the vet's scrubs and remarked that maybe Sara would like to be a vet when she grew up. Alice's mother said she had wondered the same thing about her daughter. I showed both mothers the work of their children, and expressed to Sara's mom how hard her daughter had worked to spell out the words in the picture. She seemed to be pleased by this. I told the mothers that their daughters had been playing together a lot, and I thought they were becoming friends. Sara’s mother turned to Alice’s mother and suggested, "Maybe we should get them together sometime.” Alice’s mother agreed.

Formal interview with Sara's mother, June 29, 2008

1) Talk about what/how your child usually draws. (Any themes, recurring patterns, etc.) Hearts, rainbows, butterflies, flowers, self, family...(trails off)

2) Discuss the kinds of things you do in response to your child's art.

Several are framed. I put stuff on the fridge, there's an accordion portfolio, some are discarded...(trails off)

3) What can you tell me about your family's communication style? 
We talk a lot. We live with her grandparents. Very verbal, social. I heard that a child's learning of language is equal to the number of words they know. So, no baby talk, proper grammar; I was an English major. I've always spoken to her on an adult level.

4) Any cultural/language considerations I should be aware of?

No. She can count to 10 in Spanish; she learns from Dora [the Explorer, a children's television program]. I studied Spanish.

\section{Seth's parents}

When I first asked Seth's mother if she would mind if he participated in this study, she seemed surprised. I had told her what the topic was, and talked a little bit about what I wanted to find out. She said, “He doesn’t like to draw much.” I expressed my surprise, and told her that Seth often, almost always, drew and painted when he was at the center. "He just likes the attention,” she said, laughing.

June 5, 2008. When Seth’s mother arrived to pick him up, I showed her his drawing of the Wiggles. I explained that he had been singing while he drew, which mad her laugh. I asked about the meaning of "Higgletytown," a word I had heard him say while he drew. "Yes, that's in the movie he has,” she told me. "He loves the Wiggles.”

On occasions in the past, Seth had brought in audio CDs of the Wiggles, planted his chair in front of the CD player, and sang every song with gusto. Seth seemed very enthusiastic about this. I mentioned to his mother that he seemed to love music. "Have you thought about whether he might learn an instrument?” I asked. “Maybe for when he is older, ” she replied. I let her know about the Kindermusik program, designed for young children. I looked up the local instructor and wrote down her phone number. Seth’s mother told me she was going to look into it. 
Formal interview with Seth's mother, July 10, 2008

1) Talk about what/how your child usually draws. (Any themes, recurring patterns, etc.) Boats, faces...(trails off)

2) Discuss the kinds of things you do in response to your child's art.

Stick on the refrigerator.

3) What can you tell me about your family's communication style?

Speak with him a lot: what did you do, did you have fun, what he dreams. This age is so creative. He talks so much about the body. Many questions about, "What is this in my body?"

4) Any cultural/language considerations I should be aware of?

(Seth’s family is from Iran.)

We speak Persian at home.

\section{Personal Reflections}

How have I changed over the course of this study? How did this experience impact me as an educator and as a researcher? At the beginning of my study, I was worried and anxious, terrified of failing in this important work. These were the emotions that initially dominated my personal research journal. For example:

May 20, 2008.

[I have been having worried feelings] about adult interaction and the children's art. I have warned the (adult) student workers about my research, and what I required from them: give me space at the art table, don't draw your own pictures near the [participants] or influence them about what they are drawing, etc. They seemed compliant. Yet I still had to verbally interact with the staff, one in particular who sat down across from my participants and talked to them while I was trying to interview and observe. Yet, what am I doing? I am asking questions and 
watching attentively, which may be influencing the children’s decisions and artistic integrity. And I am a supervisor, modeling how to interact with children to the undergraduate workers. I can hardly fault them for doing as I do. I can hope that as the study progresses, I can become a little less of a presence. And hopefully the other workers will pick up on how to stay less involved and watch from a distance.

Later in the study, as I got my feet under me, I began to focus less on my experience (or lack of experience) as a researcher and more on the experiences of the participants as they created art. I began to see the teachable moments that arose as my participants created art and I got to observe their learning, particularly as they grew accustomed to my attentive presence. I became much more focused on the moment, and tried to "stop time" so I could record as many details as possible. I also became so excited about the participants' learning and art creation and communication; I could see them blossoming over the course of the study, communicating with me in a more relaxed and open manner. It was clear that my unwavering interest in and support of their art creation meant something positive to them. It was hard for me to be in the researcher's role, as I was usually thinking about the teaching possibilities which arose. I found myself combining these roles into something new and very useful: teacher-research fusion, or tea-search as I called it.

Take, for example, Adam, a child who was hesitant about verbal communication. I knew to increase his learning and get him to use more language, I should get him to express himself in any medium he enjoyed. He liked to draw, and over the course of this study, as I attended closely to his art each and every time he created any, he began to grow more and more verbal. Towards the beginning, if I asked him what he planned to draw, he would tell me sometimes to wait, or that he would tell me when he was finished. By the end of the study, he was narrating his intent from the beginning of his drawing, even weaving a little story into the marks on paper he created. "This time I'm going to draw 
a monster," Adam said on June 23, 2008. "Here is his eye and his other eye. And this is his smile," he narrated as he drew a large rounded shape, with facial details. "Is he a scary monster?” I asked. "No. He’s nice.” Adam beamed at me, confident and proud of his work.

Over the course of the study, as well as over the subsequent months that I sorted and made sense of the findings, my respect for children's ideas, their minds and their work, increased. This experience has changed me personally and professionally; I will never again look at children's art without considering the communicative intent.

I also transitioned in my professional life from being a post-graduate student to teaching higher education during the course of this study. This shift in perspective made me think about the implications of my research for beginning teachers. I included some of these thoughts and connections in Chapter 6, conclusions and recommendations

\section{Chapter 5: Data Analysis}

\section{Coding}

I sorted the results of my data collection based on the following criteria: total number of art works created, communicative function, whether the art creation was a social event (and if so, with whom was the art created), whether the child had a stated intention for the drawing, and finally whether or not the art had a verbal component. The communicative functions were coded as follows: c.f.1—instrumental, c.f.2—regulatory, c.f.3-interactional, c.f.4—personal, c.f.5—heuristic, c.f.6imaginative, and c.f. 7—representational/informative.

After coding for these criteria, I categorized the data. In some cases, I found myself recategorizing art which I had previously categorized differently. For example, Sara drew many hearts. At one point early in the data collection process, I asked her why she draws hearts. She replied, 
“Because I like everybody.” This fits with Halliday’s personal function of language, wherein language is used to convey personal feelings or emotions. I had initially categorized her hearts as imaginative and representational; on review, I felt I should include all five of her heart drawings in the c.f. 4 category-personal function.

\begin{tabular}{lcccccccccccc}
\hline Participant & \# total & c.f. 1 & c.f.2 & c.f.3 & c.f.4 & c.f.5 & c.f.6 & c.f.7 & social art & \# intent & verbal component \\
\hline Adam & 12 & 1 & 0 & 2 & 0 & 0 & 6 & 9 & 3, dad & 5 & 4 \\
\hline Alice & 30 & 0 & 0 & 13 & 0 & 1 & 1 & 29 & $5-S a r a, 1-m o m$ & 26 & 8 \\
\hline Sara & 20 & 1 & 1 & 3 & 5 & 1 & 8 & 19 & 3 , Alice & 3 & 2 \\
\hline Rose & 11 & 2 & 0 & 1 & 0 & 0 & 2 & 8 & 0 & 1 & 2 \\
\hline Seth & 7 & 0 & 0 & 0 & 0 & 0 & 3 & 5 & 0 & 5 & 5 \\
\hline
\end{tabular}

Table 2. Analysis of Data

I also found that in most cases, each participant's artwork had components of different communicative functions. It was rare that a participant's drawing only fit into one category. This shows the complexity of the young child's drawn communication, wherein, for example, one drawing could communicate imaginatively, representationally, and interactionally all in one drawing. The children's interpretation of their own drawings was key to this analysis. I also took the parent interviews into consideration during the analysis process. These were especially helpful in defining trends or themes to each child's work, such as Alice's dogs and cats, or Adam's machines. It was also interesting to note that 2 of the 5 participants were bilingual, Seth and Alice; both of these children had the most verbal components to their art out of the participants observed.

I had to admit that categorization of each drawing was extremely subjective. Different teachers or researchers could easily have categorized an artwork that I called instrumental as representational, 
or one I called representational could have been viewed as personal. I felt that this flexibility in interpretation was endemic to art in general. Each person who reads a text or views a painting or watches a play brings his or her lens to bear when seeking to interpret the meaning of what is shown; this research was designed by me, thus the interpretation and categorization was most meaningful to me.

What is generalizable here is the template of Halliday's communicative functions of language that any teacher or researcher could utilize to view children's art in a communicative sense.

There was children's art that could have fit into any category, depending on how I “read” it. Seth’s drawing of his blanket and pillow, for example, could have been instrumental if he was missing his room at that moment, regulatory if he wanted me to go there or see it, interactional because he was showing his things to me, as well as personal because these were his things-and children do not have many things that are all theirs, heuristic if he was asking me to visit his room, imaginative because his blanket is not pink in reality, or representational because he showed things that are real as they are as much as he could at that moment. I decided the art was primarily representational in this case, because Seth's interpretation stated most clearly that this was bed. He did not stress that this was "his” bed; he told me that he was not tired, and he did not invite me to his house. This scenario illustrates the mental wrangling that went on as I attempted to categorize some of the art observed. Mostly, the children told me orally what the art work was about, and it was easy to categorize from their response. 
Moreover, respect for the ideas of children, and listening to their communication are central themes for this research. It is fitting that their interpretations of their artwork were considered first when determining the communicative function. My interpretation was based on their interpretation.

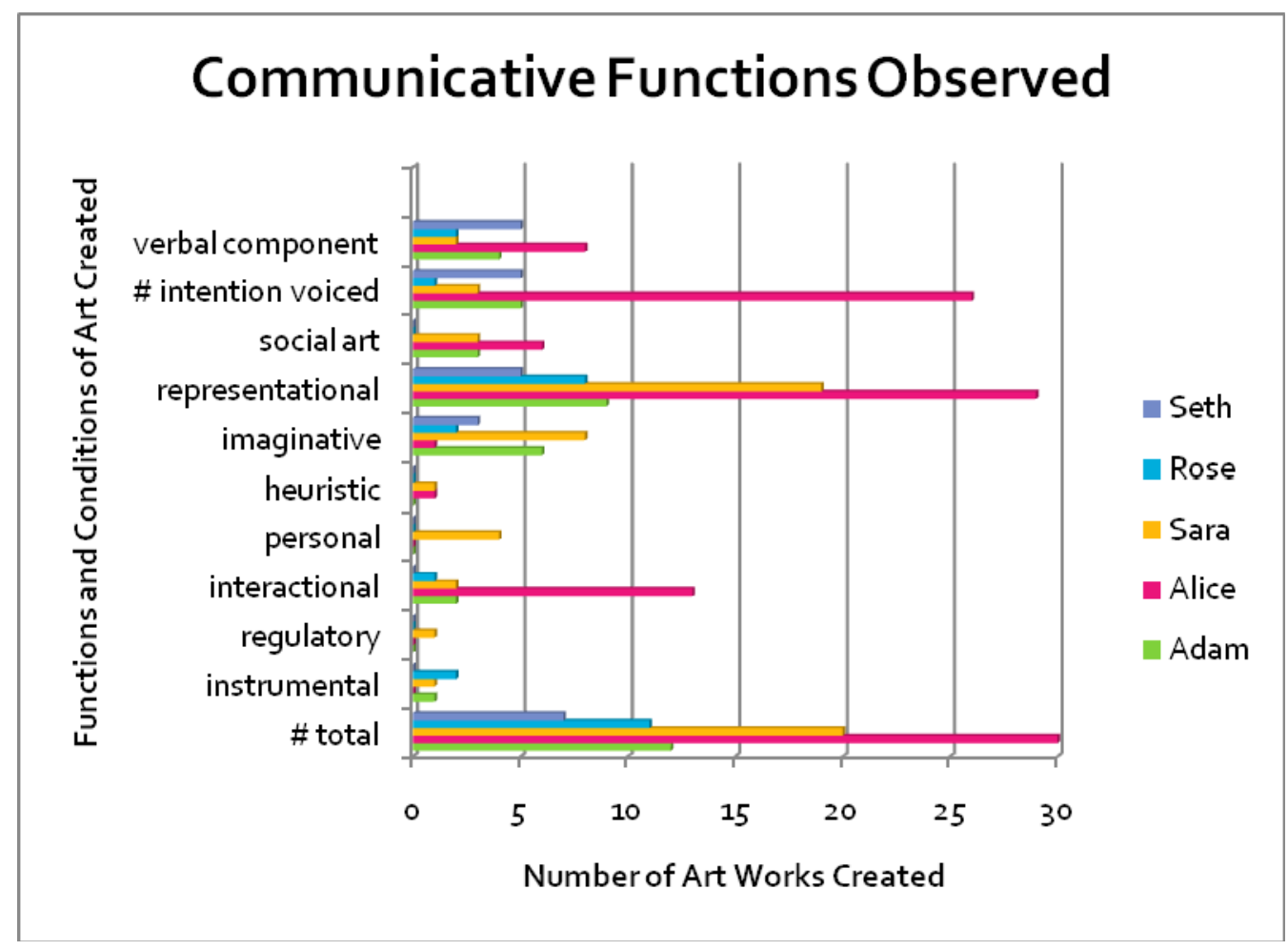

Figure 54. Graph of Data Analysis

Summary of Analysis

First I will discuss each child's art in summary, also I will summarize across the data as appropriate. Finally, I will analyze the process of analysis.

Adam. Over the six week period, Adam created 12 drawings. He utilized his sketchbook and colored markers for most of these. He additionally created art with many different forms of paint, including tempera, dot painters, and watercolors and different kinds of paper, including construction paper, tissue paper, manila paper, and large drawing paper. 
Only his very first drawing I considered to be instrumental in function. Several of his drawings were interactional; most of these involved his mother and father. He created one drawing, for example of a machine, the function of which was to protect his mother from monsters.

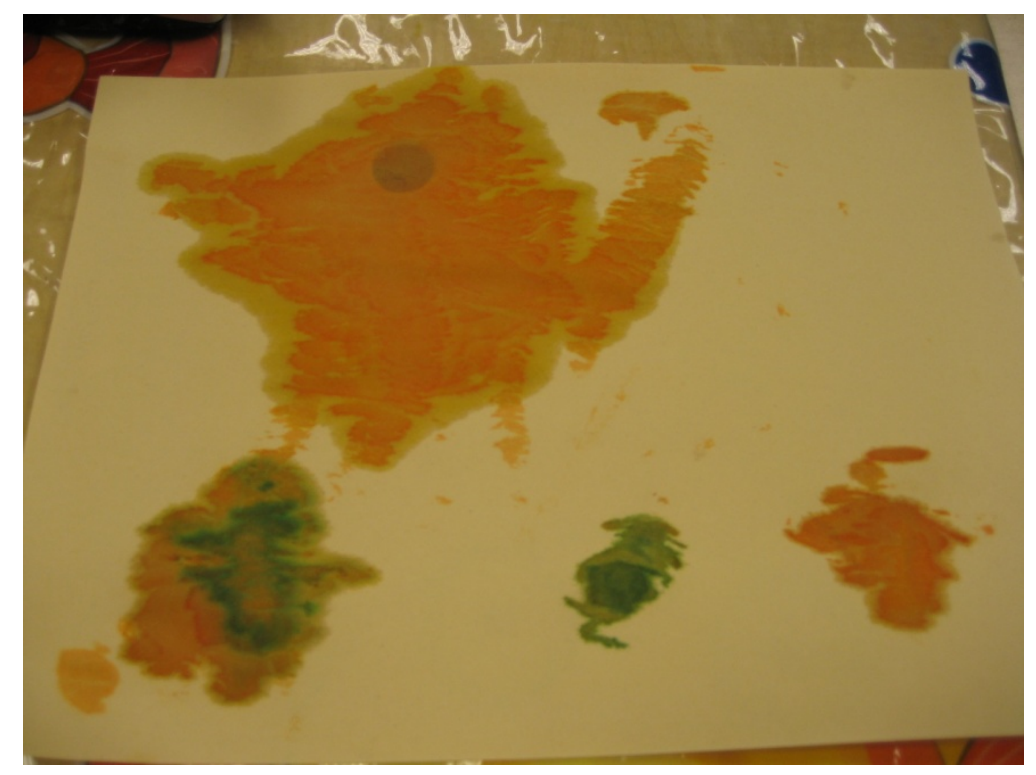

Figure 55. Adam's monster-fighting machine.

Adam's drawings were primarily a mix of representational and imaginative communication. His art leaned more towards the representational/informative function of language. As I noted previously, he was enamored of nonfiction books, of machines and vehicles, and usually seemed to have some real life experience on which he based even his imaginative drawings. For example, he drew a waterfall that he had visited, which was representational, but then he added a giant which was imaginary.

Adam did not usually draw with peers as part of social interaction. His 3 social art events all took place with his father on the first day of data collection. Otherwise, he usually only spoke to me when he was finished drawing. He is an only child, and I noticed that he tended to seek out myself or another adult rather than children to play with. 
Five out of 12 drawings had a stated intention. This seemed to become more frequent over the six-week period. It is possible that he noticed my questions about the content of his drawings, so he began to state the content at the onset more often. Or perhaps he grew more comfortable with my support for his efforts, and just opened up more.

Four of his 12 drawings had a verbal component. He narrated through the drawing process a couple of times, particularly at the end of the six weeks, when it was just he and I working together alone. Adam also utilized sound effects to describe the workings of his "toy machine” on day one.

Alice. Alice was the most prolific of the participants. It was not uncommon for her to draw for the entire time she spent in the care setting, which was usually close to two hours at a time. She utilized her sketchbook and colored markers for most of the drawings. She also chose, at times, to work with other materials, including paints, construction paper, and scissors.

Alice created 30 drawings in the six week period, of which 29 had a primarily representational/informative function. She seemed at times to be instructional with her art, like a teacher, as she talked about what shapes she was drawing, or about other components of the content. She seemed to have templates in her mind which she referred to in her art. Dogs, for example, had to have an oval body, four oval legs, a round head, facial features, and some sort of round tail. 13 out of 30 drawings had an interactional function. She tended to write the names of her family members as part of her drawings.

Alice also began drawing with Sara during the course of this research. At first it was in parallel, but soon the two girls move on to collaborative efforts, such as the snake they made together. By the end of the six-week period, it seemed clear that a relationship between the two participants was developing, perhaps started by their mutual interest in art. Of her social art events, 5 were with Sara. 
Only one involved her mother. Though there was an almost three year age gap between the two girls, Sara is the same age as Alice's brother, so Alice was accustomed to interacting with an older child.

Alice created one drawing that was clearly heuristic in function. She questioned how to portray a "swimming turtle", or sea turtle, and then answered her question through her drawing. She also tested her theories about the sea, by drawing the sea around the turtle, in the only context she created solely for the creature she had chosen to portray.

Alice also only had one drawing that had an imaginative function, and even that was primarily representational; in that drawing she portrayed a snake "flying," which made her laugh, indicating to me that she knew that snakes do not fly. Many of her color choices were imaginative, such as pink or green cats and dogs, but she did not refer to the color when she described the content of the drawing to me. These appeared to be simply the colors that appealed to her artistically when she chose to represent her idea.

Alice typically stated her intention when beginning to work on a drawing. 26 out of 30 had a stated intent. Although she usually worked in silence, 8 drawings had a verbal component, and most of these were interactional or collaborative drawings; a few times she narrated or spoke to herself as she drew, for example telling what part of the dog's body she would draw next, or counting the snakes next to the number 4 .

Sara. Sara was the oldest participant. She turned 6 years old two weeks after the data collection period was over. Perhaps due to her age and development, she had the most balanced range of communicative functions for her art. There was one drawing of hers I had to categorize as instrumental; this was an exploration of color wherein she covered the whole paper with stripes of different hues, as she discussed the ones she liked best. 
Sara created 20 drawings, 19 of which had a representational/informative function. Often she combined functions, such as imaginative with the representational. For example, she created a Christmas tree that had a trunk and leaves, as trees do, but also had pink clouds and a giant letter S, which she admitted was not quite possible in real life.

As discussed at the beginning of the chapter, she utilized the personal function of language in her art 5 times. Sara was the only participant to use this function in the time period observed. She drew hearts to show her "like” for “everybody.” This is an example of drawing to communicate one’s feelings or emotions.

Sara was the only participant observed to use the regulatory function. She and Alice, in the course of play, were enacting a veterinary scenario. Sara drew the course of treatment for helping the toy puppy get better, and presented it to Alice as instructions. She used art to effect another person's actions. Three of her 20 drawings had an interactional function; those three drawings were created socially with Alice.

Sara was very quiet, and usually created her art in silence. Although it seemed clear from the precision and lack of hesitation in her drawings that she had intent for the art, she did not typically state the intention first. She had very few drawings with a verbal component. One of these was the heuristic drawing, wherein Sara wondered how to create a bicycle in her art. As she discussed the components of a bicycle that interested her, she tested out the theory of wheels by creating wheels and attaching them to a "pot of gold."

Like Alice, Sara seemed to have templates in mind for certain favorite themes central to her art. Rainbows were usually in color order, and arc-shaped. Pots of gold all had a certain shape, and seemed to express a wish for riches. Variations on these themes, and hearts as well, were utilized throughout the six weeks. 


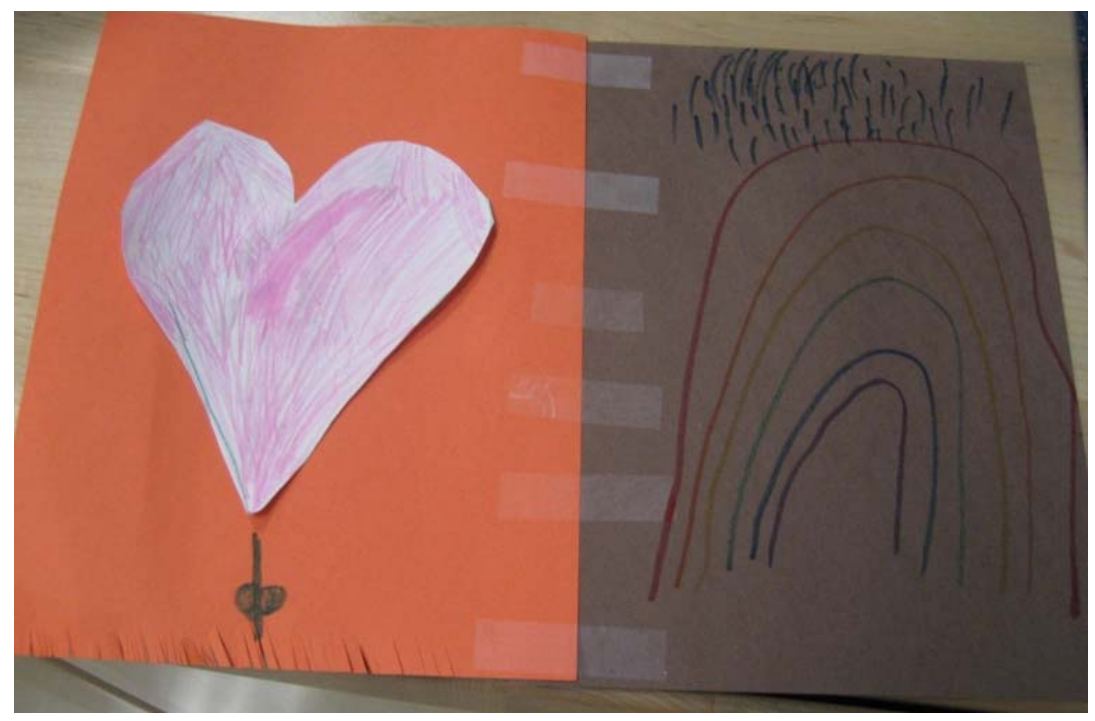

Figure 56. Sara's heart and rainbow

Rose. Rose was the most elusive participant. Due to her mother's pregnancy-induced illness, she was absent for much of the six week period of data collection. However, when she attended the care setting, she drew prolifically and with gusto. In just two sittings, she created almost as many drawings as Adam, and more than Seth who was in attendance more frequently.

Rose seemed to use art as instrumental communication more than the other participants. She delighted in the media, exploring color, line, and other basic elements of art. Her first drawing was "big of colors,” in her words. She was almost breathless in her excitement over the art she was creating, and sped through her drawing creation as if unable to slow down.

Eight of her eleven drawings had some kind of representational function. She sought to show things that she knew most often, such as the fence in her yard, or the shape of a diamond. Although to look at her art, an outside observer might see mostly kinetic scribbles, or abstract shapes, it is Rose’s interpretation of her art which shows the communicative intent.

One drawing that she made was interactional, though not in the strictest sense of building and maintaining relationships. Her drawing of fire invited participation, as she warned me about the heat 
and how it might injure one. This was art communicating an invitation to play, which I accepted. She then extended the interaction, as she pretended to put a band-aid on me for my “ouchie.”

Rose did not often voice her intent before drawing; sometimes her drawing would start as one thing and morph into another as it unfolded. For example, she started drawing a fence that turned into fire. It seemed that she would draw first, then see the meaning of it along the way, or when she was finished. However, Rose was extremely confident about the content of her artwork. She never hesitated to tell me what she had created, to name her art or at least a portion of it. In fact, she seemed frustrated at having to slow down or discuss the drawings with me, implying that I should know what she had made. Sometimes there was an air of exasperation in her answers to my questions.

Seth. Seth drew the least out of all the participants. His art was usually created with markers and his sketchbook. He was the second-oldest, and the only four-year-old participant. Seth tended to create art which communicated representational or imaginative ideas, without much overlap. He drew certain things from real life which seemed to be important to him, such as his favorite band, The Wiggles, or his pillow and blanket on his bed at home. Otherwise, he created things which were absolutely imaginative, such as monsters devouring giants.

Unique to Seth's art creation was the degree to which his art had a verbal component. Because he did not seek out other children to draw with, or look at anyone while he was talking about his drawing, I could only assume that his running commentary was a way of communicating with or perhaps entertaining himself as he drew. However he chose to speak in English, not Persian, so perhaps he was speaking to me or to the room at large.

Almost all of his drawings had a stated intent at the onset, or he would state the intent as he worked. Throughout most of Seth's drawings he talked, joked, laughed, and sang through the entire process. It was as if he was in a kind of trance state creating the art and thinking out loud about what 
he was doing and then saying what that made him think of. I tried to capture the nature of his drawing monologues with my notes during the data collection, but when I wrote them up, I found that conventional punctuation and grammar really didn't fit the situation.

Seth may have used the art creation process to explore and practice language. If this is so, it strengthens one of my initial hypotheses, that art helps children learn about the qualities of language. There is no way to be sure about this, but it is interesting and not unfounded to speculate; Seth did have one of the biggest verbal components to his art of any of the participants. It is possible that Seth's art as symbol construction “...bridges the gap between external and internal modes of thought and that the running monologues that accompany play [art] are gradually transformed into the soundless "inner" speech of thought. Vygotsky saw symbolic play as an adaptive mechanism for promoting cognitive growth and the interface of language and play as a vital part of that growth (Bergen \& Mauer, 2000, 47).”

\section{Analysis of the analysis}

Analyzing the data, I started to realize that the categorization of these artworks could seem arbitrary to an outside observer. Therefore, I tried to include my thoughts in each step of the process, from research design to collection to analysis of the data. I hoped that by showing the data in detail, the reader will be able to follow the reasoning behind the analysis. In this way, my findings could also be argued with, which is the only way to make sure this research is valid.

I could not really describe in the data everything that made these children who they were, not only for the sake of protecting their privacy, but because that kind of detail or knowledge is impossible. It was also impossible to describe the depth and character of relationships I have with these children, whom I taught for almost two years. Instead, I tried to show how each child was in the classroom, how each chose to interact with materials, with others in the environment, and let this 
speak about the child's personality. I hoped that the reader could get a sense of who each child was through the discussion of his or her art over the six week period.

I am encouraged by the results of the data analysis. It is unmistakably evident that a wide variety of communication took place through the art of these young children, most of whom were only three years old at the time of the study. This research process has made me as a teacher so much more aware of my students as humans with multifaceted lives, intelligence, and ideas; at times it took my breath away that I got to be the one entrusted with the communication of the kinds of creative and original ideas these participants thought of. Designing, conducting, and analyzing this research has been most humbling and exalting simultaneously. I can only hope that this research shows those who are unfamiliar with the world of early childhood education the amazing cognitive abilities of these young learners.

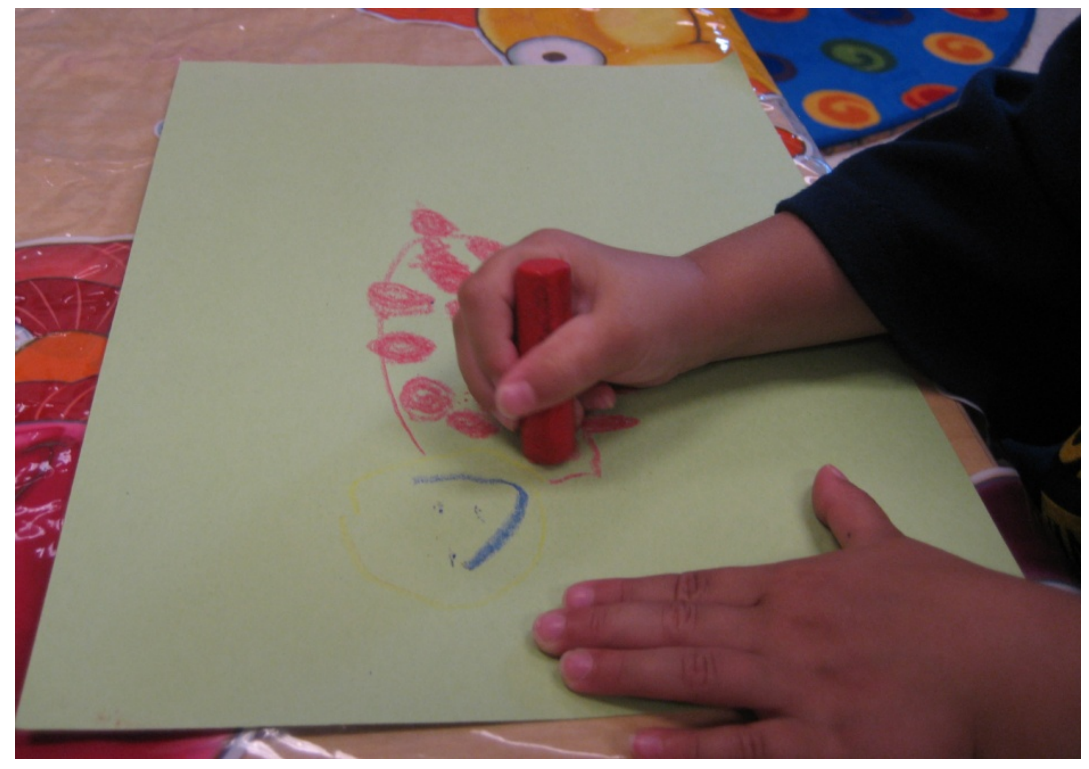

Figure 57. Alice draws a turtle

Chapter 6: Conclusions and Recommendations

It has been shown through this research project that young children can and do communicate through their visual art, specifically through their drawings. It has also been shown that Halliday's 
communicative functions of language were utilized by the children in the study. Not all the children communicated all seven ways, but all the seven types of communication were represented visually within the six week period of data collection.

Each young child in the study demonstrated complex communication through his/her art, wherein several communicative functions were utilized at once. This weaving together of types of communication was not altogether expected, but was an interesting outcome. Because of the abundance of communication through art, further study of this phenomenon seems indicated.

\section{What does this study mean in the instructional context?}

In the introduction of this paper, it was noted that increasingly standardized testing leads instruction. This is often to the detriment of the quality of the teaching and learning taking place in the classroom (Bracey, 2000). An exciting outcome of this study is the prospect of art as a genuine tool

for assessment. Drawing, in particular, has the potential to show educators what students know about a subject in a real way. Art forces application and synthesis of knowledge, both of which are higher order thinking skills, so the value of this type of assessment is that a deeper level of understanding is being tested, not merely factual recall (Bustle, 2004). Further, skills could be tested in context. In this manner, drawing as evaluation of children's learning could lead to more engaged learning, as well as higher quality teaching.

Because art creation led practice and play with language, use of art as language learning tool seems warranted. The approach to language learning that focuses on the lived experiences of the learner (Abramson, Ankenman, \& Robinson, 1995) was utilized by a participant himself. Seth drew to show the important things in his world: his bed, his favorite band, and the things that made him laugh. Sensitive teachers could pick up on this and use drawing as a springboard for learning opportunities, extending vocabulary through conversation. 
Each student is an individual who has a specific personality, life, and set of experiences influencing their learning on any given day. The more information teachers have about the specifics of a student's experiences and thinking improves our abilities to teach to that specific child. As a teacher, I get to know my students' temperaments and capabilities to establish in my mind what the personal norm is for each. Then, in the teachable moment, which is different for each child, I can best adapt my support for their learning. As an expert, I get to choose what direction to aim my teaching. Because I teach diverse students of varying abilities, cultures, and backgrounds, I tend to aim my teaching at development of cognitive skills that are useful in all disciplines, such as creativity, logic, reasoning, problem solving, and communication. In the context of this study, I aimed my teaching at encouraging communication through and about art.

Even though the art created in the course of this study was not contextualized by project work, as would have been the Reggio Emilian ideal, social-constructive learning still took place. Trends sprang up amongst the participants in the study, such as snakes, which occupied a prominent place in many of the children's drawings. Whether created in proximity to one another, or alone, the children who drew snakes seemed to have many artistic elements in common; the interest in snakes transcended the individual level to become a group phenomenon. As a teacher, one could capitalize on this and help provide the context for a group project for those who were interested in snakes and other reptiles.

Drawing to question and to build and test theories, the heuristic function of language in this study, is a very exciting realm for teaching and learning. Informally, the participants who utilized this function through their art designed their own learning experience. One could literally watch them constructing knowledge. In this context, teachers could discover how their students learn, and utilize that knowledge in future instruction. 
The children's drawings seemed to be a rich vein of possibility for future project work. Sara's bicycle, for example, that she wished to understand visually could have made a wonderful project. Imagine if a skilled teacher had guided her as she translated the idea of a bicycle into different media; perhaps something more three-dimensional would have made sense to her, such as clay or recycled materials: plastic milk rings, pipe cleaners, bits of soda bottles. Other children would have been drawn in, undoubtedly, and the social interactions would have extended and improved the learning. I recommend, based on the outcomes of this study, providing a multitude of opportunities for young children to freely draw, particularly with an interested adult. It is key that the adult truly be interested, attentive to each aspect of the child's art creation process. That kind of attention is encouraging to young children, and emphasizes the importance of his/her art as work.

I also recommend including sketchbooks as a part of the early childhood learning environment. There are so many elements of children's ideas communicated visually that could be utilized for instruction or reflected in the curriculum or learning environment. Sketchbooks give the young child a sense that their art is valued because it is collected in a centralized location. They also give teachers a place to begin when planning for projects or themes.

I found that looking through their sketchbooks from the beginning seemed to give the participants ideas for future drawings, as well as a sense of confidence which is necessary for risktaking. The sketchbooks turned out to be a form of auto-documentation, in which the children kept track of their ideas and could follow their own learning over time. Every child in the study showed a progression in skill over the course of time; they seemed better able to draw what they wanted to draw the more often they drew. This was not the purpose of the study, but it was an interesting side benefit.

Additionally, children should have access to a variety of art supplies and media. In this study, children were inspired to create art with tempera paint, watercolors, dot painters, markers, crayons, 
colored pencils, and chalk. These were utilized with construction paper, tissue paper, finger paint paper, scissors, glue, cotton swabs, paintbrushes, and water. All of these materials were displayed on

the children's eye level, and were freely available at all times. There was also a large art table close to the materials, which invited art creation. Variety and accessibility as well as choice were the elements which maximized creative opportunities for these participants. Inclusion of art materials in profusion, displayed prominently in the classroom communicates the importance of creativity and expression to children and families. Young children tend to pick up on nonverbal cues, and will gravitate towards that which their teachers value.

\section{The curricular context}

One of my purposes in undertaking this research was to validate art as an academic necessity, particularly with young children. In order to show the academic utility of art, I looked at communication, an important cognitive skill which spans all disciplines and subjects. I was able to show that not only does communication take place through art, but that art actually fosters communication. This is evident by the amount of verbal communication which was a part of each child's work, as well as by the sheer number of communicative art works created in a six week period.

If, as Dewey wrote, learning takes place through communication (1916), children’s communication through their art deserves an answer. In early childhood education, the answer is designed to draw out the meaning and the learning of the child's ideas; we want to get the child to use language. We are trying to build up the young child's cognitive faculties, so we support the creation of more language, more ideas, and more art.

I realized over the course of this study that the translation of ideas across media, which Forman (1998) believed increases knowledge construction, really begins with the translation of idea to art, then the ideas in the art are re-translated to language. So, for example, Adam had to take his idea about a 
bubble machine, for example, and translate it from a thought into intentional marks on paper. His intention was then translated into his confidently spoken words, "It’s a machine. It makes bubbles.” He, and many of the other participants, grew much more verbal with me over the course of the study, perhaps showing that repeated practice in translation of this kind can result in greater understanding of the languages and media involved.

Among the implications of this research for early childhood education are the importance of creative expression and child-centered learning. I followed the children's lead through their art, and was able to gain a greater understanding of their interests, as well as what they knew, felt and thought about. I observed them scaffolding their own knowledge construction, as well as stretching each other's knowledge. For example, Sara helped Alice make a snake and cut out the shape. Through this interaction these children not only gained knowledge about how to represent what they know about snakes, but also practiced fine-motor skills, problem-solving, creativity, hand-eye coordination, and also cooperative and collaborative skills.

Art seems to strengthen relationships in the learning environment. I observed that the interactions based on art during the course of this study seemed to grow over time in depth and complexity. The participants seemed to open up, blooming under the extra attention to their art and ideas. Most of the younger children seemed to grow more comfortable speaking to me during the artbased interviews over the course of the study. Even after the drawing events had taken place, I noticed the participants seemed to feel closer to me, as they sought my company more often both in and outside the classroom.

Drawing together seemed to help children relate to each other. Sara and Alice developed a friendship based on their shared interest in drawing, initially. I observed them interacting in dramatic play areas after drawing together, or reading to each other after drawing. The art creation process 
acted as a base upon which the day's play was based for these girls. Barroquierro reported similar findings in her research (2004).

It has already been stated elsewhere in this paper the degree to which genuine relationships are important for quality early childhood education. The NAEYC advocates the formation and maintenance of positive relationships as an essential element in developmentally appropriate child care programs (NAEYC, 1997). Relationships which are genuine and positive create a supportive atmosphere in which young children feel safe and supported.

In many successful research-based early childhood curricula, such as High/Scope (Arts Education Partnership, 1998), the Creative Curriculum (Teaching Strategies, Inc., 2002-2008), and the Reggio Emilia approach (Edwards, Gandini, \& Forman, 1998), as well as in NAEYC standards for early learning (NAEYC, 1997), art-related skills are valued. “Art enhances the development of a wide range of perceptual, physical, language, cognitive, and social-emotional skills. The arts are also valuable in and of themselves, developing aesthetic judgment and bringing personal satisfaction. (Arts Education Partnership, 1998)”

Inherent in the value of art is the value of the individual, of creativity, of diversity, of communication and expression. Because young children all come to school with varied backgrounds, cultures, ability levels, and intelligences, art-based learning would seem to be an educational necessity. Yet, as discussed in the first two chapters of this paper, the public school system in the U.S. seems preoccupied with other academic subjects, particularly math and reading. It is my fervent hope that this study will contribute to the field the knowledge that child-initiated art can help children construct knowledge in a learner-centered and developmentally appropriate way. Maybe this research will remind educators and policy makers that true learning is not just about memorizing and reciting facts. 
In the appendix, I have included samples of early learning in science, literacy, and numeracy from the participants' sketchbooks. From these, one can see that a three year old can explore concepts like one-to-one correspondence from her own art creation, as Alice did, by writing the number and drawing that amount. She drew three snakes next to the number 3, counting as she did so. Adam showed that he was practicing early literacy, even surprising himself with the letter $\mathrm{N}$ in one of his drawings. "Look, Clover. I made an N!”

Over time, the children's descriptions of their drawings became more confident, and they included more words and details. Adam began to use his art as a springboard for stories near the end of the study. Sara, Alice, and Seth all included letters and words in their drawings at least once, if not several times. These were meaningful literacy learning experiences, not rote skill-and-drill.

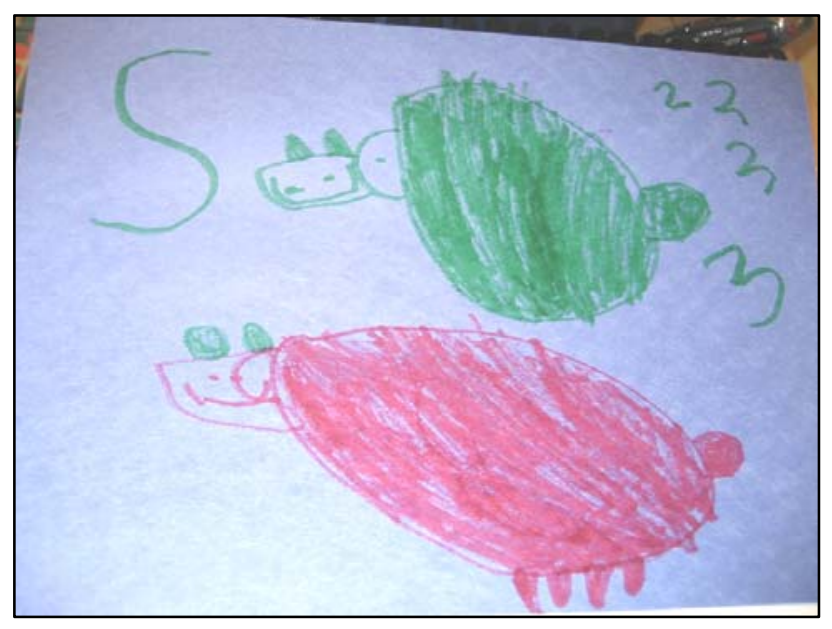

Figure 58. Alice’s cats

Beyond literacy and numeracy, art can be a path to educational success. At the beginning of this paper I asked, "What can be done to ensure that every child has a richness of opportunities to grow and learn?” If we understand that there is a link between experience and ability (Noble, Tottenham, \& Casey, 2005), and that giving children free rein to express their ideas through drawing leads to enhanced cognitive development (Arts Education Partnership, 1998), it is logical to conclude 
that learning through art could help high risk, special needs, English Language Learners, and other special populations of students. After all, when young children have rich experiences, such as those afforded by visual art creation, there are new brain connections being formed (Elliott, 2005). Further, the experience of a teacher or other caring adult attending closely to the child's art creation, asking thoughtful questions, and responding to the child's visual communication may strengthen the child's confidence in his or her abilities as a learner and communicator.

\section{Implications for Teacher Education}

This study and its findings should be added to teacher education programs. Teacher educators can introduce the idea of child communication through art to discussions about early language learning, and to early cognitive and creative development. It would be beneficial to a pre-service teacher to consider how to interpret children's drawings, and how to extend and respond to the child's ideas.

Teacher educators can discuss the ways to utilize and include art in the academic curriculum, such as expression of student interest and experience. It has long been recognized that reflecting student interests in the curriculum leads to engaged learning (Dewey, 1916). Art can help children build knowledge and theories; art should be included as an important part of the scientific process, the writing process, and other typical academic subjects. It is the responsibility and privilege of each teacher to "listen" to these ideas, and to respond to them through conversation, curriculum and instruction. For the youngest of children drawing may be the only way they can express an idea. Teacher education should include the importance of respect for the ideas of children, as well as ways to draw out those ideas and make them central in teaching, learning and curriculum decisions. 


\section{Implications for the future of education}

If the purpose of education in a multicultural democracy is to provide opportunities for success for all, than the more ways that learning can take place, the more chances for success for diverse learners. Honoring what we as educators know about multiple intelligences and learning styles necessitates embracing the arts as genuine paths to understanding. We need to include everything in the curriculum that engages students and gets them involved actively in the construction of knowledge.

In the $21^{\text {st }}$ century, as our knowledge becomes more visually transmitted through media such as television and internet, visual communication and literacy may become an ever more valuable set of skills (Flood, Heath, and Lapp, 2005). Do we want the citizens of the future to be passive recipients of visual communication, or active constructors of their own knowledge (Dickinson \& Schaffer, 1991)? It is certain that learners growing up today face a more visually represented array of information than any other generation. Human creativity is combining with technology to do astonishing things.

There are some theorists who believe that creativity will be the basis of the economy in the future. "The future belongs to a very different kind of person with a very different kind of mindcreators and empathizers, pattern recognizers and meaning makers. These people-artists, inventors, designers, storytellers, caregivers, consolers, big picture thinkers-will now reap society’s richest rewards...(Pink, 2005, 1).” Some believe that a paradigm shift is underway, moving us from the Information Age to what Pink calls the Conceptual Age (Pink, 2005).

In this new age, employers desire more creative, innovative, flexible workers; this push is causing more funding and research to go into education (Robinson, 2001). The Conceptual Age requires a shift in our understanding of the nature of creativity as intelligence. "There's much more to intelligence than academic ability and much more to education than developing it (Robinson, 2001, 7).” Teaching and learning through the arts can maximize our creativity and engage us holistically. 
What will the future of education be? Some believe a union of the methods and study of arts and sciences is possible (Robinson, 2001). Technology brings into our lives a rich array of sensory messages. Art or visual representation is only one aspect of the multiple ways media can be used to communicate. There are sounds, moving images, music, physical sensations, and other powerful forms of representation. "The existence of multimedia calls for multiple forms of literacy, forms that can represent the world of ideas, emotions, and events with multiple symbols (Semali \& Fueyo, 2001, par. 4).” The world of multimedia opens up limitless possibilities for teaching and learning; being open to the concept of multiple literacies is the beginning of utilizing these contexts.

The world of multiple media and multiple literacies provides a way to re-think and reconceptualize curriculum, including critical confrontation of cultural assumptions (Semali \& Fueyo, 2001). Translating ideas across media and contexts improves the body of knowledge being constructed. Honoring different learning styles also gives a chance to every student to shine, to bring his or her strength to the educational forefront. In a multicultural democracy, schools should utilize curricula which reflect multiple ways of knowing and learning.

In the educational climate of modern times, with heavy emphasis on educational testing, it is important to once again consider the needs of the learner. Constructing curricula on inquiry-based learning allows educators to capitalize on students’ prior knowledge, including language and culture, to meet the students where they are. This orientation enables students to perceive their individual identity and their lives as necessary components of learning and connotes a sense of trust in students’ interest and educational effort (Van Sluys \& Laman, 2006). The arts have an important role to play in curricula of this nature, and can be used to improve and evaluate student learning.

For example, let us look at early literacy efforts. Students who are English Language learners, or who have disabilities, or who are from low socioeconomic backgrounds are often among those 
whom schools are struggling to educate; these are often the students for whom traditional testing is skewed against (Noble, et al., 2005). Among other early interventions designed to promote academic success for these populations, multiple modalities are now being implemented to teach literacy skills; this approach incorporates visual, auditory, and tactile learning as well as multimedia technology (Johnston, Thurlow, Thompson, \& Clapper, 2008). Many of the literacy skills taught and tested for under state standards are the same skills practiced by the young participants of this study; some of these skills are: higher order thinking skills, vocabulary growth, learning about language conventions and context, critical analysis, questioning and responding to questions, mining and organizing information, socialization, and reflection about self (Johnston, Thurlow, Thompson, \& Clapper, 2008). In other words, teaching and assessment could include creative expression through the arts as accommodations for students with special needs.

Further, art offers proof of student cognition, beyond the measurement of standardized testing. Educators interested in utilizing the arts as assessment of student learning will find, as I have in this study, that their students think and know more than they can say with words. Collecting examples of student generated art over time in a portfolio enables a way of seeing and understanding the learner's knowledge construction. Assessment of portfolios of students' art will undoubtedly reveal cognitive development difficult to measure quantitatively. By integrating arts into the curriculum, students and teachers benefit. "Within this frame, the arts are not only learned, they help constitute the process of learning itself (Wakeford in Rabkin and Redmond, 2004, 102).”

\section{Implications for future research}

In designing and conducting this research, I relied on my instincts as a professional teacher to guide me. I knew how to observe and interact verbally with young children in the educational setting based on more than twelve years in the field. I planned to study a phenomenon which interested me as 
a teacher, as well as a scholar/researcher. I knew that this research would not resemble research that I had come in contact with before in my graduate studies, yet I was excited to undertake doing something new and different, and also authentic.

Whatever my intentions, I ended up with a mix between illuminative and critical interpretive data collection and analysis (Edwards, 2001). I tried hard to let the experiences and activities of the participants speak, but found my own voice speaking too. It was my hope that my own inferences brought the reader into my mind, allowed the reader to see through my eyes, and access the experiences of my life. It was nearly impossible for me to have conducted the research and left out my own ideas about what was taking place. This would have seriously affected the content, depth, and richness of the data being collected.

It was an intention of mine to write this study in a way that would not exclude anyone who was interested. I purposely tried to avoid jargon, lingo, and unnecessary wordiness that may have sounded smart, but might have obscured the meaning for readers who are not postgraduate students or professional researchers. I sought a tone that was knowledgeable and also accessible, warm and human.

For future reference I included in Appendix A a list of do's and don’ts about doing qualitative early childhood educational research of this sort. I hope that classroom teachers and professional educators of all types will be inspired by my example to conduct research in the setting in which they are already a part. I don't feel that the act of researching should be restricted to the upper echelons of post-graduate education. Educators asking questions and undertaking to find the answers should be a celebrated part of teaching for every level of the profession.

For future research on young children's art as communication, it would be interesting to see if there are correlations with children’s culture, gender, age or developmental level. Might some 
populations especially benefit from the use of art as visual communication? If so, what factors might increase chances for successfully utilizing these findings?

We live in an era in which visual communication is being discovered anew as a rich realm for teaching and learning. I believe the arts are boundless with possibility for education; perhaps this research will inspire educators to enthusiastically and fearlessly embrace their students' creative potential. 


\section{References}

Abramson, S., Robinson, R., \& Ankenman, K. (1995). Project Work with Diverse Students: Adapting Curriculum Based on the Reggio Emilia Approach. Childhood Education, 71(4), 197+. Retrieved April 5, 2007, from Questia database:

http://www.questia.com/PM.qst?a=0\&d=5002225875

Arts Education Partnership. (1998). Young Children and the Arts: Making Creative Connections - A Report of the Task Force on Children's Learning and the Arts: Birth to Age Eight. Washington, DC. Retrieved September 13, 2008 from: http://www.highscope.org

Barroquierro, D. (2004) An examination of the function of language in young children's artistic experience. Dissertation. Urbana, Illinois: University of Illinois at Urbana-Champaign.

Beliavsky, N. (2006). Revisiting Vygotsky and Gardner: Realizing Human Potential.The Journal of Aesthetic Education (40) 2, 1-11. Retrieved May 1, 2007 from Project Muse database:

http://muse.jhu.edu.www.libproxy.wvu.edu/journals/the_journal_of_aesthetic_educatio n/v040/40.2beliavsky.html

Benson, E. (2003). Intelligent intelligence testing. APA Monitor on Psychology, 34 (2), 56. Retrieved April 30, 2007 from APA Online: http://www.apa.org/monitor/feb03/intelligence.html

Bergen, D., \& Mauer, D. (2000). Chapter 3 Symbolic Play, Phonological Awareness, and Literacy Skills at Three Age Levels. In Play and Literacy in Early Childhood: Research from Multiple Perspectives, Roskos, K. A. \& Christie, J. F. (Eds.) (pp. 45-62). 
Mahwah, NJ: Lawrence Erlbaum Associates. Retrieved November 2, 2008, from Questia database: http://www.questia.com/PM.qst?a=o\&d=27735032

Bond, L., ed. (1995). “Critical Issue: Rethinking Assessment and Its Role in Supporting Educational Reform.” NCREL. Retrieved February 13, 2007: http://www.ncrel.org/sdrs/areas/issues/methods/assment/as700.htm Bracey, G. (December 5, 2000). High Stakes Testing. Center for Education Research, Analysis, and Innovation, School of Education: University of Wisconsin-Milwaukee. Retrieved April 26, 2007 from NEA website: http://epsl.asu.edu/epru/documents/cerai00-32.htm

Brearly, L. (2004) New Forms of Creative Representation and Exploration within Doctoral Research: Implications for Students and Supervisors. Presented at the AARE (Association of Active Researchers in Education) Conference in Melbourne, Australia. Retrieved August 13, 2007, from: http://www.aare.edu.au/aer/aer.htm

Bruner, J. (1990). Acts of Meaning. Cambridge, Massachusetts: Harvard University Press.

Bustle, L.S. (2004, February). The role of visual representation in the assessment of learning. Journal of Adolescent \& Adult Literacy, 47(5). Retrieved September 14, 2008 : http://www.readingonline.org/newliteracies/lit_index.asp?HREF=/newliteracies/jaal/204_column/index.html

Cadwell, L. B. (2003). Bringing Learning to Life: The Reggio Approach to Early Childhood Education. New York: Teacher’s College Press.

Chomsky, N. (1986). Knowledge of Language: Its Nature, Origin, and Use. Westport, CT: Praeger. Retrieved April 6, 2007, from Questia database: http://www.questia.com/PM.qst?a=0\&d=24399921 
Clark, A. (Fall, 2006) Changing Classroom Practice to Include the Project Approach. Early Childhood Research and Practice, (8)2. Retrieved March 28, 2007: http://ecrp.uiuc.edu/v8n2/clark.html

Clemens, S. G. (1999). “Editing: Permission to start wrong.” Early Childhood Research and Practice (1) 1. Retrieved February 12, 2008: http://ecrp.uiuc.edu/v1n1/clemens.html

Corsaro, W.A. \& Nelson, E. (July, 2003) Children's Collective Activities and Peer Culture in Early Literacy in American and Italian Preschools. Sociology of Education, (76) 3, 209227.

Darby, J. T. \& Catterall, J.S. (1994). The Fourth R: The Arts and Learning Teachers College Record (96) 2, 299-328.

Davis, J. H. (2005). Framing Education as Art: The Octopus Has a Good Day. New York: Teacher's College Press.

Dewey, J. (1916). Democracy and Education. New York: The Free Press.

Dewey, J. (1920). The School and Society. Chicago: University of Chicago Press.

Dickinson, S. \& Schaffer, M. (1991). Art, Images, Communications and Children Leonardo, (24) 2, Connectivity: Art and Interactive Telecommunications. 189-192. Retrieved May 6, 2007 from JSTOR database: http://links.jstor.org/sici?sici=0024094X\%281991\%2924\%3A2\%3C189\%3AAICAC\% 3E2.0.CO\%3B2-R

Doll, W.E. (1993). A Post-Modern Perspective on Curriculum. New York: Teacher’s College Press.

Education Commission of the States. (1996). Bridging the Gap between Neuroscience and Education. Summary of a workshop cosponsored by Education Commission of the 
States and The Charles A. Dana Foundation. Denver, Colorado: July 26-28, 1996.Retrieved February 13, 2007: http://www.ecs.org/clearinghouse/11/98/1198.htm

Edwards, A. (2001). 8 Qualitative Designs and Analysis. In Doing Early Childhood Research: International Perspectives on Theory and Practice (pp. 117-135). Crow’s Nest, N.S.W.: Allen \& Unwin. Retrieved September 6, 2008, from Questia database: http://www.questia.com/PM.qst?a=0\&d=102045438

Edwards, A. (2001). Qualitative designs and analysis. Doing Early Childhood Research In Classrooms. EDO-PS-95-10. ERIC Digest; Urbana, IL: ERIC Clearinghouse on Elementary and Early Childhood Education. Retrieved September 27, 2004: http://ceep.crc.uiuc.edu/eecearchive/digests/1995/edward95.html.

Edwards, C. P. (2002). Three Approaches from Europe: Waldorf, Montessori, and Reggio Emilia. Early Childhood Research and Practice (4) 1. Retrieved August 17, 2007: http://ecrp.uiuc.edu/v4n1/edwards.html

Edwards, Carolyn Pope and Springate, Kay Wright (1995). “Encouraging Creativity in Early Childhood Classrooms.” EDO-PS-95-10. ERIC Digest; Urbana, IL: ERIC Clearinghouse on Elementary and Early Childhood Education. Retrieved September 27, 2004: http://ceep.crc.uiuc.edu/eecearchive/digests/1995/edward95.html.

Edwards, C., Gandini, L., \& Forman, G., eds. (1998). The Hundred Languages of Children: The Reggio Emilia Approach—Advanced Reflections. Westport, Connecticut: Ablex Publishing.

Efland, A.D. (2002). Art and Cognition: Integrating the Visual Arts in the Curriculum. New York: Teacher’s College Press.

Eisner, E.W. (2002). The Arts and the Creation of the Mind. New Haven, Conn.: Yale 
University Press.

Elliott, A. (2005). New evidence linking the arts and learning in early childhood. Every Child (11) 2. Accessed February 17, 2007: www.findarticles.com

Ellis, Donald G. (1999) From Language to Communication, Second Edition. Mahwah, New Jersey: Lawrence Erlbaum Associates.

Ferrero, E. \& Teberosky, A. (1982). Literacy before Schooling. Portsmouth, New Hampshire: Heinemann Educational Books Inc.

Flood, J., Heath, S.B., \& Lapp, D. (2005) Handbook of Research on Teaching Literacy through the Communicative and Visual Arts. Mahwah, NJ: Lawrence Erlbaum Associates. Retrieved April 5, 2007, from Questia database at:http://www.questia.com/PM.qst?a=o\&d=106235760

Forman, G. (1994). Different media, different languages. In Reflections on the Reggio Emilia approach, eds. L. Katz. \& B. Cesarone, 37-46. Urbana, IL: ERIC Clearinghouse on EECE.

Forman, G (1998). The Hundred Languages of Children: The Reggio Emilia ApproachAdvanced Reflections. Westport, Connecticut: Ablex Publishing.

Franklin, Margery. (1994) Art, Play, and Symbolization in Childhood and Beyond: Reconsidering connections. Teachers College Record (95) 4, 526-541.

Freire, P. (1970). Pedagogy of the Oppressed. New York: Continuum.

Gardner, H. \& Perkins, D., eds. (1989). Art, Mind, and Education. Urbana, Ill.: University of Illinois Press.

Gardner, H. (1980). Artful Scribbles: The Significance of Children’s Drawings. New York: Basic Books. 
Gardner, H. (1983). Frames of mind: The theory of multiple intelligences. New York: Basic.

Gardner, H. (1990). Art Education and Human Development. Los Angeles, CA: Getty.

Gardner, H. (2004) Frames of Mind: The Theory of Multiple Intelligences. New York: Basic Books.

Gellens, S., \& Early Childhood Association of Florida. (2000). Activities That Build the Young Child's Brain. Retrieved April 30, 2007 from the ERIC database.

Glassman, M. \& Whaley, K. (2000) The use of long-term projects in early childhood classrooms in light of Dewey's educational philosophy. Early Childhood Research and Practice (2)1. Retrieved October 5, 2007: http://ecrp.uiuc.edu/v2n1/glassman.html

Goffin, S. G. (August, 2000) The Role of Curriculum Models in Early Childhood Education. ERIC Digest \# EDO-PS-00-8. Retrieved August 17, 2007 from ERIC Clearinghouse on Elementary and Early Childhood Education: http://ceep.crc.uiuc.edu/eecearchive/digests/2000/goffin00.pdf

Gormley, W. T. Jr., Gayer, T., Phillips, D., \& Dawson, B. (2005).“The Effects of Universal Pre-K on Cognitive Development.” Developmental Psychology (41) 6, 872-884. Retrieved February 13, 2007: http://www.apa.org/journals/releases/dev416872.pdf, Greene, M. (1995). Releasing the Imagination: Essays on Education, the Arts, and Social Change. San Francisco, CA: Jossey-Bass.

Halliday, M.A.K. (1973). Explorations in the Functions of Language. New York: Elsevier. Halliday, M.A.K. (1974) A Sociosemiotic Perspective on Language Development. Bulletin of the School of Oriental and African Studies, (37)1, 98-118.Retrieved May 4, 2007 from JSTOR database: http://www.jstor.org/stable/614108

Hancock, L., \& Wingert, P. (1997). The new preschool. Newsweek, 129(9), 36. Retrieved April 
29, 2007 from the Academic Search Premier database:

http://web.ebscohost.com.www.libproxy.wvu.edu/ehost/detail?vid=49\&hid=14\&sid=89 c557a7-b6e7-4c87-a46b-d585a8823845\%40sessionmgr9

Haney, W., Russell, M., \& Bebell, D. (2004). Drawing on education: Using Drawings to document schooling and support change. Harvard Educational Review (74) 3, 241271.

Hatch, J. A., ed. (1995) Qualitative Research in Early Childhood Settings. Westport, Connecticut: Praeger.

Henson, K. T. (Fall, 2003). "Foundations for learner-centered education: A knowledge base". Education. Retrieved April 6, 2007: http://www.findarticles.com/p/articles/mi_qa3673/is_200310/ai_n9332038

Hertzog, Nancy B. (Spring, 2001) Reflections and Impressions from Reggio Emilia: “It's not about art!” Early Childhood Research and Practice (3) 1. Retrieved December 16, 2007: http://ecrp.uiuc.edu/v3n1/hertzog.html

Holt, J. (1967). How Children Learn. New York: Dell.

Johnson, C., Thurlow, M., Thompson, S., \& Clapper, A. (2008, March). The potential for multi-modal approaches to reading for students with disabilities as found in state reading standards. Journal of Disability Policy Studies, 18(4), 219-229. Retrieved September 26, 2008, from CINAHL with Full Text database.

Kantrowitz, B., \& Wingert, P. (1991). The best schools in the world. (Cover story). Newsweek, 118(23), 50. Retrieved April 29, 2007 from the Academic Search Premier database.

Karnowski, L. (1986, November). How Young Writers Communicate. Educational Leadership, 44(3), 58. Retrieved June 25, 2007, from Academic Search Premier 
database.

Katz, L. (2003). State of the Art of Early Childhood Education, 2003. . Retrieved Monday, April 30, 2007 from the ERIC database.

Katz, L. G. \& Cesarone, B., eds. (1994). Reflections on the Reggio Emilia Approach. Urbana, Illinois: ERIC Clearinghouse on Elementary and Early Childhood Education.

Katz, L. 1995. Talks with teachers of young children: A collection. Norwood, NJ: Ablex.

Katz, L. G., \& Chard, S. (2000). Engaging children's minds: The project approach (2nd ed.). Norwood, NJ: Ablex.

Kincheloe, J. L. (2002). Teachers as Researchers: Qualitative Inquiry as a Path to Empowerment. New York: RoutledgeFalmer. Retrieved November 2, 2008, from Questia database: http://www.questia.com/PM.qst?a=o\&d=108444759

Klein, E. L. (2001). 6 Children's Perspectives on their experiences in early education and childcare settings. In Psychological Perspectives on Early Childhood Education: Reframing Dilemmas in Research and Practice, Golbeck, S. L. (Ed.) (pp. 131-146). Mahwah, NJ: Lawrence Erlbaum Associates. Retrieved August 17, 2007, from Questia database: http://www.questia.com/PM.qst?a=o\&d=108202866

Lindsey, G. (1998). Brain Research and Implications for Early Childhood Education. Childhood Education, 75(2), 97+. Retrieved April 29, 2007, from Questia database: http://www.questia.com/PM.qst?a=o\&d=5002304870

Logue, M. (2007, January). Early Childhood Learning Standards: Tools for Promoting Social and Academic Success in Kindergarten. Children \& Schools, 29(1), 35-43. Retrieved June 19, 2007, from Academic Search Premier database.

Malchiodi, C. (1998). Understanding Children’s Drawings. New York: The Guilford Press. 
McArdle, F. (2005). “What if...Art as language in early childhood.”Every Child (11) 2. Retrieved on March 5, 2007 from: www.findarticles.com

Meyer, L. (2005). The Complete Curriculum: Ensuring a place for the arts in America's schools. Arts Education Policy Review, 106(3). Retrieved Friday, May 04, 2007 from the ERIC database

Milne, A., \& Plourde, L. (2006, September). Factors of a Low-SES Household: What Aids Academic Achievement?. Journal of Instructional Psychology, 32(3), 183-193. Retrieved June 19, 2007, from Academic Search Premier database.

Moss, P. (1999). "Early Childhood Institutions as a Democratic and Emancipatory Project.” Early Education Transformed. Abbott, L. and Moylett, H., eds. London: Falmer Press.

National Association for the Education of Young Children (1997). Developmentally Appropriate Practice in Early Childhood Programs Serving Children from Birth to Age 8: A Position Statement from the NAEYC. Washington, DC. Retrieved November 12, 2004: http://www.naeyc.org/about/positions/pdf/PSDAP98.PDF.

New, Rebecca S. (2000). "Reggio Emilia: Catalyst for Change and Conversation.” EDO-PS00-15. ERIC Digest. Urbana, IL: ERIC Clearinghouse on Elementary and Early Childhood Education. Retrieved from the WWW September 27, 2004: http://ceep.crc.uiuc.edu/eecearchive/digests/2000/new00.html.

Nicholas, J.G. (April, 2000). Age Differences in the Use of Informative/Heuristic Communicative Functions in Young Children With and Without Hearing Loss who are Learning Spoken Language. Journal of Speech, Language \& Hearing Research, (43)2, 380. 
Noble, K., Tottenham, N., \& Casey, B. J. (2005). Neuroscience Perspectives on Disparities in School Readiness and Cognitive Achievement. Future of Children (15)1, 71-89. Retrieved August 14, 2007 from Project Muse database: http://muse.jhu.edu.www.libproxy.wvu.edu/demo/future_of_children/

Olsson, C. (March, 2005). The Use of Communicative Functions among Pre-school Children with Multiple Disabilities in Two Different Setting Conditions: Group Versus Individual Patterns. Augmentative and Alternative Communication, 21 (1), pp. 3-18. Retrieved from EBCSOHost database May 3, 2007.

Patton, M.Q. (2002). Qualitative Research \& Evaluation Methods. Thousand Oaks, CA: Sage Publishing.

Perrone, V. (1991). ACEI POSITION PAPER: On Standardized Testing. Retrieved April 26, 2007 from ACEI site: http://acei.org/onstandard.htm\#children

Pinar, W.F., Reynolds, W.M., Slattery, P., \& Taubman, P.M. (2000). Understanding Curriculum. New York: Peter Lang.

Pink, D. (2005). A whole new mind. New York: Penguin.

Pitri, E. (2007). Art Books for Early Childhood Classroom Communication. Art Education, 60(2), 33-39. Retrieved Tuesday, May 08, 2007 from the Education Research Complete database.

Poole, D. (1994). Routine Testing Practices and the Linguistic Construction of Knowledge. Cognition and Instruction, (12) 2, 125-150. Retrieved June 23, 2007: http://www.leaonline.com.www.libproxy.wvu.edu/doi/abs/10.1207/s1532690xci1202_3 ?cookieSet=1\&journalCode $=$ ci

Rabkin, N. \& Redmond, R. (2004). Putting Arts in the Picture: Reframing Education in the 
$21^{\text {st }}$ Century. Chicago, Ill.: Columbia College Chicago.

Rapp, D., Sloan, K., \& Hostrup, J. (2006). Contesting NCLB and High-Stakes Accountability: Continuing Acts of Resistance. Journal of Curriculum \& Pedagogy, 3(1), 95-100. Retrieved Friday, May 04, 2007 from the Education Research Complete database

Rinaldi, C. (2006). In Dialogue with Reggio Emilia: Listening, researching, and learning. New York: Routledge.

Robinson, K. (2001). Out of our minds. Chichester, West Sussex: Capstone Publishing, Ltd. Rock, D.A. \&. Stenner, A.J. (2005) Assessment Issues in the Testing of Children at School Entry. Future of Children (15)1,15-34. Retrieved August 14, 2007 from Project Muse database: http://muse.jhu.edu.www.libproxy.wvu.edu/demo/future_of_children/

Scott-Little, C., Kagan, S.L., Frelow, V.S. (Fall 2003). Creating the conditions for success with early learning standards: Results from a national study of state-level standards for children's learning prior to kindergarten. Early Childhood Research and Practice, (5) 2. Accessed March 28, 2007: http://ecrp.uiuc.edu/v5n2/little.html

Semali, L., \& Fueyo, J. (2001, December/January). Transmediation as a metaphor for new literacies in multimedia classrooms. Reading Online, 5(5). Available: http://www.readingonline.org/newliteracies/lit_index.asp?HREF=semali2/index.html

Sidelnick, M., \& Svoboda, M. (2000, October). The bridge between drawing and writing: Hannah's story. Reading Teacher, 54(2), 174. Retrieved June 25, 2007, from Academic Search Premier database.

Slaby, R., Loucks, S., \& Stelwagon, P. (2005). Why Is Preschool Essential in Closing the Achievement Gap?. Educational Leadership \& Administration, 17, 47-57. Retrieved Monday, April 30, 2007 from the Education Research Complete database. 
Sternberg, R.J. \& Grigorenko, E. L. (2004) Successful Intelligence in the Classroom. Theory Into Practice (43) 4, 274-280. Retrieved May 1, 2007 from Project Muse database:http://muse.jhu.edu.www.libproxy.wvu.edu/journals/theory_into_practice/v04 3/43.4sternberg.html

Strickland, D. S. \& Riley-Ayers, S. (2006) Early Literacy: Policy and Practice in the Preschool Years. National Institute for Early Education Research Policy Brief. Retrieved May 4, 2007 from the NIEER website: http://nieer.org/docs/?DocID=143 Talay-Ongan, A. (2000). Neuroscience and Early Childhood: A Necessary Partnership. Australian Journal of Early Childhood, 25(2), 28. Retrieved March 28, 2007, from Questia database: http://www.questia.com/PM.qst?a=o\&d=5001781087

Teaching Strategies, Inc. (2002-2008). The Creative Curriculum System: Creative Curriculum for Preschool. Retrieved November 3, 2008: http://www.teachingstrategies.com/page/CCPS_Overview.cfm

Vakil, S., Freeman, R., \& Swim, T. (2003, January 1). The Reggio Emilia Approach and Inclusive Early Childhood Programs. Early Childhood Education Journal, 30(3), 187. (ERIC Document Reproduction Service No. EJ670164) Retrieved June 29, 2007, from ERIC database.

Van Sluys, K., \& Laman, T. (2006, November). Learning about language: Written conversations and elementary language learners. Reading Teacher, 60(3), 222-233. Retrieved September 26, 2008, doi:10.1598/RT.60.3.2

Wallace, C. (Nov., 1987) A Functional Approach to Early Reading in Multilingual Classrooms. Reading, (21) 3, 144-51. Retrieved August 7, 2007: http://search.ebscohost.com/login.aspx?direct=true\&db=eric\&AN=EJ365878\&site=eho 
st-live

Walsh, G. \& Gardner, J. (2005). Assessing the Quality of Early Years Learning Environments. Early Childhood Research and Practice (7) 1. Retrieved August 17, 2007: http://ecrp.uiuc.edu/v7n1/walsh.html

Wells, G. (1994). The complimentary contributions of Halliday and Vygotsky to a "languagebased theory of learning." Linguistics and Education, 6, 41-90. 
Appendix A

Table A1: Do's and Don'ts of Qualitative Early Childhood Educational Research

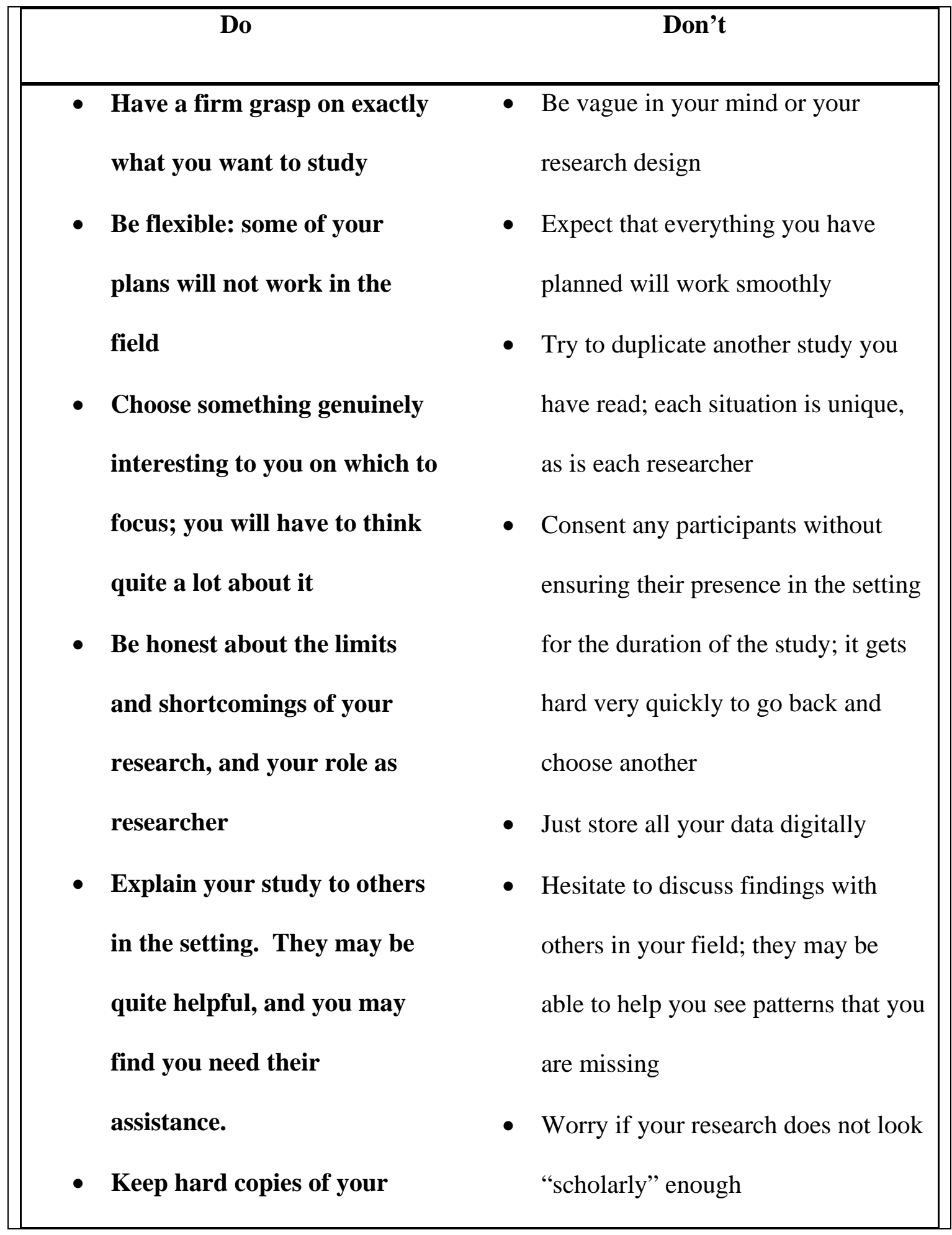




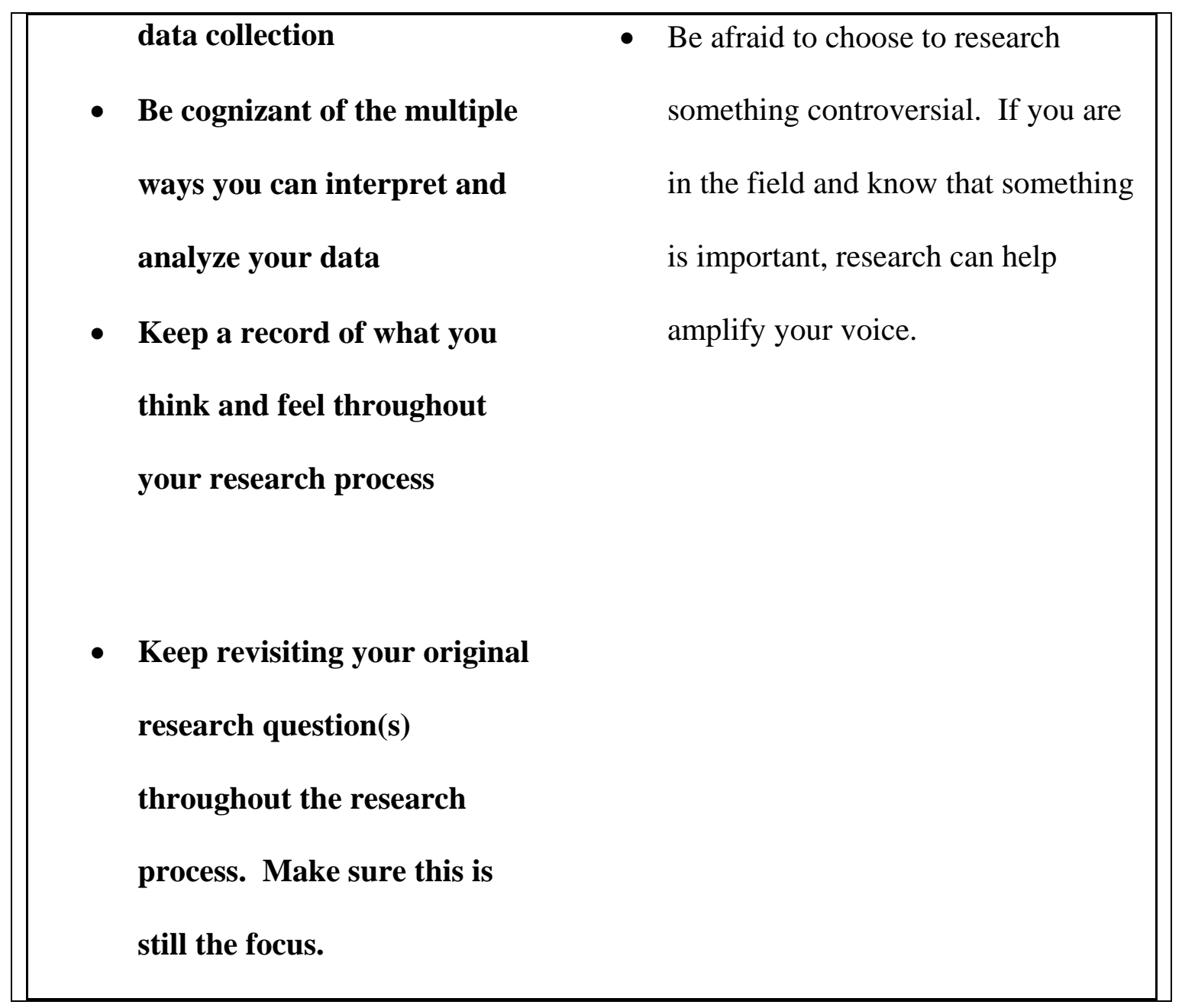


Appendix B

Examples of Adam's Communicative Functions of Art

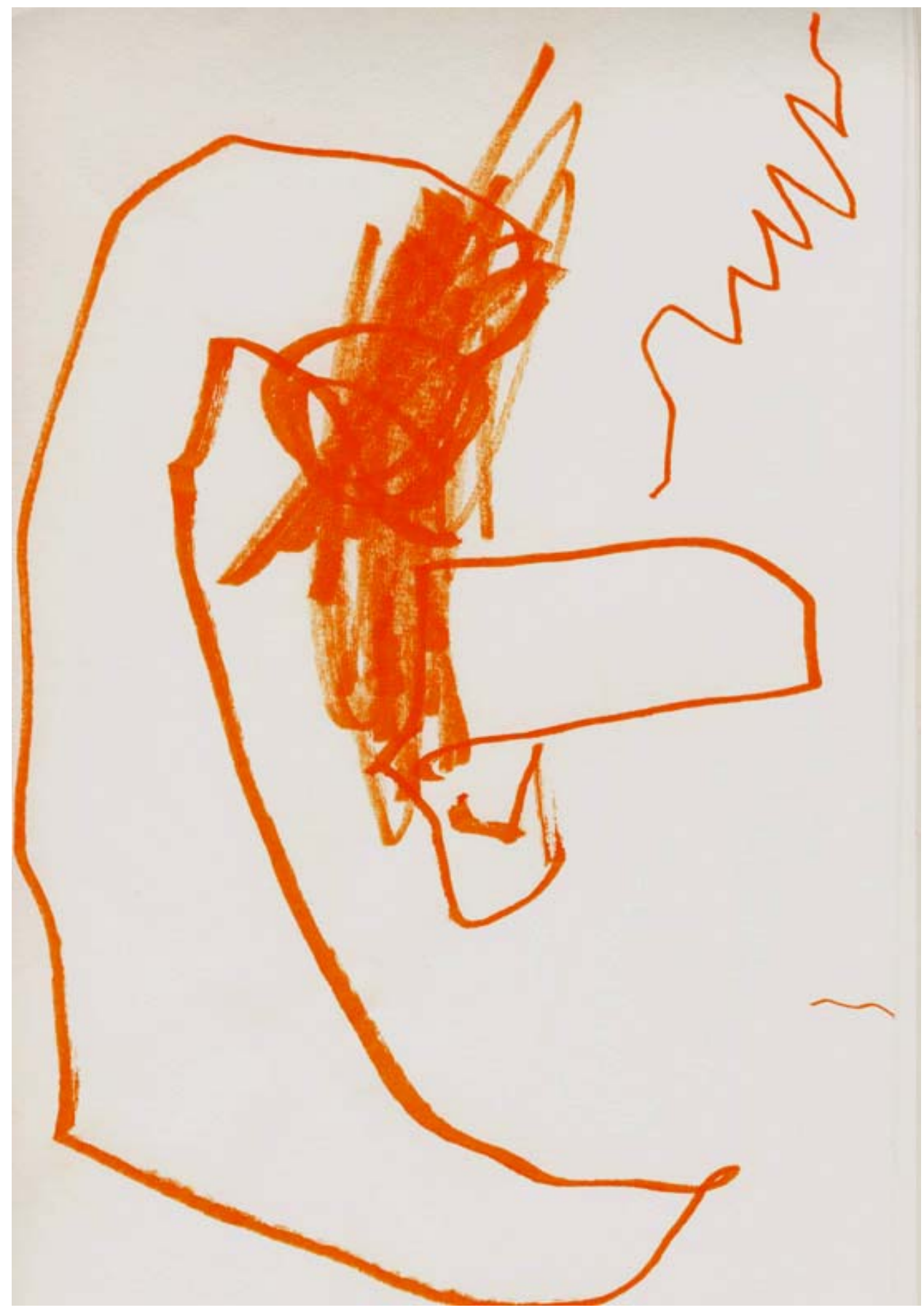

Figure B1. Adam's instrumental function. 


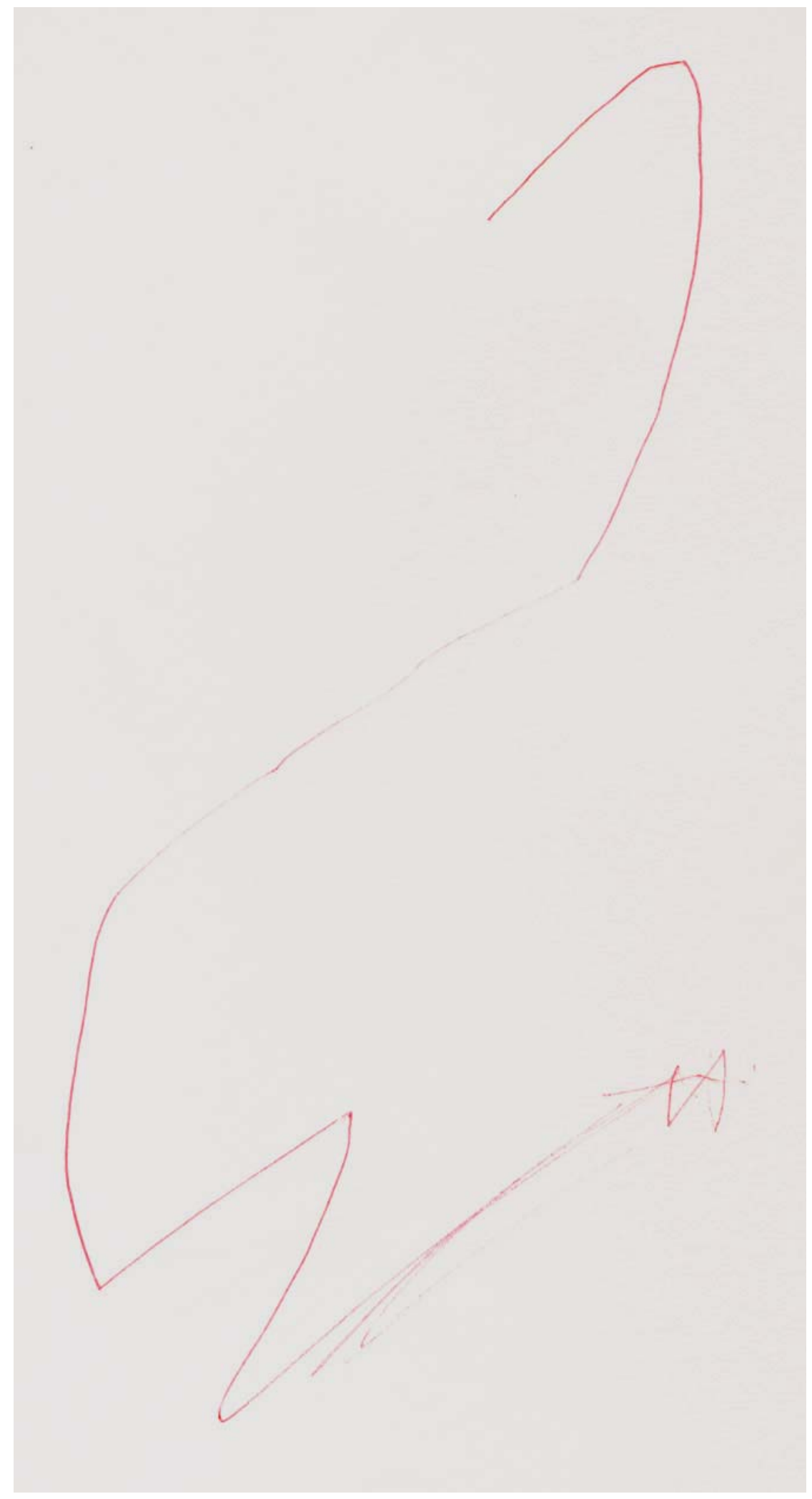

Figure B2. Adam's interactional function: A snake. 


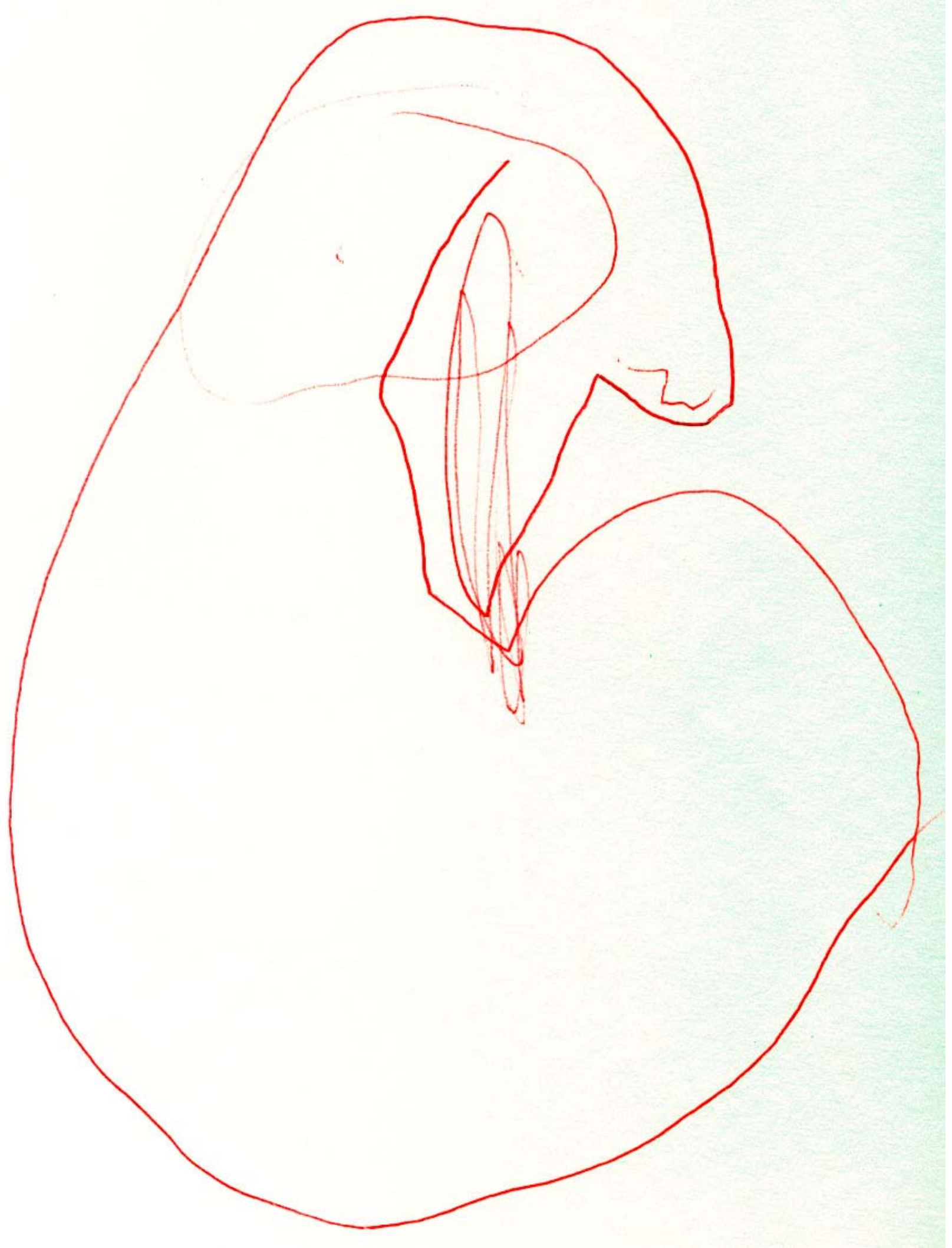

Figure B3. Adam's imaginative function: A nice monster. 


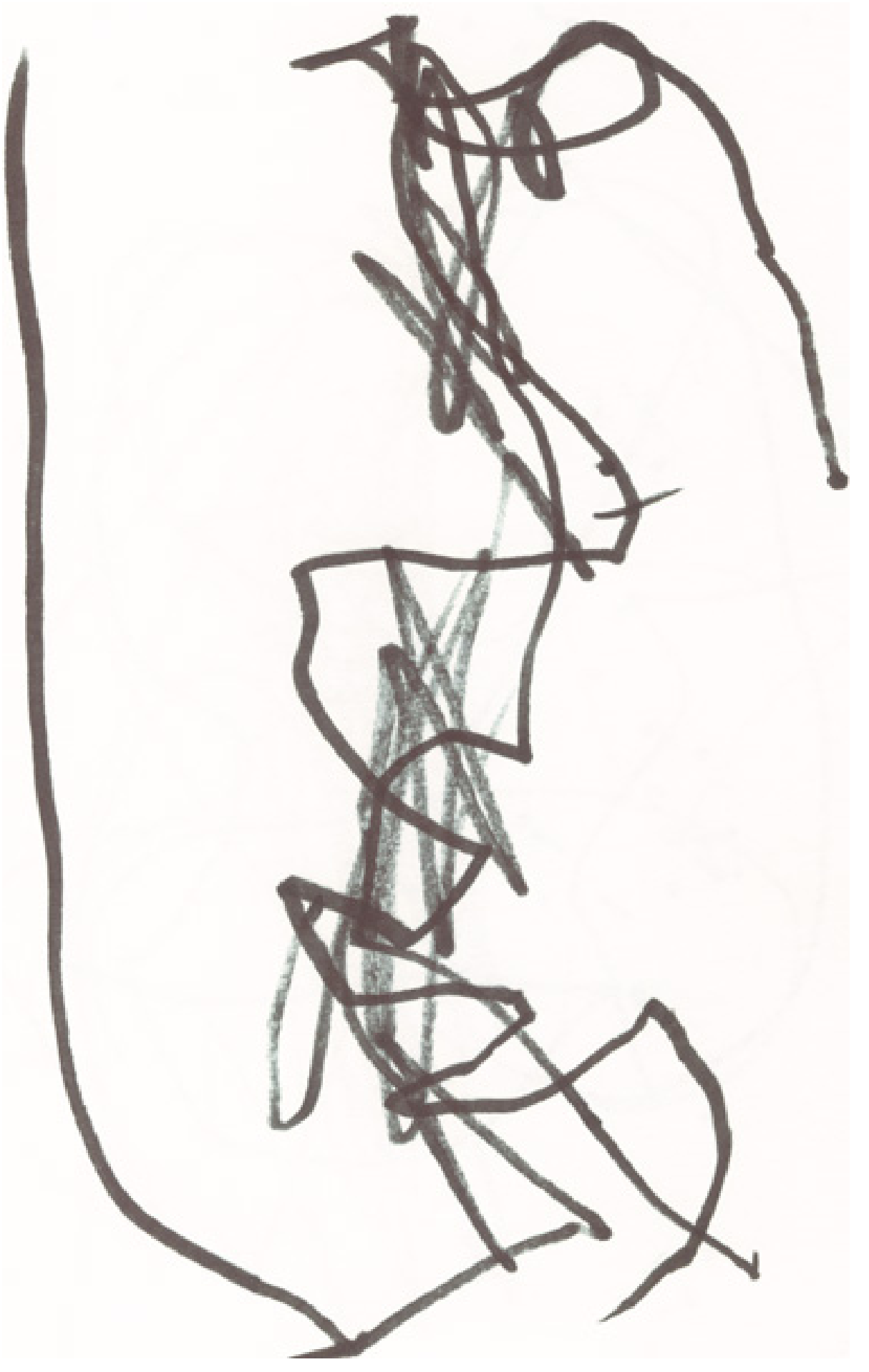

Figure B4. Adam's representational function: A light pool. 
Appendix C

Examples of Alice's Communicative Functions of Art

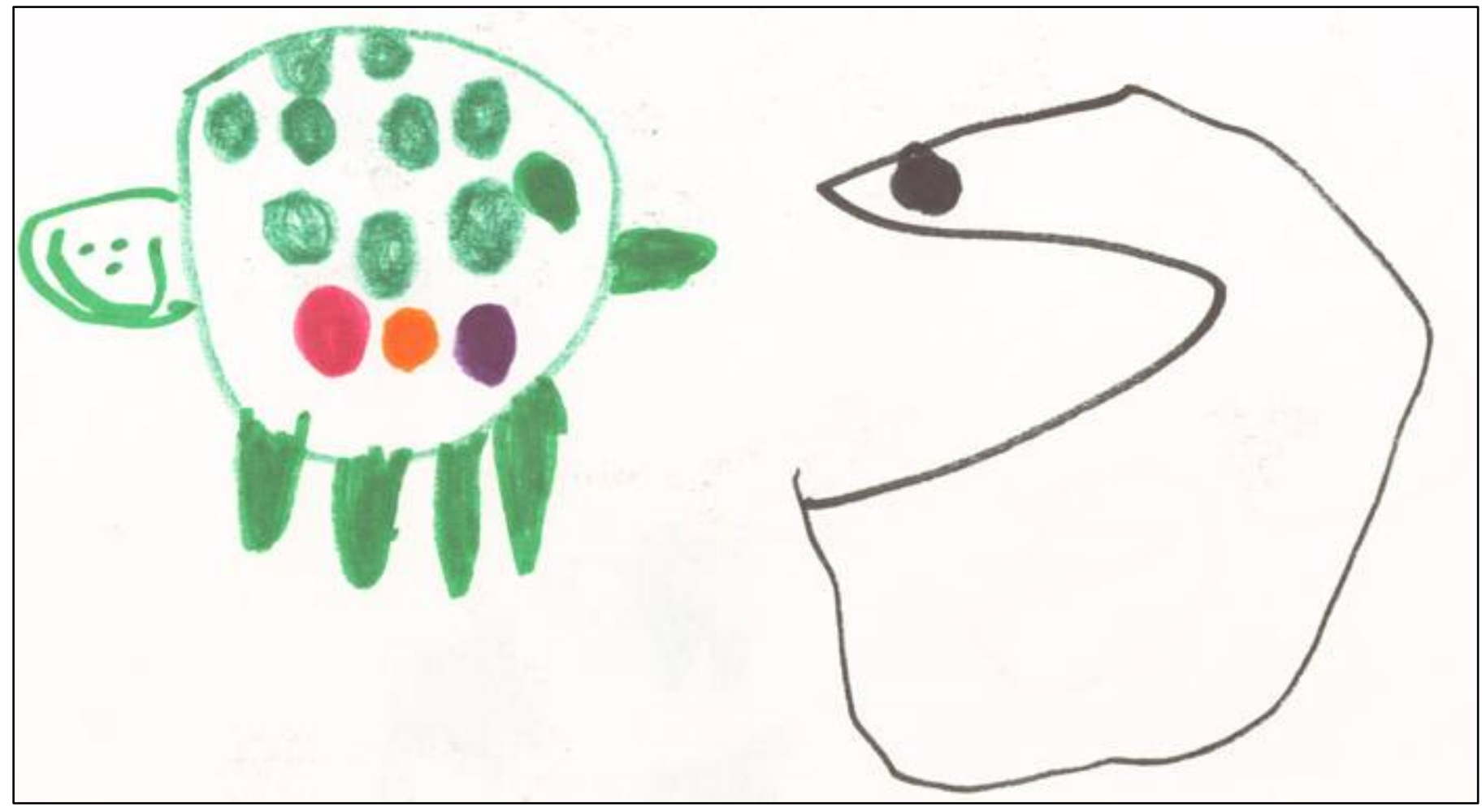

Figure C1. Alice's representational function 


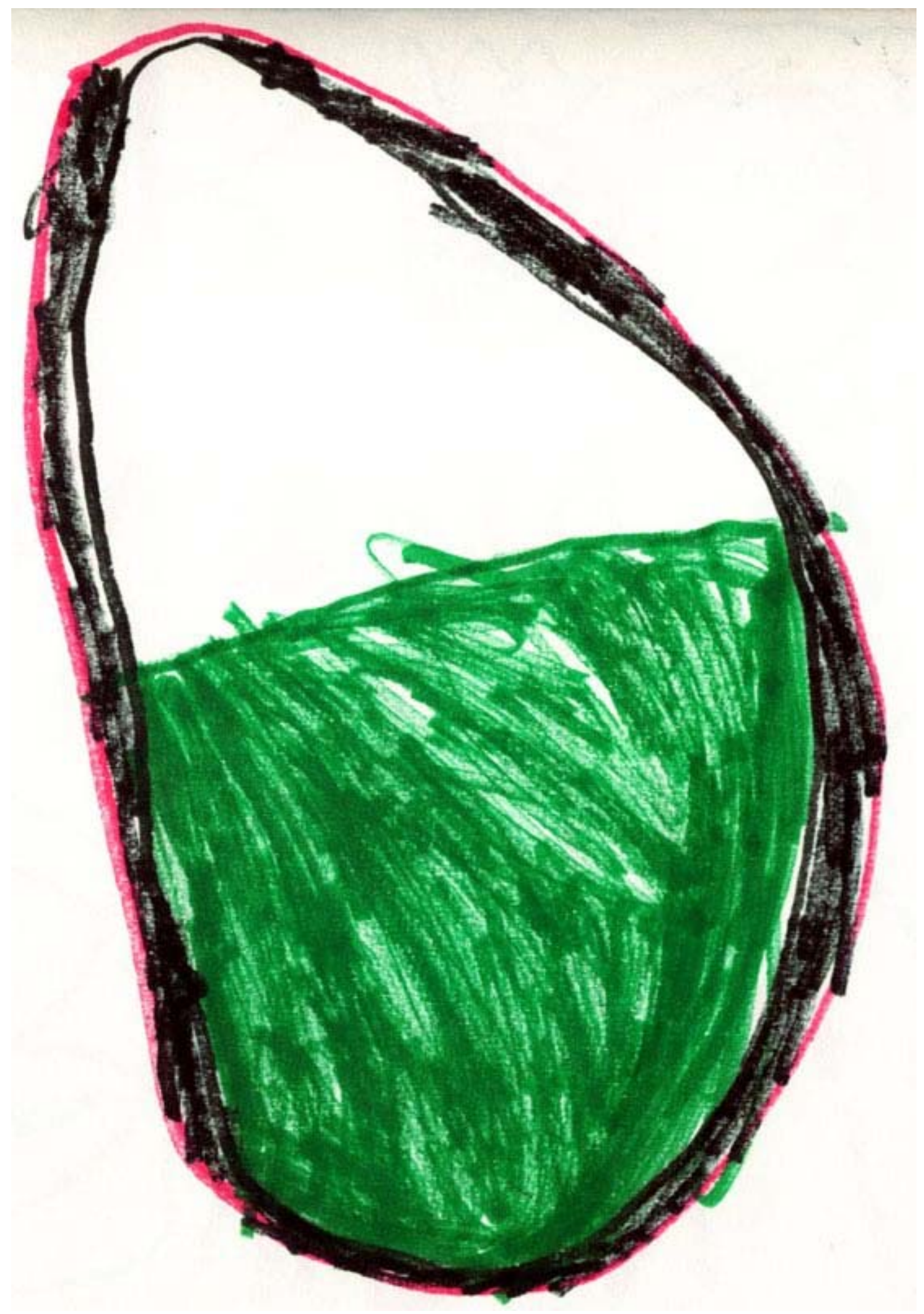

Figure C2. Alice's interactional function 


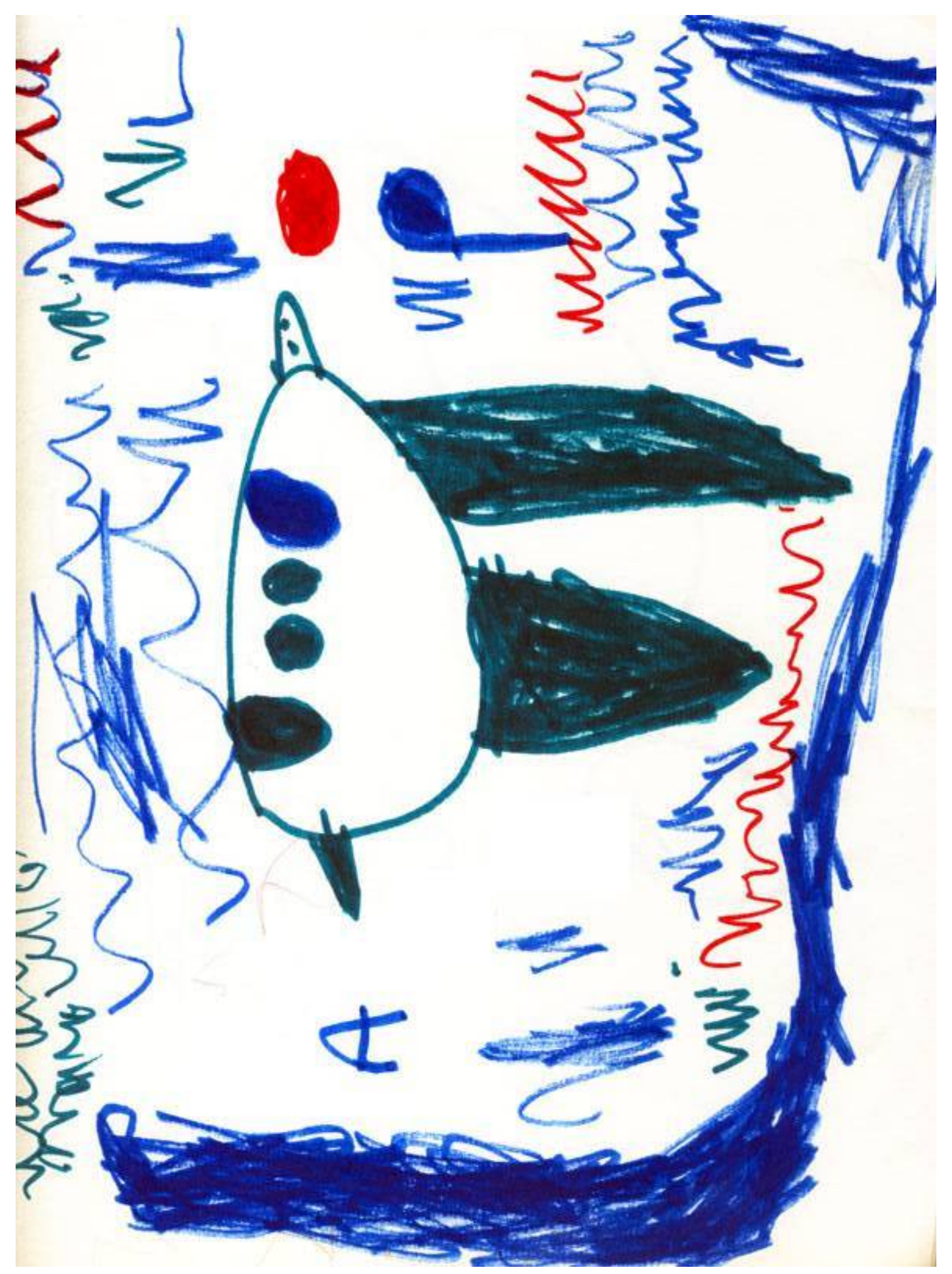

Figure C3. Alice's heuristic function 


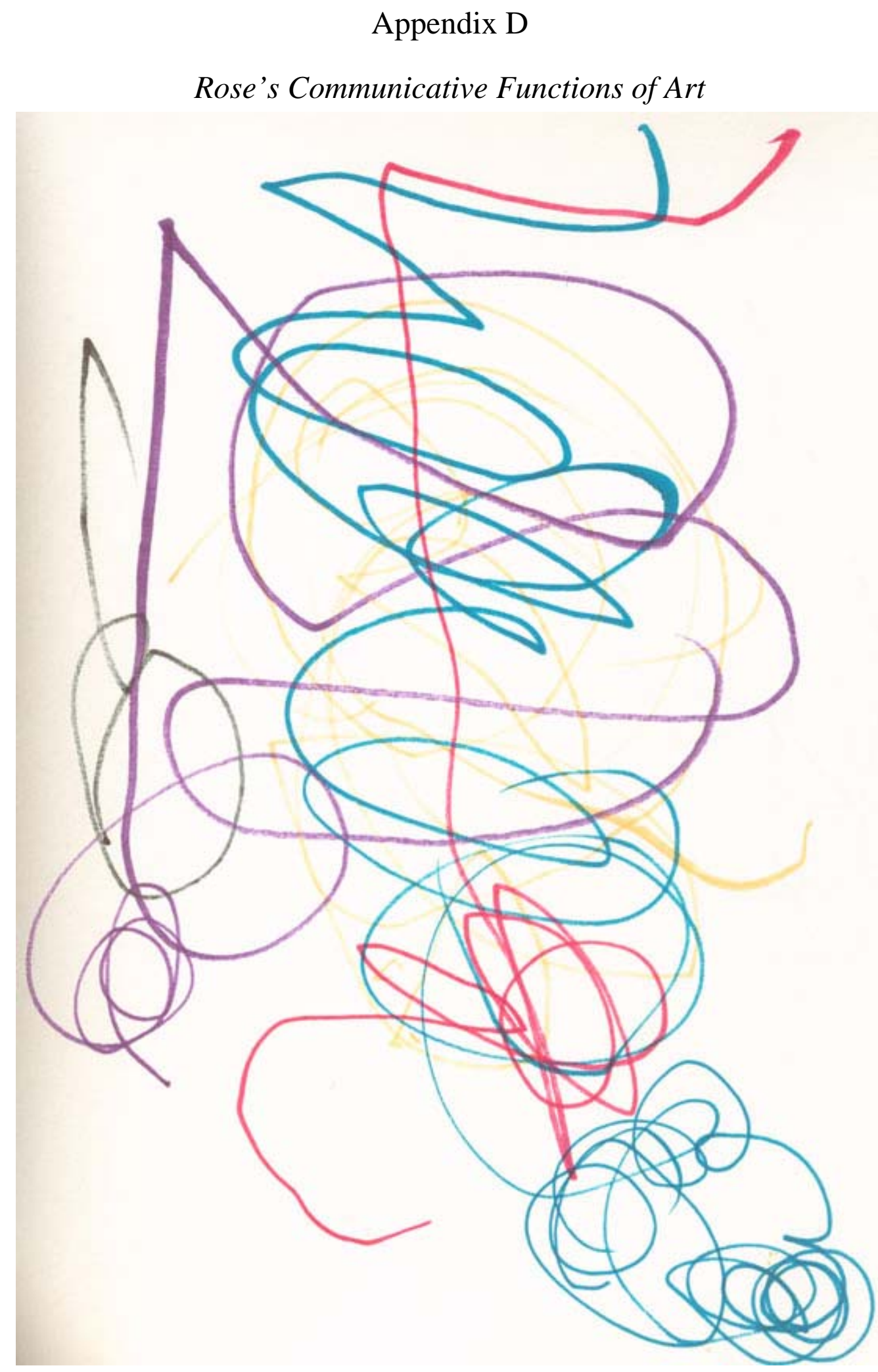

Figure D1. Rose's instrumental function: Big of colors. 


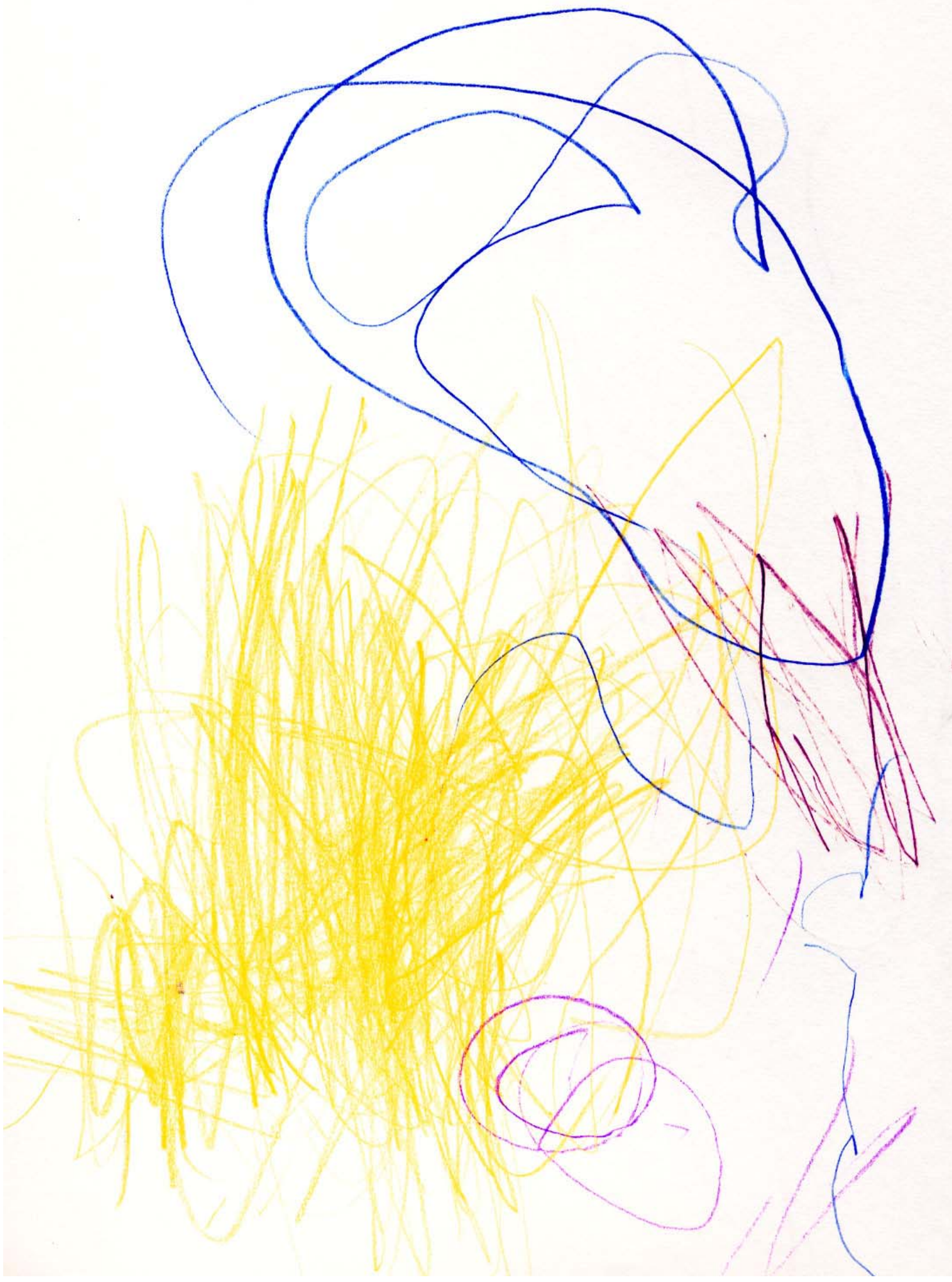

Figure D2. Rose's interactional function: Fire 


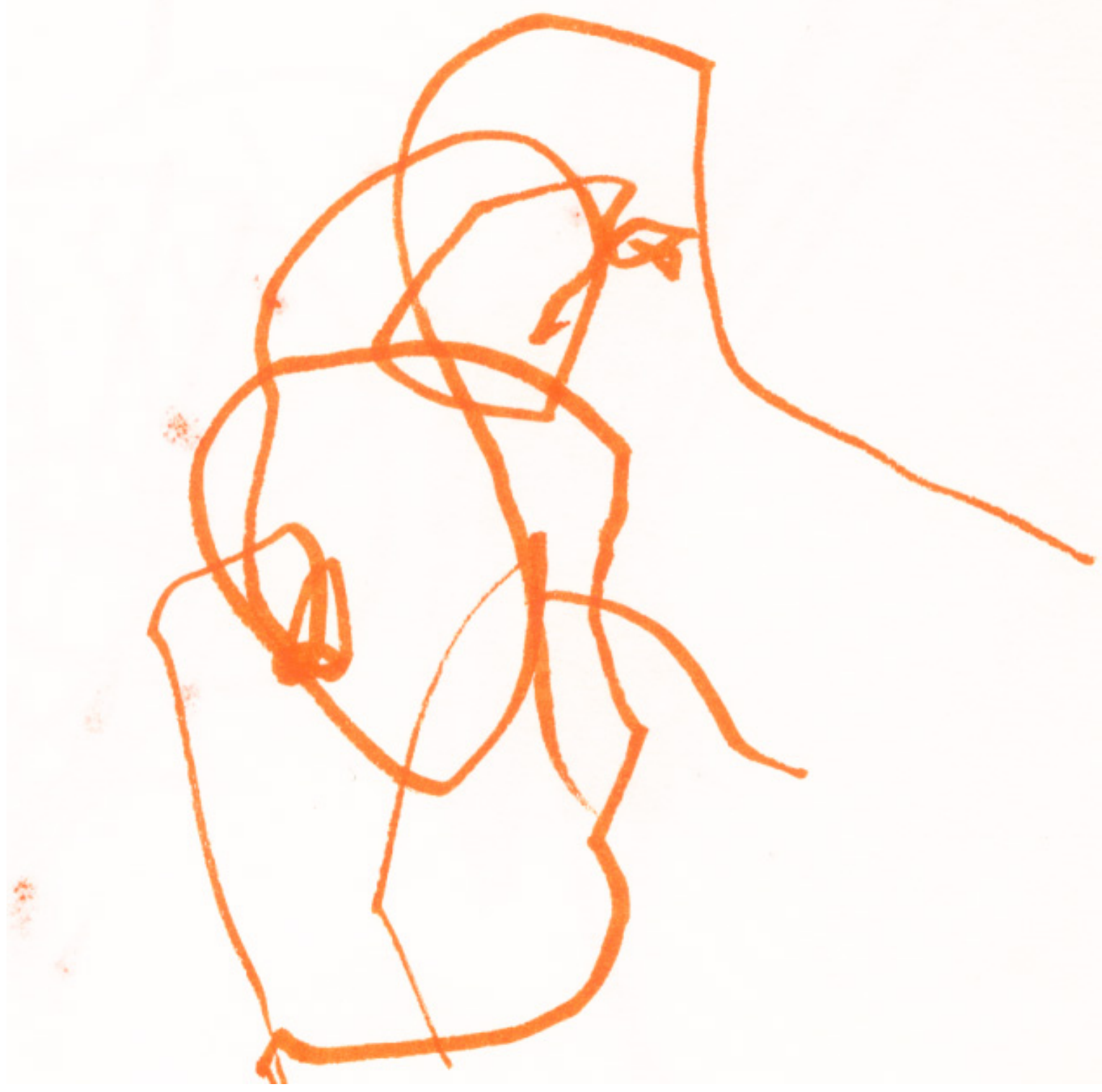

Figure D3. Rose’s imaginative function: the "Vacuum Nest." 


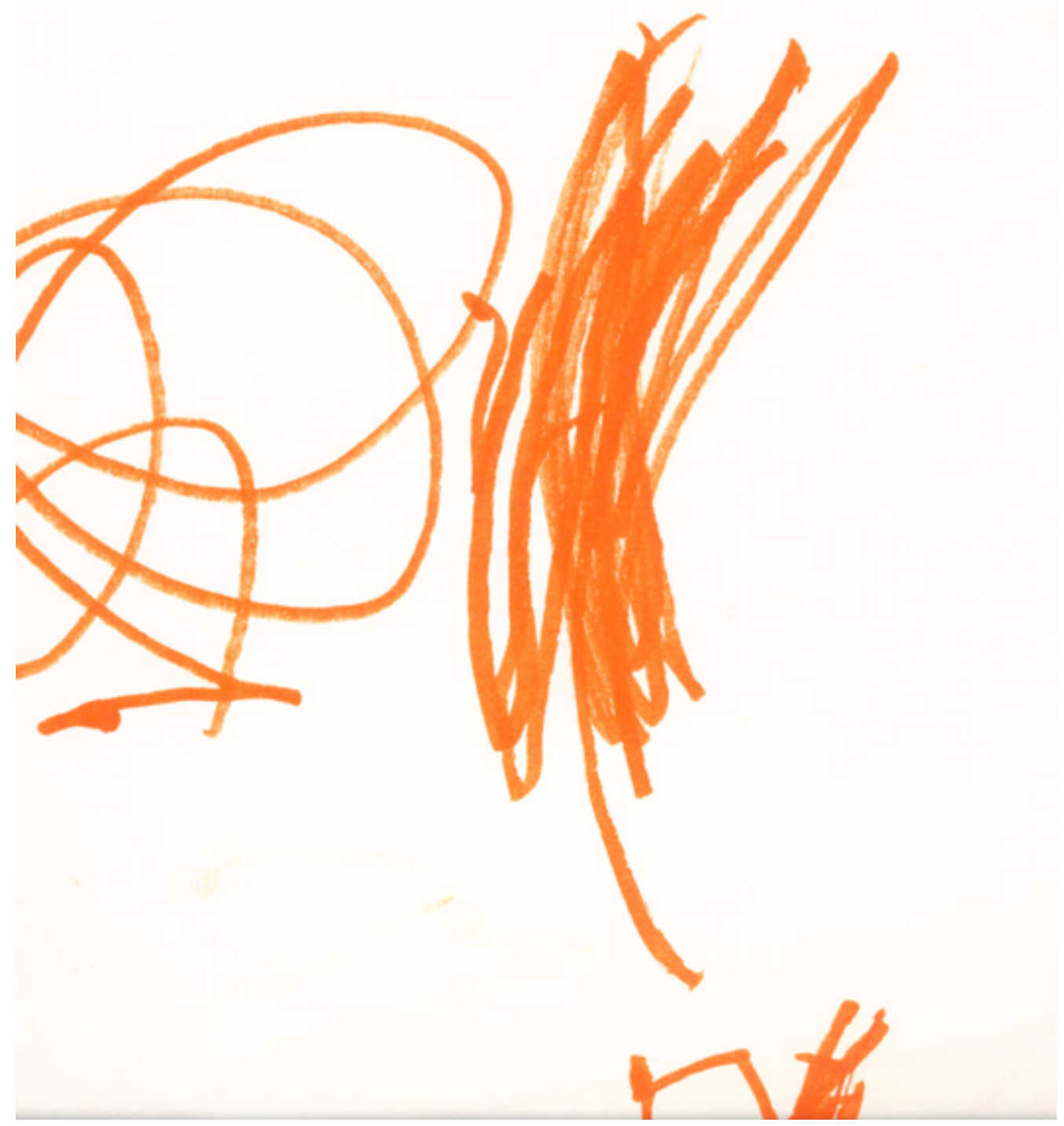

Figure D4. Rose’s representational function: A necklace. 
Appendix E:

Sara's Communicative Functions of Art

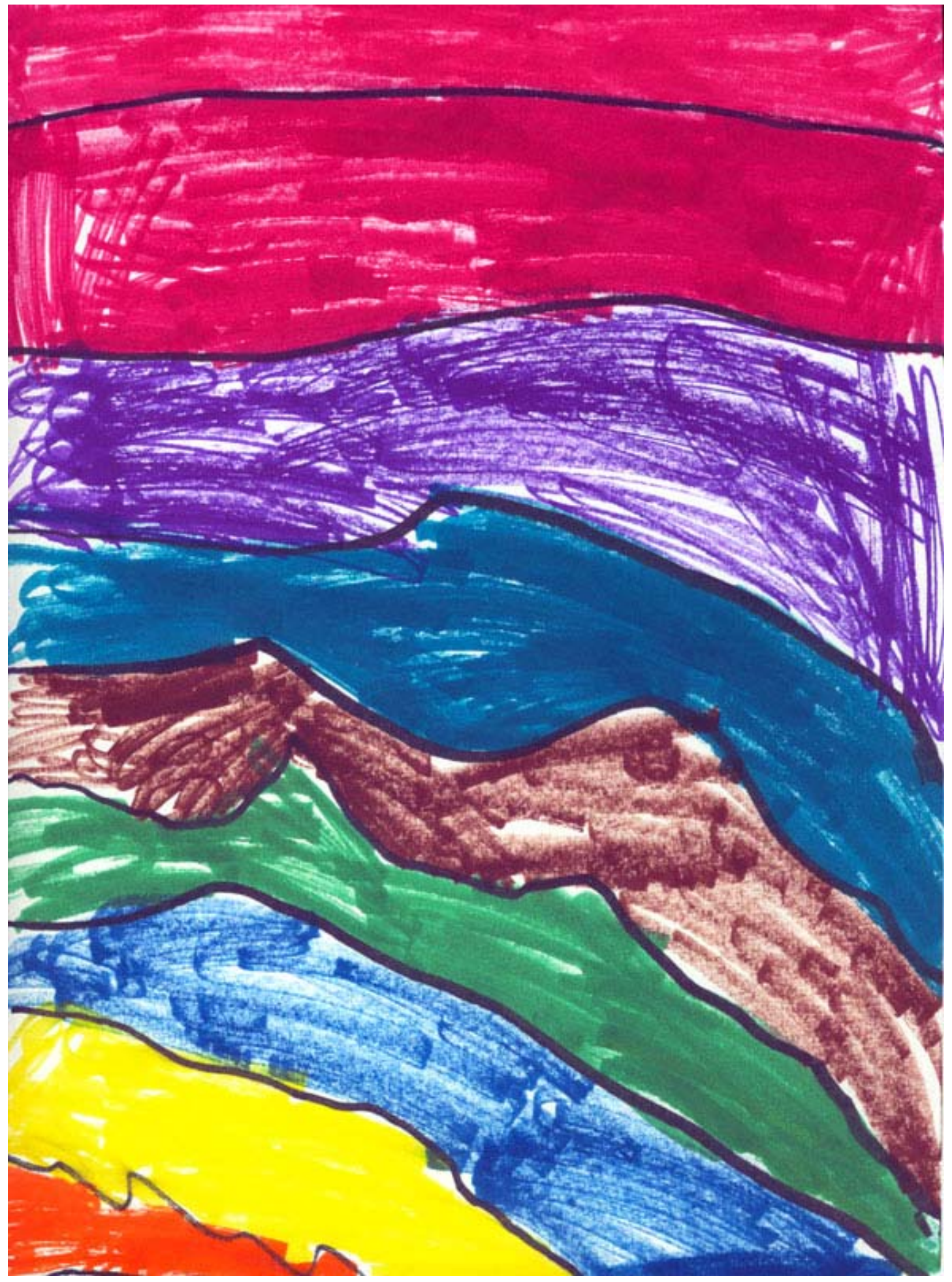

Figure E1. Sara's instrumental function 


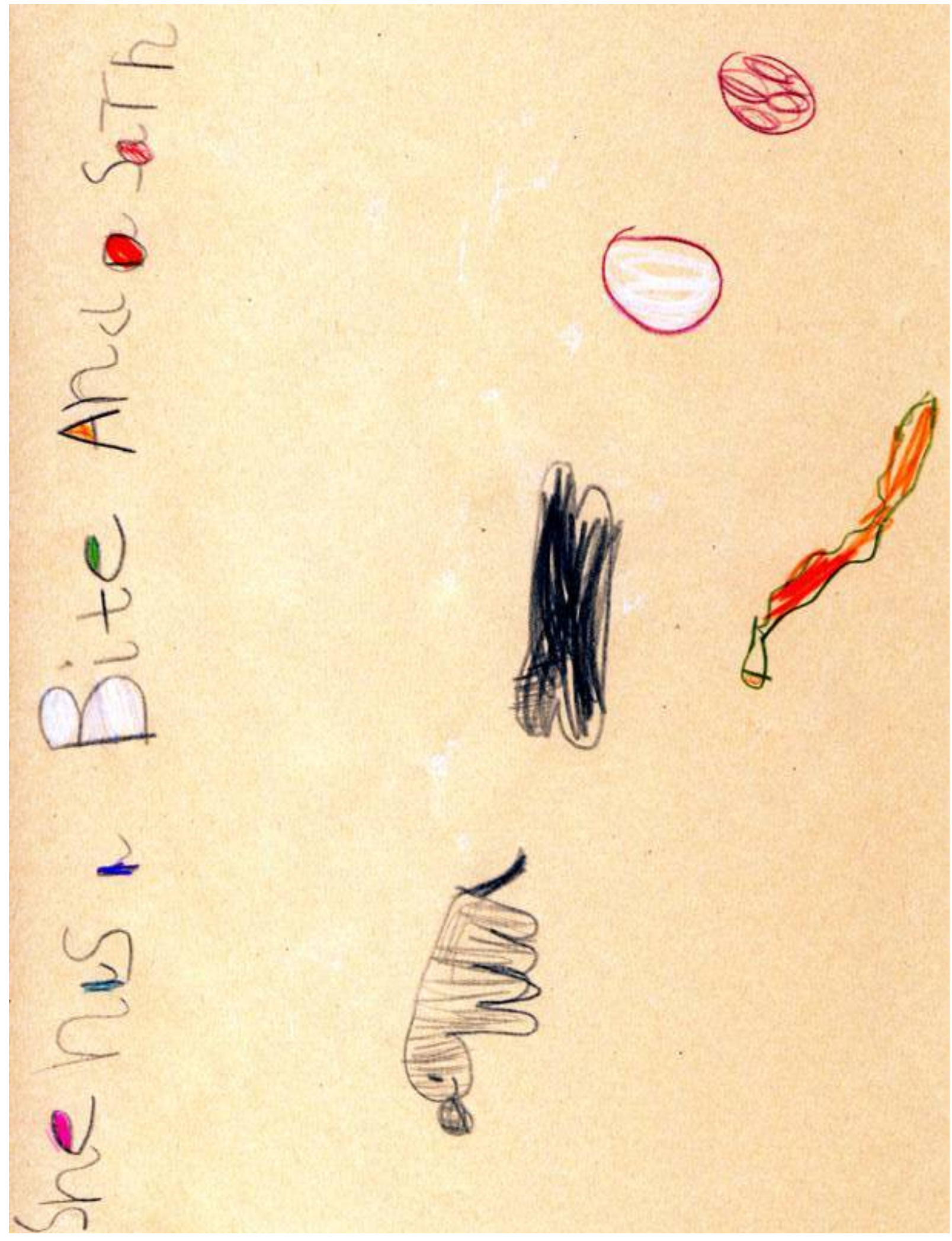

Figure E2. Sara's regulatory function 


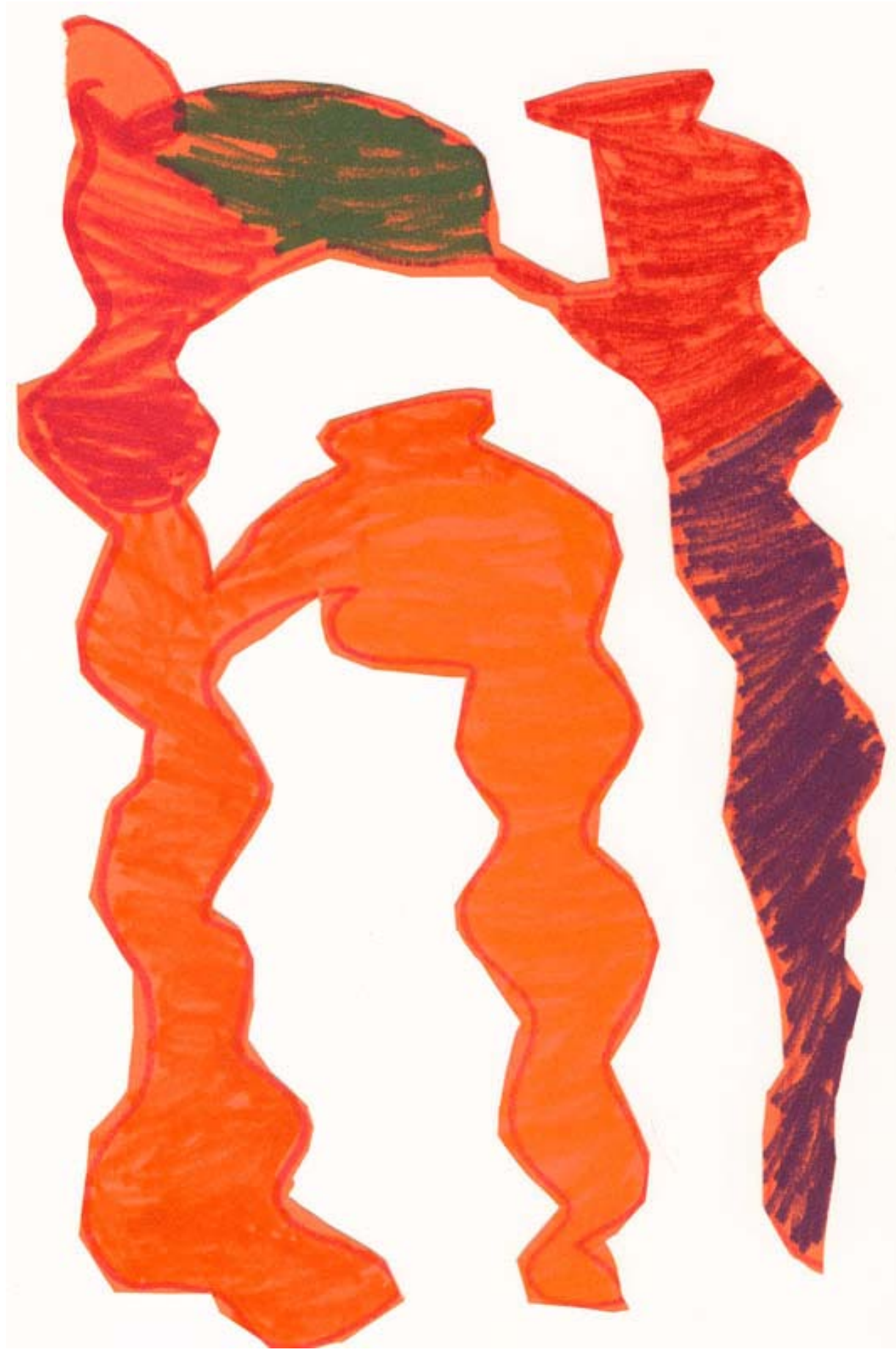

Figure E3. Sara's and Alice's interactional function 


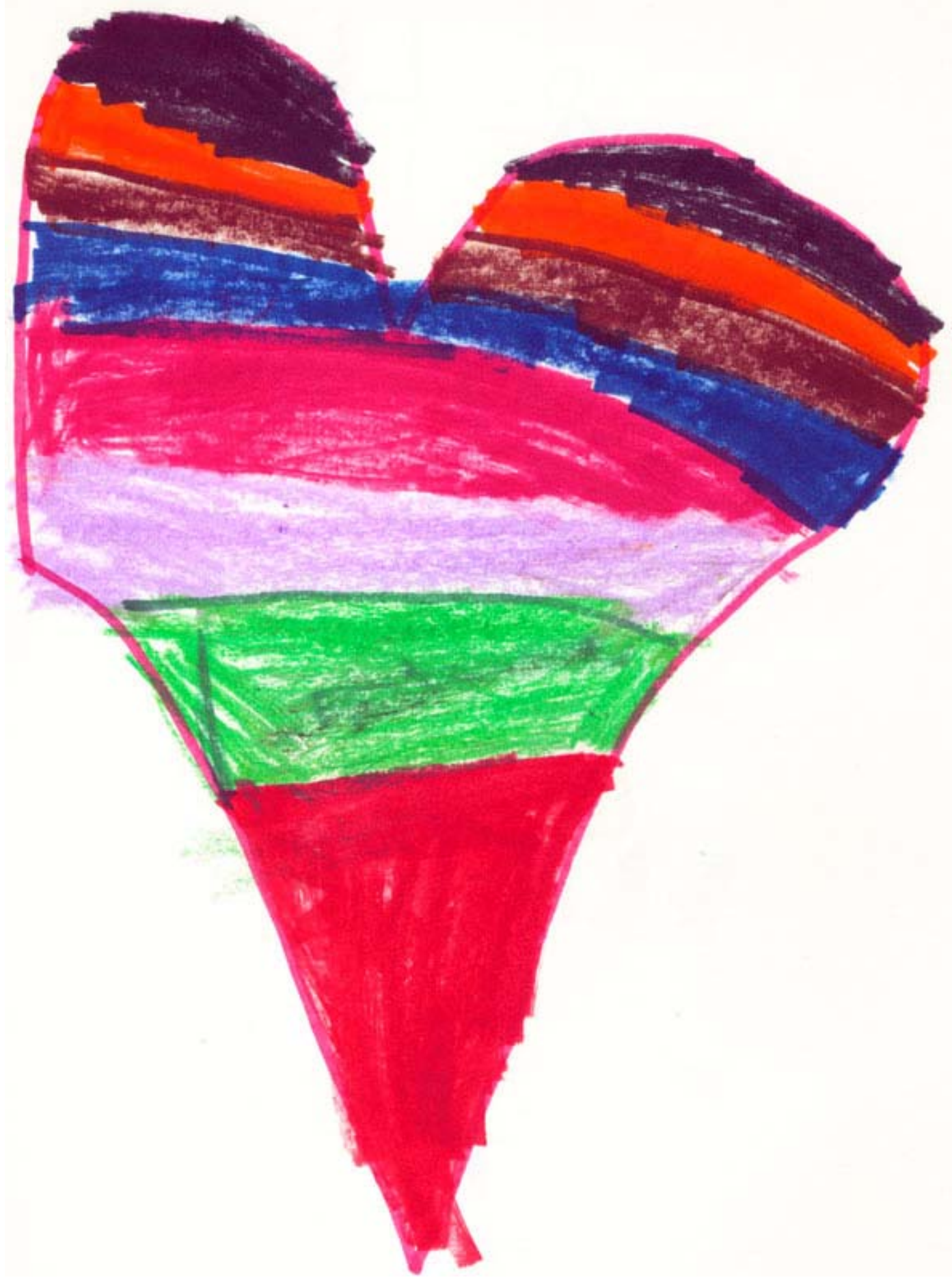

Figure E4. Sara's personal function 


$$
\theta
$$




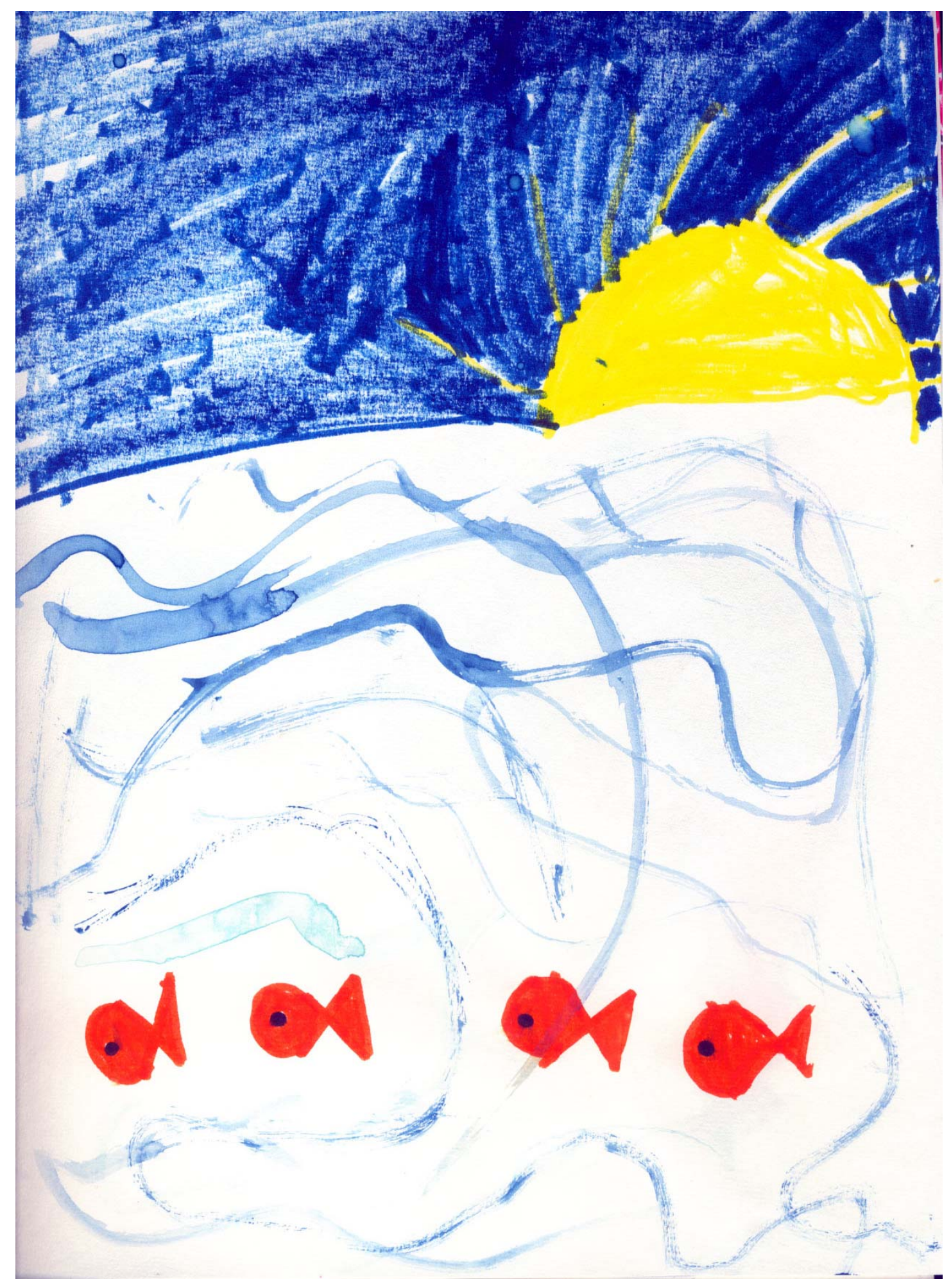

Figure E6. Sara's representational function 
Appendix F

Seth's Communicative Functions of Art

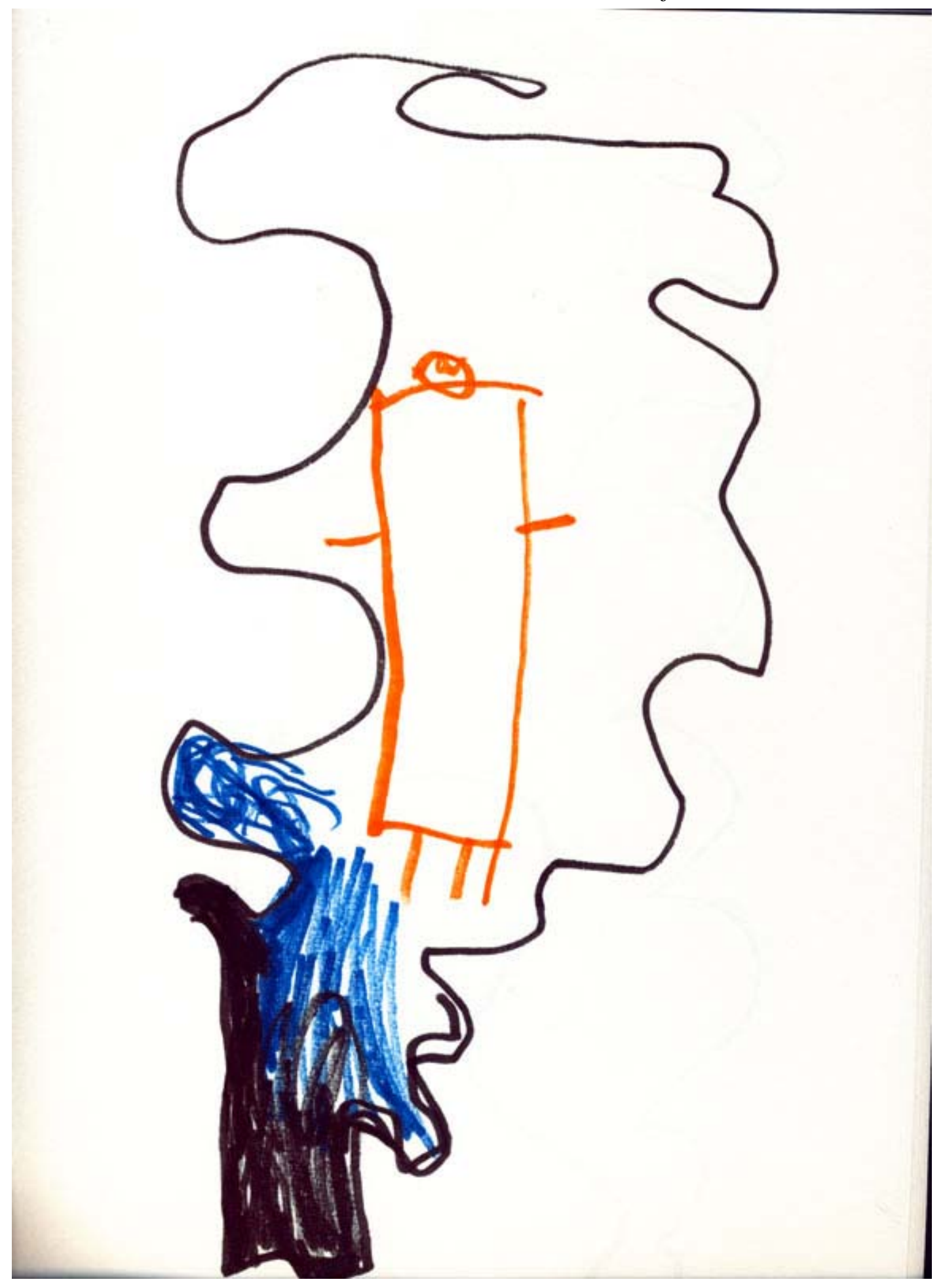

Figure F1. Seth's imaginative function

153 


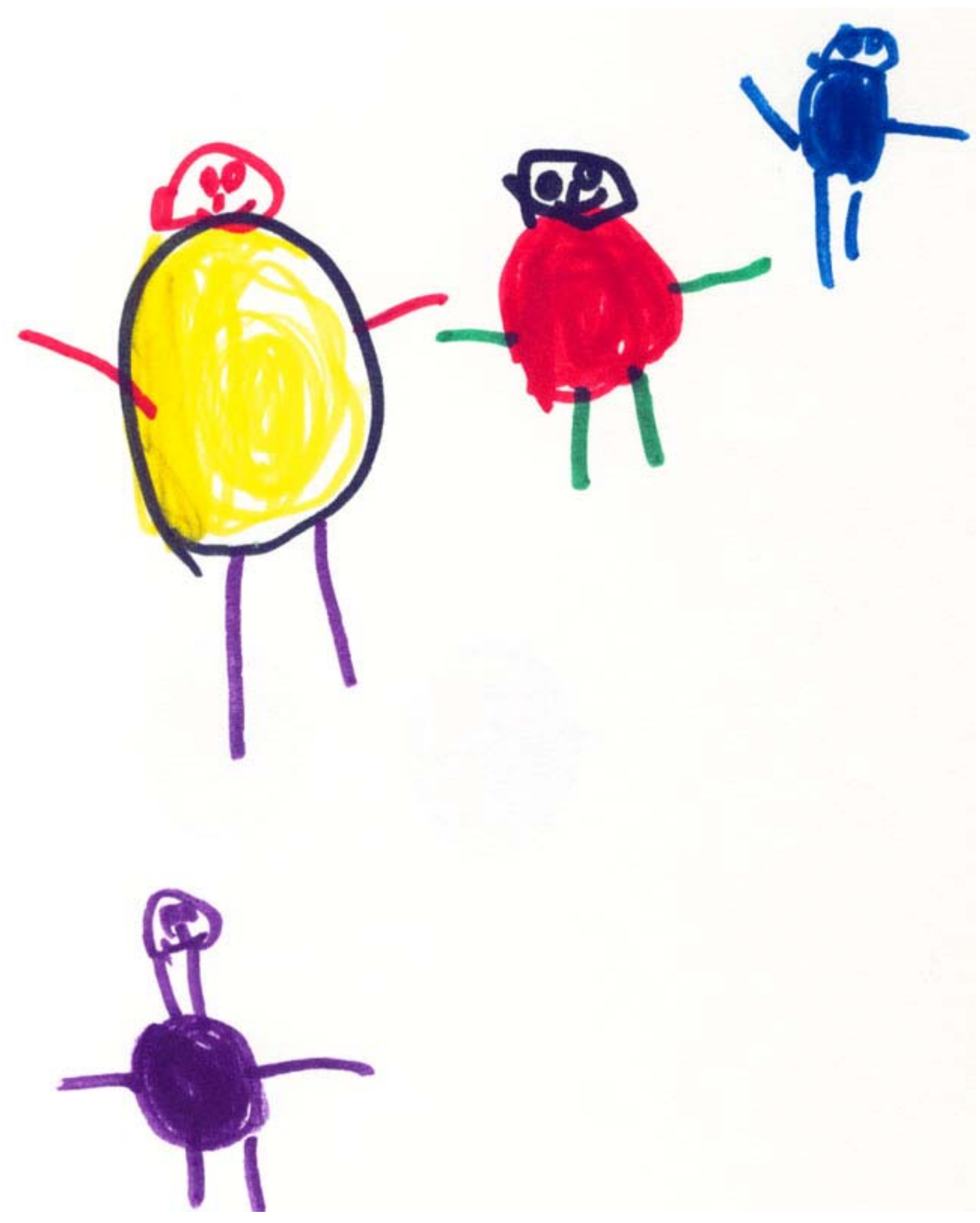

Figure F2. Seth's representational function

154 


\section{Appendix G}

\section{Examples of early literacy and numeracy}

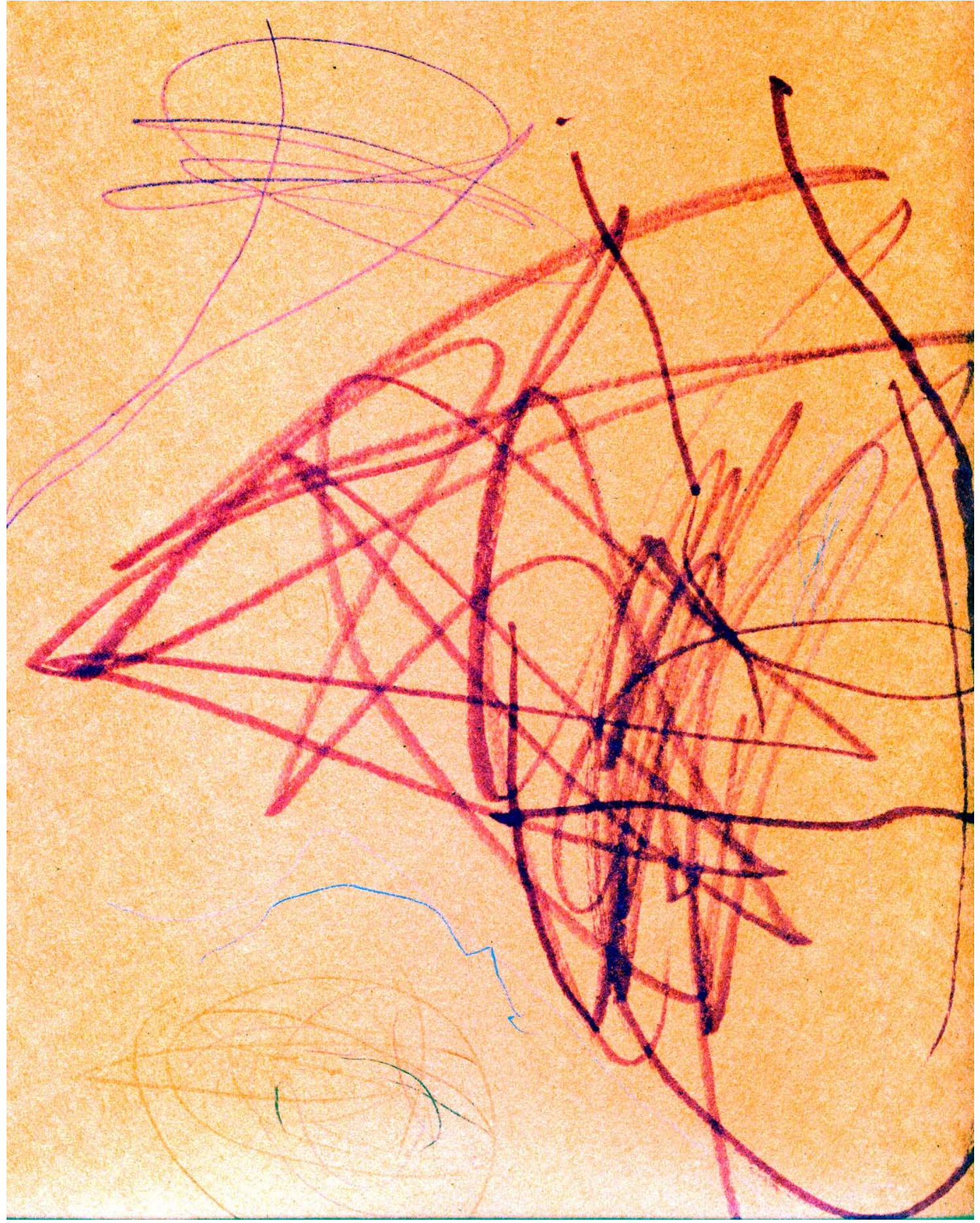

Figure G1. Adam's letter N 


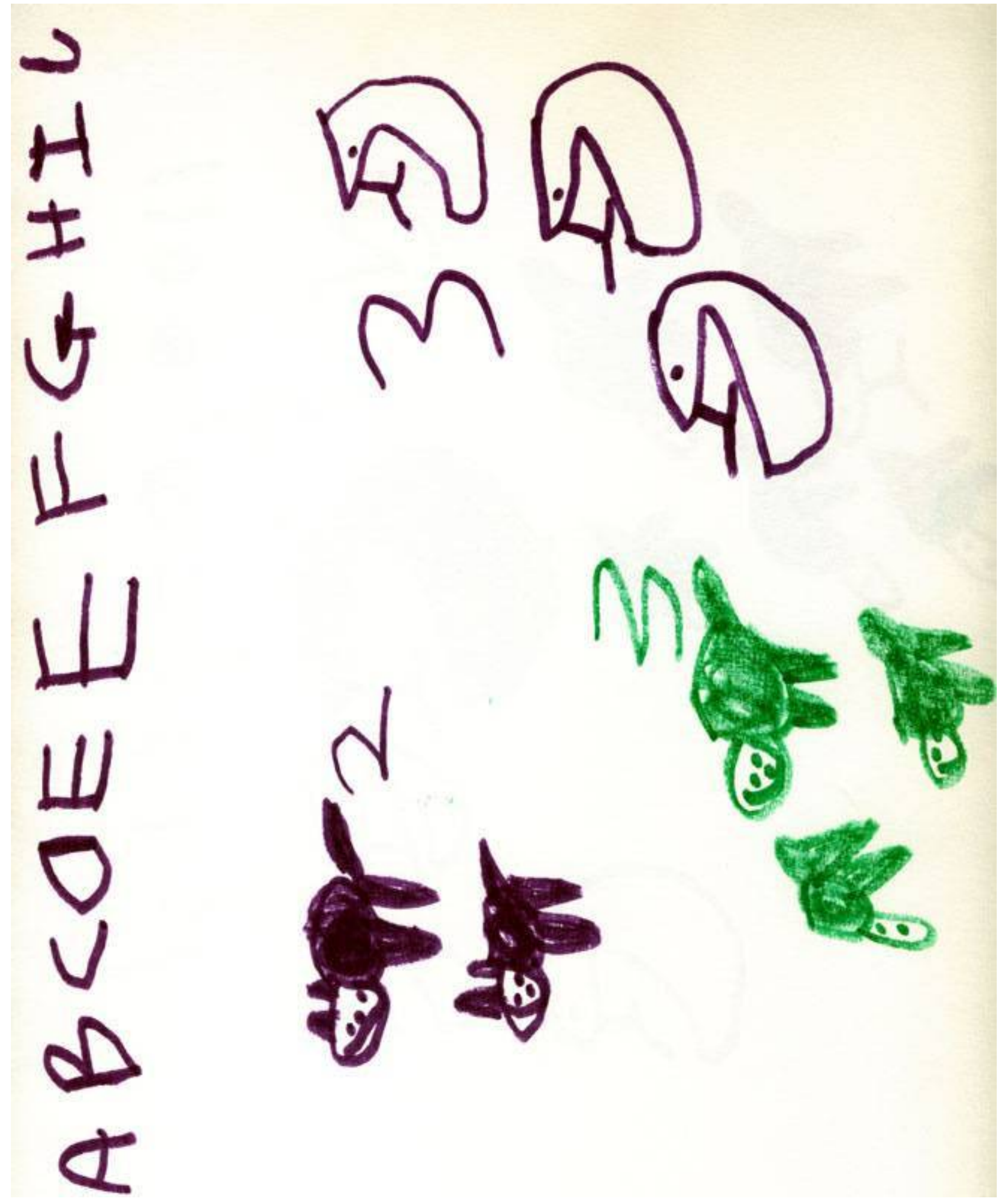

Figure G2. Alice's letters and numbers (with one-to-one correspondence) 


$$
\begin{aligned}
& 4+4=8 \\
& \text { ool1 IIII } \\
& 1+2=3 \\
& 3+1=4 \\
& \text { sss } 5 \text { sss }
\end{aligned}
$$




\section{Appendix $\mathrm{H}$}

\section{Observation Form}

Date: Time: Child: Artwork\#:

Setting:

Solo/in group/pair:

Part of play: $y / n$, more:

Art lead interaction: $\mathrm{y} / \mathrm{n}$, more:

Materials chosen:

Verbal Communication-questions/statements:

What I see:

Participant description:

Communicative function/s: Instrumental, regulatory, interactional, personal, heuristic, imaginative, representational/informative

Notes: 


\section{Appendix I \\ Parent Interview Protocol}

Parent/parents of Date/time of interview

1) Talk about what/how your child usually draws. (Any themes, recurring patterns, etc.)

2) Discuss the kinds of things you do in response to your child's art.

3) What can you tell me about your family's communication style?

4) Any cultural/language considerations I should be aware of? 